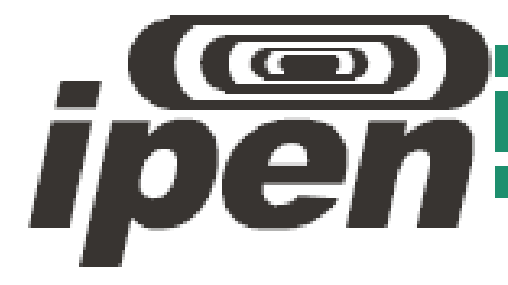

AUTARQUIA ASSOCIADA À UNIVERSIDADE DE SÃO PAULO

Estudo sobre a composição elementar nas amostras de líquen epifítico utilizado como bioindicador da poluição aérea na cidade de São Paulo

EDMILA MONTEZANI

Dissertação apresentada como parte dos requisitos para obtenção do grau de Mestre em Ciências na Área de Tecnologia Nuclear - Aplicações.

Orientadora: Prof ${ }^{a}$. Dra . Mitiko Saiki

São Paulo

2010 
INSTITUTO DE PESQUISAS ENERGÉTICAS E NUCLEARES

Autarquia associada à Universidade de São Paulo

Estudo sobre a composição elementar nas amostras de líquen epifítico utilizado como bioindicador da poluição aérea na cidade de São Paulo

EDMILA MONTEZANI

Dissertação apresentada como parte dos requisitos para obtenção do grau de Mestre em Ciências na Área de Tecnologia Nuclear Aplicações.

Orientadora: Prof ${ }^{a}$. Dra ${ }^{\mathrm{a}}$. Mitiko Saiki

São Paulo 
A Deus.

Aos meus pais Ivo e Nanci e às minhas irmãs, Érica e Edlaine. 


\section{AGRADECIMENTOS}

Primeiramente a Deus, meu Pai divino, por mais esta oportunidade de realização.

Aos meus pais, Ivo e Nanci Montezani, minhas irmãs Érica e Edlaine e ao meu cunhado, Paulo Evaristo, que, mesmo distantes, torceram por mim do início ao término deste trabalho. Muito obrigada pelo carinho, dedicação, paciência e incentivo.

Agradeço de todo o coração a minha avó Lourdes Munhoz Zonette pelo carinho e pelo incentivo, desde o início da minha vida acadêmica.

De uma maneira muito especial a minha orientadora Dra. Mitiko Saiki, pelo trabalho oferecido, pela confiança em mim depositada, pela dedicação e acompanhamento sem os quais não teria conseguido concluir esta dissertação. Muito obrigada por acreditar em meu potencial.

Ao Instituto de Pesquisas Energéticas e Nucleares, IPEN-CNEN/SP pela oportunidade concedida para realizar este trabalho.

Aos meus familiares, pelo carinho e incentivo. Obrigada por fazerem parte da minha vida e, assim, torná-la mais agradável.

Ao Joel Lima, por estar sempre disposto a me ajudar, ouvir, incentivar. Mais do que isso, obrigada pelo carinho, amor, companheirismo, cumplicidade, sinceridade, paciência e por estar ao meu lado sempre que possível.

Aos meus grandes amigos Fernando Moreto e Roberto Fonseca, pela amizade, incentivo e auxílio sempre que necessitei. Obrigada por me fazerem acreditar que eu pudesse recomeçar.

Aos meus amigos do IPEN: Regina, Cristina Tessari, Paola Oliveira, Irene, Tata, Déborah, Guilherme Zahn, Andréia Brito, Vera, Daniele, Guilherme Moura, Edson Alves, Edson Moreira e João Guilherme. Muito obrigada pelos ótimos momentos em que convivemos. Espero que nossa amizade continue para sempre.

A Dra. Marília Gabriela e ao Dr. Renato Semmler, pela amizade, incentivo e pelas sugestões valiosas para a conclusão deste trabalho. 
Agradeço de uma maneira muito especial ao Pedro Gozalo, Celso Guimarães, Márcia Costa, Selma Violato, Luciano laralhan e Francisco Bonfim por serem pessoas raras, com o objetivo único de darem alegria às pessoas. Quero agradecer de coração por tudo o que me ajudaram a realizar e não me deixarem desistir. Muito obrigada, meus grandes amigos.

Ao Prof. Dr. Oswaldo Luis do Valle Costa e ao Dr. Wagner Zucchi, pelo auxílio em técnicas estatísticas e amizade.

A minha amiga Hélène Jeanne Janinne Poulingue, pelos ensinamentos e momentos de alegria, mesmo estando do outro lado do continente.

Ao Prof. Dr. Márcio Cardim, pelo carinho, incentivo e companheirismo, desde o início da minha vida acadêmica.

À Roberta Ferreira, Ariany Silva, Luciana Silva, Doris Godoy, Adriana Palmeira, Rafael Godas e Karen Kiku, pela amizade e pelos momentos de alegria.

Aos meus amigos profissionais professores que sempre acreditaram que o futuro do país está baseado na boa educação.

Ao ensino público e gratuito que pude usufruir ao longo da minha vida acadêmica.

A todos que de forma informal, me auxiliaram no desenvolvimento deste trabalho.

A todos os estudantes do Brasil.

A todos. 
"Você precisa fazer aquilo que pensa que não é capaz de fazer." Eleanor Roosevelt 


\title{
ESTUDO SOBRE A COMPOSIÇÃO ELEMENTAR NAS AMOSTRAS DE LÍQUEN EPIFÍTICO UTILIZADO COMO BIOINDICADOR DA POLUIÇÃO AÉREA NA CIDADE DE SÃO PAULO
}

\section{Edmila Montezani}

\begin{abstract}
RESUMO
Estudos sobre a poluição atmosférica têm se intensificado nos últimos anos, devido à grande diversificação de fontes poluidoras do ar e ao efeito ocasionado à saúde das populações. Conseqüentemente, diversas técnicas têm sido investigadas para avaliação da poluição aérea e dentre elas, uma que tem ganhado considerável atenção é a do biomonitoramento. Neste trabalho foram avaliados os níveis de elementos químicos na atmosfera da cidade de São Paulo, por meio de biomonitoramento passivo, usando a espécie epifítica Canoparmelia texana, para comparar os resultados obtidos das amostras coletadas em diferentes pontos da cidade de São Paulo bem como de um ponto de referência da cidade de Ubatuba, SP. Para análise, os liquens coletados foram previamente limpos, secos e moídos. O método de análise por ativação neutrônica (NAA) aplicado constituiu em irradiar alíquotas das amostras junto com os padrões sintéticos dos elementos, no reator IEA-R1 por 16 horas e sob um fluxo de nêutrons térmicos de cerca de $5,0 \times 10^{12} \mathrm{n} \mathrm{cm}^{-2} \mathrm{~s}^{-1}$, seguida da espectrometria de raios gama, para determinação de $\mathrm{As}, \mathrm{Br}, \mathrm{Ca}, \mathrm{Co}, \mathrm{Cr}, \mathrm{Cs}, \mathrm{Fe}, \mathrm{K}, \mathrm{La}, \mathrm{Rb}, \mathrm{Sc}$, Se e $\mathrm{Zn}$. Os resultados das análises das amostras de liquens em replicatas apresentaram uma boa reprodutibilidade, indicando a homogeneidade das amostras preparadas. A precisão e a exatidão dos resultados foram avaliadas por meio das análises de materiais de referência certificados IAEA-336 Lichen e INCT-TL-1 Tea Leaves, cujos resultados apresentaram, em geral, uma boa precisão e exatidão, com os desvios padrão relativos entre 0,4 a $14,8 \%$ e erros relativos entre 0,2 a $8,7 \%$. Na cidade de São Paulo, os liquens foram coletados nos locais a saber, Parque Dom Pedro II, Congonhas, Cidade Universitária, Lapa, Moóca, Morumbi, Nossa Senhora do Ó, Parque do Ibirapuera, Pinheiros, Santana,
\end{abstract}


Santo Amaro e Taboão da Serra. As concentrações dos elementos nos liquens indicaram uma grande variabilidade entre amostras de diferentes pontos de amostragens. Estes resultados submetidos à análise de clusters indicaram três grandes grupos de pontos de amostragem, de acordo com a similaridade química obtida nos liquens. A amostra coletada em Ubatuba indicou, para a maioria dos elementos químicos, concentrações inferiores ou da mesma ordem de grandeza quando comparados com daqueles coletados na cidade de São Paulo. As mais altas concentrações na amostra de líquen de Ubatuba foram obtidas para $\mathrm{Br}, \mathrm{Ke}$ $\mathrm{Zn}$. Os resultados das análises de liquens indicaram que as origens dos elementos presentes na atmosfera da cidade de São Paulo podem ser atribuídas principalmente às emissões veiculares, seguida de emissões industriais e do solo. Nos liquens, foram determinados os elementos chamados de marcadores de emissões veiculares ( $\mathrm{Br}$, Co, Sb e $\mathrm{Zn}$ ), de emissões industriais ( $\mathrm{Cr}$, Co e $\mathrm{Fe}$ ) e do solo (Sb, Se, Rb e La). 


\title{
A STUDY ON ELEMENTAL COMPOSITION IN EPIPHYTIC LICHEN SAMPLES USED AS BIOINDICATOR OF AIR POLLUTION IN SÃO PAULO CITY
}

\section{Edmila Montezani}

\begin{abstract}
Studies on air pollution have intensified in recent years, due to the diversity of emissions and the effect caused to the health of populations. Consequently, several techniques have been investigated for air pollution evaluation and among them one that has gained considerable attention is that of biomonitoring. In this study chemical elemental levels in the atmosphere of São Paulo city were evaluated, by means of passive biomonitoring, using epiphytic Canoparmelia texana species, in order to compare between the results obtained in samples from different sites of São Paulo city and in a reference site of Ubatuba city, SP. Neutron activation analysis (NAA) procedure applied in the analyses consisted of irradiating aliquots of samples along with synthetic standards of elements in the nuclear reactor IEA-R1 for 16 hours under a thermal neutron flux of about $5.0 \mathrm{x}$ $10^{12} \mathrm{n} \mathrm{cm}^{-2} \mathrm{~s}^{-1}$, followed by gamma ray spectrometry for the determination of As, $\mathrm{Br}, \mathrm{Ca}, \mathrm{Co}, \mathrm{Cr}, \mathrm{Cs}, \mathrm{Fe}, \mathrm{K}, \mathrm{La}, \mathrm{Rb}, \mathrm{Sc}$, Se and Zn. Results obtained in the analyses of lichens samples in replicates presented good reproducibility indicating homogeneity of the prepared samples. The precision and accuracy of the results were evaluated by the analyses of certified reference materials IAEA-336 Lichen and INCT-TL-1 Tea Leaves. Results obtained in the reference materials presented, in general, good precision, with relative standard deviations between 0.4 and $14.8 \%$ and good accuracy with relative errors between 0.2 and $8.7 \%$. In São Paulo city, the lichens were collected in the following sites: Parque Dom Pedro II, Congonhas, Cidade Universitária, Lapa, Moóca, Morumbi, Nossa Senhora do Ó, Parque Ibirapuera, Pinheiros, Santana, Santo Amaro and Taboão da Serra. Element concentrations found in lichens indicated a great variability depending on the sites where the samples were collected. The results obtained in the lichens submitted to the cluster analysis indicated three groups of sampling
\end{abstract}


sites according to the chemical similarity obtained in lichens. Lichen collected in the reference site of Ubatuba indicated that most of element concentrations are lower or at the same order of magnitude when compared with those obtained in lichens collected in São Paulo city. The highest element concentrations in the sample from Ubatuba were obtained for $\mathrm{Br}, \mathrm{K}$ and $\mathrm{Zn}$. Results obtained in this study indicated that the origins of elements present in the atmosphere of São Paulo city are due to mainly vehicular emissions followed industrial emissions and from soil. Elements named vehicular emission markers ( $\mathrm{Br}, \mathrm{Co}, \mathrm{Sb}$ and $\mathrm{Zn}$ ), industrial markers ( $\mathrm{Cr}$, Co and $\mathrm{Fe}$ ) and from soil ( $\mathrm{Sb}$, Se, $\mathrm{Rb}$ e $\mathrm{La}$ ) were determined in the lichens. 


\section{SUMÁRIO}

Página

1. INTRODUÇÃO

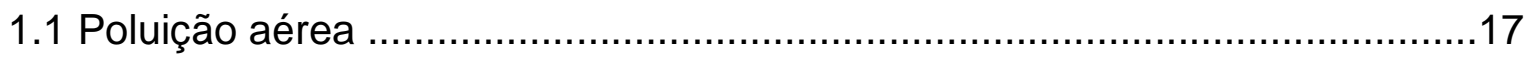

1.2 Efeitos da poluição atmosférica sobre a saúde humana …….......................18

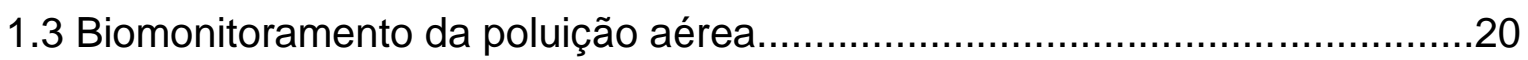

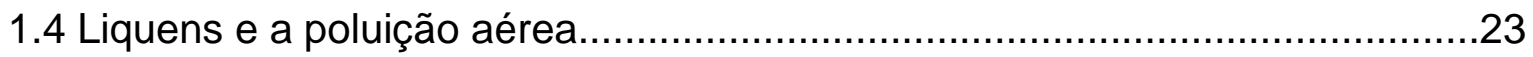

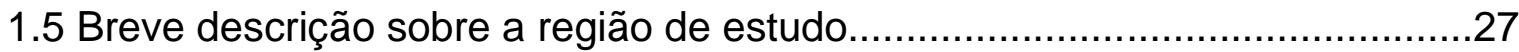

1.5.1 Aspectos gerais da região metropolitana de São Paulo.................................27

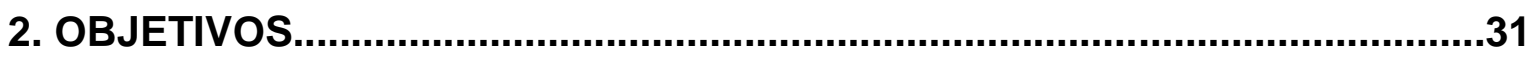

2.1 Objetivos geral e específicos..................................................................

3. METODOLOGIA

3.1 Metodologia de análise por ativação com nêutrons........................................32

3.2 Vantagens e desvantagens da utilização da técnica de NAA...........................35

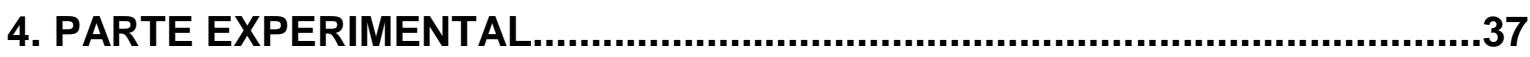

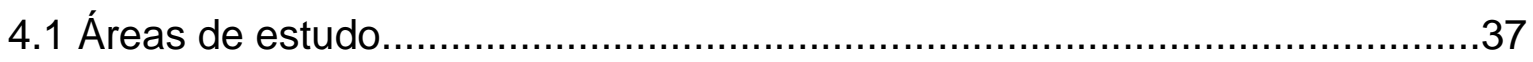

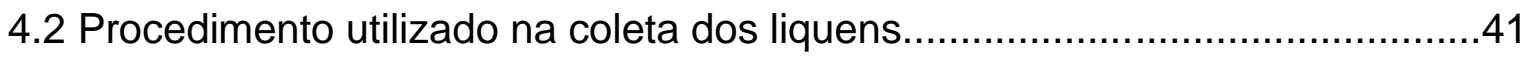

4.2.1 Pesagens das amostras de líquen para análise por ativação com nêutrons.

4.3 Preparação de padrões sintéticos dos elementos............................................43

4.4 Análise de materiais de referência certificados..............................................4

4.5 Procedimento para análise por ativação com nêutrons...................................4

5. RESULTADOS E DISCUSSÃO.

5.1 Resultados das análises de materiais de referência certificados IAEA-336 Lichen e INCT-TL-1 Tea Leaves

5.2 Verificação da homogeneidade das amostras de liquens preparadas para análise 
5.3 Resultados das análises das amostras de liquens coletadas neste

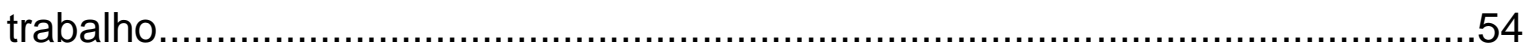

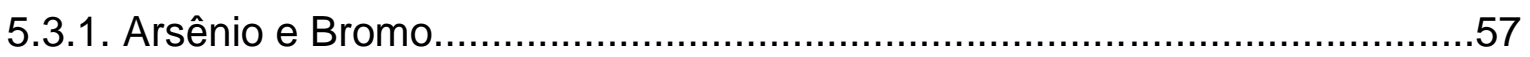

5.3.2 Cromio e Ferro

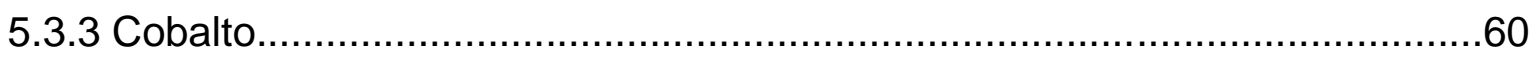

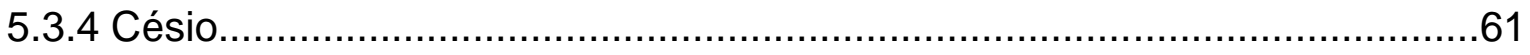

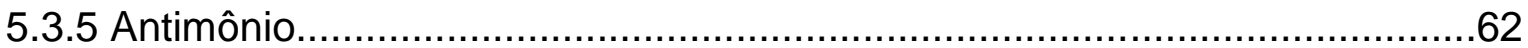

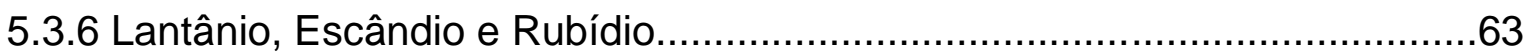

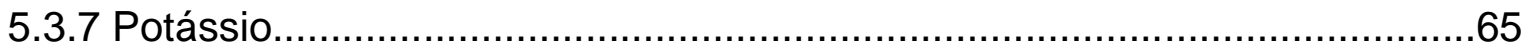

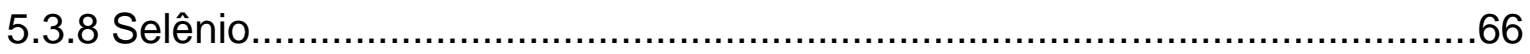

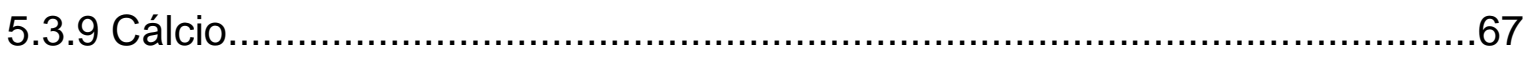

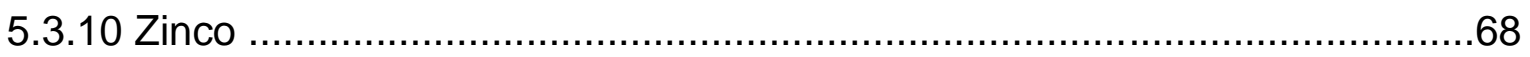

5.4 Análise de Cluster e Análise Discriminante ...............................................69

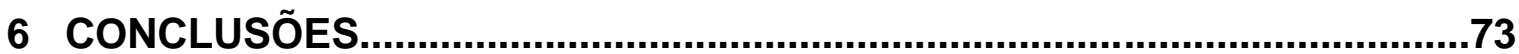

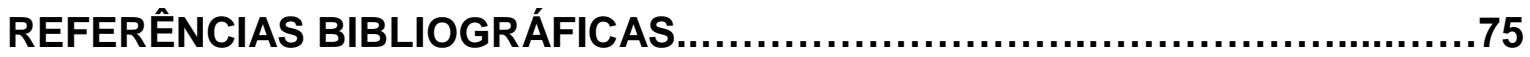




\section{LISTA DE TABELAS}

Tabela 1.1. Contribuição relativa das fontes de poluição do ar na RMSP em 2009.

Tabela 4.1. Códigos e nomes das principais rodovias que compõem o sistema rodoviário da Região Metropolitana de São Paulo .39

Tabela 4.2. Dados dos locais de amostragens de líquen na cidade de São Paulo e na região de Ubatuba,SP.

Tabela 4.3. Concentrações de elementos nas soluções padrão e respectivas massas dos elementos utilizadas .43

Tabela 4.4. Dados dos radioisótopos com suas respectivas energias de raios gama e meias vidas (IAEA, 1990), utilizados neste estudo. 46

Tabela 5.1. Fórmulas utilizadas para o cálculo das grandezas apresentadas nas Tabelas 5.2 e 5.3

Tabela 5.2. Concentrações de elementos no material de referência certificado IAEA-336 Lichen

Tabela 5.3. Concentrações de elementos no material de referência certificado INCT-TL1 Tea Leaves. .50

Tabela 5.4. Concentrações de elementos obtidas nas análises em replicatas de três amostras de liquens. .54

Tabela 5.5. Concentrações de elementos obtidas para os liquens coletados em diferentes pontos da cidade de São Paulo e de Ubatuba-SP. .55 


\section{LISTA DE FIGURAS}

Figura 1.1. Foto do líquen da espécie crustáceo .24

Figura 1.2. Foto do líquen da espécie foliáceo 25

Figura 1.3. Foto do líquen da espécie dendrítico ou frutuoso. .25

Figura 3.1. Esquema que ilustra o processo de captura de nêutron por um núcleo seguida da emissão de raios de gama pronto e de decaimento (modificado)........33

Figura 4.1. Mapa das principais rodovias que compõem o sistema rodoviário da Região Metropolitana de São Paulo. 38

Figura 4.2. Foto mostrando a remoção do líquen na casca da árvore. .41

Figura 5.1. Valores de Z-score obtidos para o material de referência IAEA-336 Lichen. 52

Figura 5.2. Valores de Z-score obtidos para o material certificado de referência INCT-TL-1 Tea Leaves .53

Figura 5.3. Concentrações de As $\left(\mathrm{ng} \mathrm{g}^{-1}\right.$ ) em liquens coletados nos diversos pontos da cidade de São Paulo e em Ubatuba. .57

Figura 5.4. Concentrações de $\mathrm{Br}\left(\mu \mathrm{g} \mathrm{g} \mathrm{g}^{-1}\right)$ em liquens coletados nos diversos pontos da cidade de São Paulo e em Ubatuba. .58

Figura 5.5. Concentrações de $\mathrm{Cr}\left(\mu \mathrm{g} \mathrm{g} \mathrm{g}^{-1}\right)$ em liquens coletados nos diversos pontos da cidade de São Paulo e em Ubatuba. .60

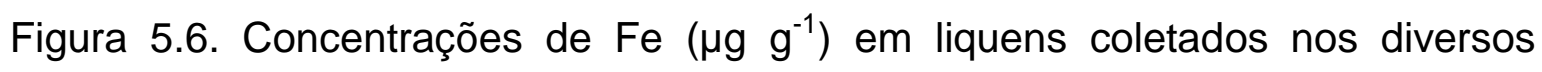
pontos da cidade de São Paulo e em Ubatuba. .60 
Figura 5.7. Concentrações de Co $\left(\mathrm{ng} \mathrm{g}^{-1}\right)$ em liquens coletados nos diversos pontos da cidade de São Paulo e em Ubatuba.

Figura 5.8. Concentrações de Cs $\left(\mathrm{ng} \mathrm{g}^{-1}\right)$ em liquens coletados nos diversos pontos da cidade de São Paulo e em Ubatuba.

Figura 5.9. Concentrações de $\mathrm{Sb}\left(\mu \mathrm{g} \mathrm{g} \mathrm{g}^{-1}\right)$ em liquens coletados nos diversos pontos da cidade de São Paulo e em Ubatuba.

Figura 5.10. Concentrações de La $\left(\mu \mathrm{g} \mathrm{g}^{-1}\right)$ em liquens coletados nos diversos pontos da cidade de São Paulo e em Ubatuba.

Figura 5.11. Concentrações de Sc $\left(\mathrm{ng} \mathrm{g}^{-1}\right)$ em liquens coletados nos diversos pontos da cidade de São Paulo e em Ubatuba

Figura 5.12. Concentrações de $\mathrm{Rb}\left(\mu \mathrm{g} \mathrm{g}{ }^{-1}\right)$ em liquens coletados nos diversos pontos da cidade de São Paulo e em Ubatuba.

Figura 5.13. Concentrações de $\mathrm{K}$ (em \%) em liquens coletados nos diversos pontos da cidade de São Paulo e em Ubatuba. .66

Figura 5.14. Concentrações de Se $\left(\mu \mathrm{g} \mathrm{g}^{-1}\right)$ em liquens coletados nos diversos pontos da cidade de São Paulo e em Ubatuba.

Figura 5.15. Concentrações de Ca (em \%) em liquens coletados nos diversos pontos da cidade de São Paulo e em Ubatuba. .68

Figura 5.16. Concentrações de $\mathrm{Zn}\left(\mu \mathrm{g} \mathrm{g}{ }^{-1}\right)$ em liquens coletados nos diversos pontos da cidade de São Paulo e em Ubatuba. 69

Figura 5.17. Dendrograma obtido através da análise de clusters nos diferentes pontos de amostragem da cidade de São Paulo e em Ubatuba-SP com as respectivas legendas: PDP - Parque Dom Pedro II, CGN - Congonhas, USP - 
Cidade Universitária, LAP - Lapa, MOC - Moóca, MOR - Morumbi, NSO Nossa Senhora do Ó, PIB - Parque do Ibirapuera, PIN - Pinheiros, SAN Santana, STA - Santo Amaro, TAS - Taboão da Serra e UB -

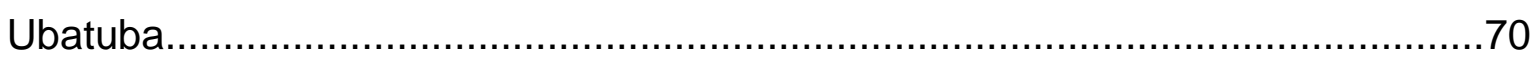

Figura 5.18. Análise discriminante dos resultados das amostras de liquens coletados em diferentes regiões da cidade de São Paulo e de

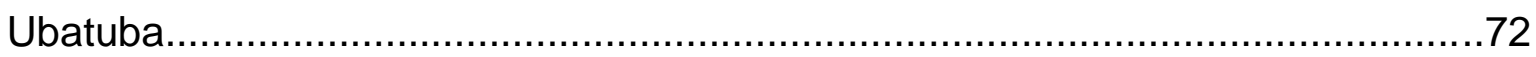




\section{LISTA DE SÍMBOLOS}

$$
\begin{aligned}
& \text { As - Arsênio } \\
& \mathrm{Br} \text { - Bromo } \\
& \mathrm{Ca} \text { - Cálcio } \\
& \text { Co - Cobalto } \\
& \mathrm{CO} \text { - Monóxido de carbono } \\
& \mathrm{Cr} \text { - Crômio } \\
& \mathrm{Cs} \text { - Césio } \\
& \text { Fe - Ferro } \\
& \text { HC - Hidrocarbonetos }
\end{aligned}
$$

IAEA - International Atomic Energy Agency

INCT - Institute of Nuclear Chemistry and Technology

K - Potássio

La - Lantânio

$\mathbf{M P}_{10}$ - Material Particulado com diâmetro aerodinâmico inferior a $10 \mu \mathrm{m}$ $\mathrm{NO}_{\mathbf{x}}-$ Óxidos de nitrogênio

NAA - Análise por ativação com nêutrons

$\mathrm{O}_{3}$ - Ozônio

Rb - Rubídio

RMSP - Região Metropolitana de São Paulo

Sc - Escândio

Se - Selênio

$\mathrm{SO}_{\mathrm{x}}$ - Óxidos de enxofre

VOCs - Compostos orgânicos voláteis

Zn - Zinco 


\section{INTRODUÇÃO}

\subsection{Poluição aérea}

Nos últimos anos, estudos sobre os efeitos da contaminação atmosférica têm se intensificado devido às evidências encontradas de que este tipo de poluição afeta na saúde das populações e nas condições climáticas. Os estudos epidemiológicos têm mostrado que há uma associação entre os níveis de poluentes e os números de mortes por doenças, como câncer pulmonar e a ocorrência de doenças respiratórias (Pope et al., 1995; Kampa e Castañas, 2008).

Caracteriza-se como poluição do ar a presença ou o lançamento de uma substância poluidora na atmosfera, em concentração acima de um limite de aceitabilidade para o bem-estar de seres humanos, animais, infra-estrutura e meio ambiente, seja ela de origem antrópica ou natural (Pires, 2005; Grauer, 2000).

Nos grandes centros urbanos observam-se condições desfavoráveis para uma qualidade de vida saudável devido ao trânsito intenso, rios, solo e ar poluídos decorrentes de lançamentos de efluentes e resíduos sólidos domésticos e industriais, assim como há problemas para a oferta de água e esgoto devidamente tratados. Estas condições inadequadas merecem maior atenção devido à relação com a saúde da população humana (Foratini, 1992).

Os problemas ambientais e de saúde também ocorrem em São Paulo, SP, uma das maiores cidades e das mais populosas do mundo. A região metropolitana de São Paulo (RMSP) possui uma população de 20 milhões de habitantes numa área de $8.051 \mathrm{~km}^{2}$ (IBGE, 2009a) e a região sofre de grave problema ambiental devido ás emissões atmosféricas de cerca de 3800 indústrias e de aproximadamente 10 milhões de veículos, de acordo com a Companhia Ambiental do Estado de São Paulo - CETESB, órgão responsável pelo controle da qualidade do ar no estado de São Paulo (CETESB, 2007).

Conforme o relatório da CETESB (2010) estas fontes de poluição são responsáveis pela emissão atmosférica de poluentes, a saber: 1,57 milhões de t/ano de monóxido de carbono (CO), 382.000 t/ano de hidrocarbonetos, 376.000 t/ano de óxidos de nitrogênio (NO), 63.000 t/ano de material particulado e 25.500 t/ano de óxidos de enxofre (SO). 


\subsection{Efeitos da poluição atmosférica sobre a saúde humana}

Apesar de serem conhecidos os efeitos negativos da poluição atmosférica sobre a saúde humana, torna-se difícil a comprovação da correlação entre os poluentes encontrados no ar e certas doenças (Peiter e Tobbar, 1998; Wapperlhorst et al., 2000).

Dentre as doenças mais estudadas decorrentes da poluição aérea estão as respiratórias, doenças do sistema central nervoso, cardiovascular, câncer entre outras.

Bakonyi et al. (2004) estudaram sobre o aumento da incidência de doenças respiratórias, nos períodos mais frios do ano, para a população da cidade de Curitiba, Paraná e concluíram que esta incidência se deve a dois fatores principais, baixa temperatura e aumento das concentrações dos poluentes primários no ar. Estes pesquisadores examinaram os efeitos que o ozônio $\left(\mathrm{O}_{3}\right)$ pode causar à saúde humana. A cidade de Curitiba possui invernos secos e com dias ensolarados, propiciando assim, todas as condições para elevação dos níveis desse agente fotoquímico. Os resultados permitiram verificar que os teores de $\mathrm{O}_{3}$ não apresentam correlação positiva com as variáveis $\mathrm{PM}_{10}$ (material particulado com diâmetro aerodinâmico menor que $10 \mu \mathrm{m}$ ) e o dióxido de nitrogênio $\left(\mathrm{NO}_{2}\right)$, visto que as concentrações de $\mathrm{O}_{3}$ não variaram da mesma forma que as destes poluentes primários.

No trabalho de Kampa e Castañas (2008) foi verificado que substâncias químicas perigosas liberadas para o meio ambiente, resultante das várias atividades naturais, podem causar efeitos adversos à saúde humana e ao meio ambiente. Neste trabalho foi estudado sobre a emissão de gases dos combustíveis fosseis tais como monóxido de carbono (CO), dióxido de enxofre $\left(\mathrm{SO}_{2}\right)$, óxidos de nitrogênio $\left(\mathrm{NO}_{\mathrm{x}}\right)$, compostos orgânicos voláteis (VOCs), ozônio $\left(\mathrm{O}_{3}\right)$, metais pesados e partículas respiráveis $\left(\mathrm{PM}_{2,5}\right.$ e $\left.\mathrm{PM}_{10}\right)$. Seus resultados mostraram que a poluição do ar pode ocasionar efeitos agudos e crônicos à saúde humana, afetando vários sistemas e órgãos diferentes. Os problemas ocasionados foram a infecção cardiática, câncer do pulmão, infecções respiratórias agudas nas crianças e bronquites crônicas em adultos (agravando doenças de coração pré-existentes), de pulmão ou ataques asmáticos. Foi verificado que exposições por um longo período a estes poluentes aumentam a 
taxa de mortalidade prematura e redução da probabilidade de vida dos seres humanos.

Wolterbeek e Verburg (2004), estudando a correlação existente entre a deposição atmosférica avaliada por meio da análise de musgos e a taxa de mortalidade de dados epidemiológicos para a população de Holanda, verificaram que a concentração total de selênio (Se) presente no musgo, pode ser correlacionada com a taxa de mortalidade, devido a câncer de próstata. Wappelhorst et al. (2000) verificaram que há uma associação entre o conteúdo de tálio ( $\mathrm{TI})$ presente nos musgos, com a incidência de doenças cardiovasculares e dos elementos $\mathrm{Ce}, \mathrm{Fe}, \mathrm{Ga}$ e Ge encontrados nos musgos, com a incidência de doenças do sistema respiratório.

De acordo com as estimativas apresentadas no boletim da Comissão Européia (EC, 2003), os atuais níveis de metais pesados tóxicos do ar podem ocasionar a morte por câncer de um milhão de indivíduos, em mais de 150 regiões da União Européia, se não forem adotadas novas medidas para redução dos níveis destes metais no ar. Também estão previstos mais de 400 novos casos de câncer de pulmão em todo território europeu em 2010, decorrente da inalação dos metais pesados presentes no ar.

Duchiade (1992) destacou sobre três tipos principais de reações ou efeitos do sistema respiratório nos seres humanos, devido aos poluentes:

- Efeitos agudos em indivíduos sadios, devido ao aumento súbito de poluição atmosférica;

- Exacerbação de doenças pré-existentes em indivíduos vulneráveis, com doenças relacionadas ao coração e doenças respiratórias prévias e,

- Fenômenos de hipersensibilidade de origem imunológica ou hiperatividade brônquica, por causarem dados reversíveis e problemas crônicos.

Cabe ainda ressaltar que no Brasil e em diversos países da América Latina, outros fatores tais como a má distribuição de renda, analfabetismo, condições precárias de habitação e degradação ambiental exercem papel importante nas condições de vida e saúde (Buss, 2000).

Os efeitos da poluição ambiental divulgados em diversos trabalhos destacam a necessidade da implementação de ações que priorizem a qualidade de vida dos cidadãos no que diz respeito aos aspectos de saúde e ambiente (Martine, 1996). 


\subsection{Biomonitoramento da poluição aérea}

Dentre as técnicas existentes para avaliação da poluição aérea, o biomonitoramento é considerado como uma alternativa bastante apropriada, quando comparada com o método convencional de medida direta de elementos poluentes, devido às vantagens de baixo custo e de manutenção. Hoje, a absorção e o acúmulo de diversos poluentes atmosféricos, incluindo os metais pesados pelas plantas (liquens, musgos, bromélias), são reconhecidos e elas são consideradas como monitores biológicos da medida da qualidade do ar (Garty, 2001; Markert, 1984).

A monitoração convencional direta apresenta, muitas vezes, dificuldades devido ao alto custo dos equipamentos coletores de materiais particulados do ar e da sua manutenção, para monitorar o grande número de pontos de amostragens necessários mesmo em áreas urbanas relativamente pequenas. A utilização de plantas acumuladoras de metais (ou bioindicadores de níveis de poluição atmosférica) é hoje considerada como uma ferramenta

bastante apropriada quando comparada a métodos convencionais de medidas de contaminantes.

Segundo Furlan (2008), entre as principais vantagens do uso do biomonitoramento ambiental estão a possibilidade de avaliar os riscos ocasionados pelos poluentes em ecossistemas, detectar os níveis crônicos ou agudos de contaminação do ar, integração de fatores endógenos da planta que possam influenciar a resposta à poluição e a integração de fatores externos, demonstrando efeitos sinérgicos e aditivos bem como a ampliação da área a ser monitorada.

Conseqüentemente, estudos relacionados ao uso de biomonitores da poluição aérea têm sido tema de inúmeros projetos de caráter multidisciplinar das áreas do meio ambiente e saúde.

Além disso, os teores elementares nos biomonitores epifíticos refletem as concentrações de contaminantes atmosféricos no ambiente monitorado, uma vez que esses organismos não possuem raízes ou não estão em contato com o solo e acumulam os elementos nutrientes da atmosfera. 
Entre os organismos que podem ser aplicados como biomonitores, os liquens são classificados como um dos biomonitores bastante apropriados para avaliação dos poluentes atmosféricos.

Os dados do biomonitoramento têm sido correlacionados com os efeitos nocivos à saúde humana, principalmente nos países da Europa. Os autores Cislaghi e Nimis (2007) verificaram a correlação existente entre a biodiversidade de liquens e a taxa de mortalidade por câncer pulmonar, para a população de Veneto, na Itália.

Recentemente, Sarmento et al (2008) verificaram a associação existente entre as concentrações de elementos $\mathrm{Br}$, I, Ni, Pb, S, Sb e V obtidos no biomonitoramento usando liquens, com a mortalidade por câncer pulmonar (neoplasma) para a população de Portugal.

Apesar dos efeitos da poluição observados em plantas não possam ser extrapolados para populações humanas, os resultados de experimentos com estas espécies tem sido utilizados para este fim, considerando a grande sensibilidade de tais organismos, mesmo em situações com baixos níveis de contaminação do ar. Desta forma, segundo Guimarães et al. (2000) é admissível considerar que, se um poluente não causa nenhum dano detectável para a maioria das espécies vegetais sensíveis, não afetará também as demais espécies, incluindo os seres humanos.

Por outro lado, as plantas bioindicadoras têm exercido papel cada vez maior no controle da qualidade do ar, tendo em vista que os efeitos negativos da poluição sobre eles são facilmente observáveis, inclusive para leigos sobre o assunto (Klumpp et al., 2001).

Desta forma, o biomonitoramento da contaminação aérea tem demonstrado ser bastante adequado, quando comparado com o método convencional de medida de elementos poluentes.

Carneiro (2004) fez uma revisão sistemática de trabalhos sobre espécies vegetais (vasculares, musgos e líquens) utilizadas como bioindicadores durante o período de janeiro de 1997 a junho de 2003, por meio de estudos experimentais e observacionais, fazendo uma associação com os poluentes atmosféricos. Os resultados deste estudo revelaram que 112 espécies vegetais, sendo 64 espécies da Angiospermae; 11 espécies da Coniferophyta; 22 espécies de liquens e 15 espécies de musgos podem ser relacionadas aos dados de 
monitoramento de um ou mais poluentes atmosféricos, a saber: metais pesados, ozônio, material particulado, dióxido de enxofre, óxidos de nitrogênio, monóxido de carbono, fluoretos, compostos orgânicos voláteis e hidrocarbonetos.

Em trabalhos anteriores, desenvolvidos no Laboratório de Análise por Ativação Neutrônica do IPEN-CNEN/SP, Saiki et al. (1997) definiram as condições apropriadas para o preparo prévio de liquens para análise e determinaram 32 elementos em amostras de fungo liquenizado Canoparmelia texana, aplicando o método de análise por ativação com nêutrons (NAA). Recentemente, Fuga et al (2008) analisaram liquens da Região Metropolitana de São Paulo (RMSP) e obtiveram mapas de distribuição das concentrações de elementos, oriundas de emissões veiculares, industriais e do solo.

Mota Filho et al (2007) utilizaram a espécie de líquen Cladonia verticillaris visando obterem dados que comprovassem a capacidade dessa espécie na retenção de poluentes atmosféricos. A espécie foi utilizada em experimento de transplante, ou biomonitoramento ativo, respondeu às agressões do ambiente na região metropolitana do Recife e Vertente do Lério, no interior de Pernambuco.

Face ao levantamento bibliográfico apresentado foi possível verificar que o uso do biomonitoramento e os estudos dos efeitos da poluição aérea são temas de inúmeras pesquisas. Atualmente, os problemas ligados à poluição ambiental constituem uma preocupação séria por parte de autoridades governamentais e de entidades ligadas à preservação do bem estar das populações.

Dentre ao grande número de tipos de materiais biológicos que são estudados para uso como biomonitores, convém ressaltar que os liquens têm sido amplamente investigados para monitoramento da poluição atmosférica de elementos químicos.

Nos trabalhos já realizados sobre o biomonitoramento da Região Metropolitana de São Paulo (Fuga, 2008; Nogueira, 2006), foi evidenciada a diversidade do perfil de São Paulo, do ponto de vista da poluição, com um grande número de fontes poluidoras.

Dentro deste contexto, julgou-se de grande interesse neste trabalho investigar sobre a deposição aérea de poluentes em diferentes pontos da cidade 
de São Paulo, por meio da determinação de elementos químicos acumulados em liquens, visando futuro estudo da correlação com a saúde da população.

\subsection{Liquens e a poluição aérea}

Como neste trabalho serão utilizados liquens no estudo da poluição aérea, serão apresentadas a seguir, algumas considerações sobre este organismo.

Os liquens são uma associação de fungos e algas verdes, ou seja, de cianobactérias. Esta associação simbiótica forma um talo que não possui raízes ou película cerosa cuja sobrevivência depende, principalmente, da deposição atmosférica de nutrientes minerais (Fuga, 2006). Estas características dos liquens, combinadas com sua extraordinária capacidade de crescer em um amplo espaço geográfico e de acumular elementos mais do que necessitam para a sua sobrevivência, faz com que sejam considerados como os melhores bioindicadores para a poluição do ar (Garty, 2001). As condições ambientais são de grande importância à sobrevivência dos liquens tendo em vista que estes se alimentam higrocospicamente, fixando elementos químicos, como por exemplo, o nitrogênio, bem como acumulam os elementos radioativos, íons metálicos entre outros poluentes. Estas características fazem com que eles sejam utilizados como bioindicadores de poluição atmosférica (Villarouco \& Andreto, 2005).

Honda (2006) relata sobre a correlação existente entre a distribuição das espécies com as fontes poluidoras e os efeitos ocasionados pelas emissões de poluentes. Este autor descreve sobre os liquens com manchas de cores verdeclaro ou avermelhadas e com bordas arredondadas comprovando a sua eficácia como bioindicador, uma vez seu organismo reagiu prontamente às modificações da qualidade do ar.

Os autores Geebelen e Hoffman (2001) consideraram as emissões de $\mathrm{SO}_{2}$ como principais fatores responsáveis pela presença ou ausência de liquens epífitas na região de Flanders, Bélgica, mesmo que as reduções significativas dos poluentes tenham sido observadas na região, nas últimas décadas do século $X X$.

Loppi e Bonini (2000) determinaram concentrações de metais (Al, As, B, Cd, Cu, Fe, Hg, Mo, Pb, Sb e Zn) em amostras da espécie Parmelia sulcata 
sob influência de emissões de fontes termais e veiculares, da região do Monte Amiata, Itália. A espécie demonstrou ser boa acumuladora e metais analisados.

São conhecidas três espécies principais de liquens, a saber: liquens crustáceos, que formam camadas como uma crosta (Figura 1.1); liquens foliáceos, constituídos por escamas ou lóbulos em forma de folha (Figura 1.2); e liquens dendríticos ou fruticolosos, semelhantes a miniaturas de arbustos, com ramificações que lhes permitem manter-se retos ou pendurar-se nas árvores (Figura 1.3) (Klickeducação, 2010).

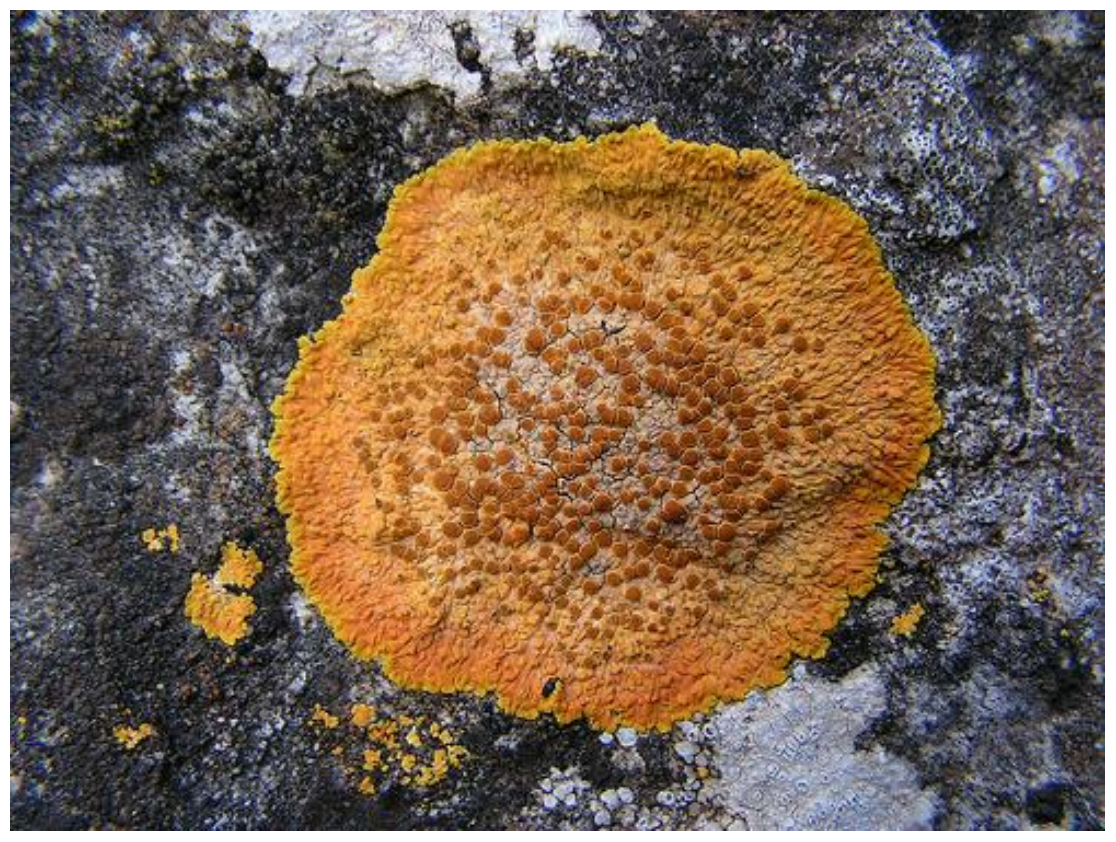

Figura 1.1. Foto do líquen da espécie crustáceo. Escala (1:1). 


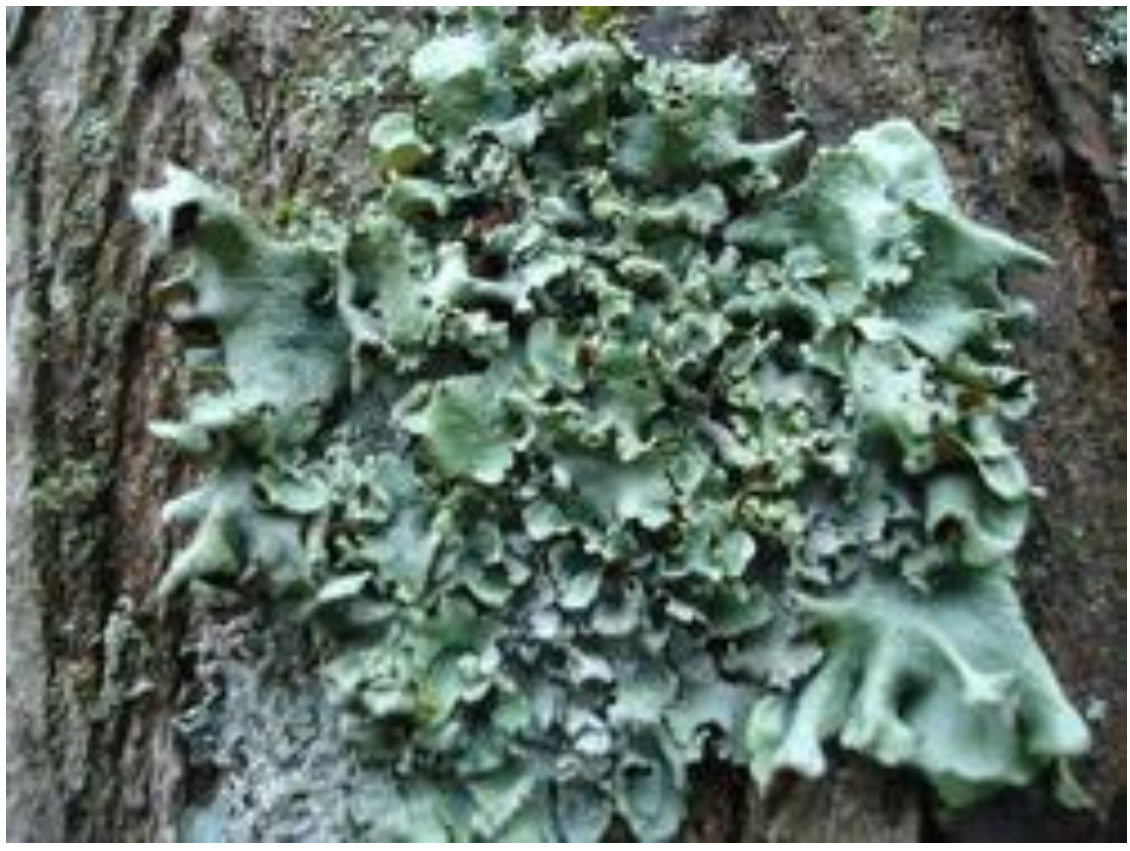

Figura 1.2. Foto do líquen da espécie foliáceo. Escala (1:1).

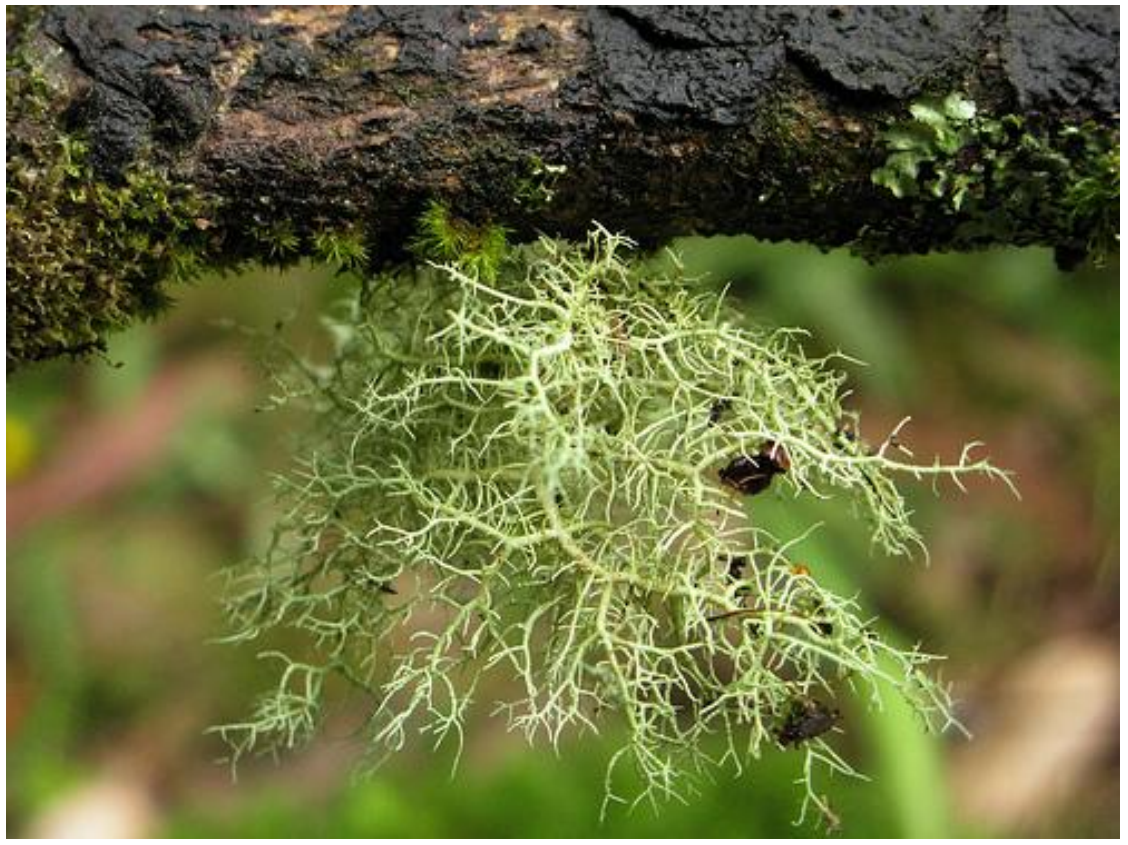

Figura 1.3. Foto do líquen da espécie dendrítico ou frutuoso. Escala (1:1).

Em estudo recente realizado pelos autores Sousa et al. (2004), foram caracterizadas 41 morfoespécies de liquens, em uma área de $270 \mathrm{~m}^{2}$, demonstrando o alto grau de cobertura dos liquens existentes em áreas com índices baixos ou inexistentes de poluição atmosférica.

Os liquens são encontrados em rochas, cascas de árvores e madeira. São seres que vivem em ambientes onde nenhum outro fungo ou alga 
se desenvolveria, pois os liquens toleram condições climáticas extremas, como temperaturas desde $-196^{\circ} \mathrm{C}$ a 60ํㅡ (Silva, 2010).

Como os organismos epifíticos não apresentam contato direto com o solo, esses formam um compartimento especial do ecossistema no contexto de estudos de ciclagem de elementos químicos (Elias et al., 2006).

De acordo com Coccaro (2001), a espécie Canoparmelia texana é um líquen epífito, folhoso, pertencente à família Parmeliaceae, encontrado em praticamente todas as cidades não litorâneas. Esta espécie aparece em regiões de poluição relativamente elevada.

A espécie Canoparmelia texana apresenta talo circular, crescimento radial e taxa de crescimento que varia de 0,5 a $5 \mathrm{~mm}$ por ano, que está relacionada com a umidade do local e a taxa fotossintética do líquen. $A$ área central do líquen corresponde à fração mais velha, ou seja, a que teve maior tempo de exposição aos poluentes.

Dentre os diversos trabalhos sobre o uso de liquens no estudo da poluição aérea, destaca-se o de Garty et al. (2003) que analisaram a qualidade do ar em torno de uma estação elétrica em Israel, onde se utiliza como combustível o carvão de pedra. Como biomonitor, estes pesquisadores utilizaram a espécie Ramalina lacera. O objetivo deste estudo foi avaliar os parâmetros fisiológicos do líquen diante de uma situação de estresse e a determinação de elementos químicos. Foram analisados alguns dados sobre os potenciais da fotossíntese, produção de etileno e a condutividade elétrica, assim como os níveis de poluentes acumulados nos liquens. As amostras coletadas próximas aos pontos de emissão de poluentes apresentaram teores mais elevados de elementos químicos. Não foi verificada nos liquens a alteração do rendimento fotossintético, entretanto a condutividade elétrica que expressa a integridade da membrana foi mais elevada nos liquens coletados nas regiões próximas à estação. Já a produção de etileno nos liquens foi elevada, assim como ocorreu para elementos químicos onde foram obtidos altos níveis de $\mathrm{S}, \mathrm{Pb}, \mathrm{Ni}, \mathrm{V}, \mathrm{Cr}$, Cu e Ba. A espécie Ramaline lacera foi também estudada para ser utilizada como sensor ambiental, cuja característica foi evidenciada por meio dos danos fisiológicos e do acúmulo de certos elementos como metais pesados e enxofre.

De acordo com Honda (2006), a sensibilidade dos liquens à poluição atmosférica tem sido estudada há mais de cem anos e suas análises vêm sendo 
realizadas há mais de duas décadas, com pesquisas de vários países e nas últimas décadas no Brasil.

Segundo Fellenberg (1980) e Gutberlet (1996), as vantagens na utilização de liquens na avaliação da contaminação ambiental, se devem às seguintes possibilidades:

- Analisar as atividades fisiológicas de substâncias nocivas;

- Verificar intoxicações crônicas decorrentes de exposições prolongadas;

- Determinar a ação de certo poluente, devido à poluição total do ar;

- Realizar os experimentos em grandes áreas, já que os organismos utilizados apresentam um custo mais baixo do que os monitores mecânicos;

- Não necessidade de energia elétrica para a exposição ou coleta;

- Os resultados obtidos por meio das análises de organismos vivos serem compatíveis com aqueles apresentados pelos equipamentos mecânicos.

Os liquens foram também muito analisados na Europa, após o acidente de Chernobyl, ocorrido em 1986, para estudar a dispersão e deposição atmosférica de radionuclídeos emitidos para a atmosfera (Biazrov, 1994; Adamo et al., 1994).

\subsection{Breve descrição sobre a região de estudo}

\subsubsection{Aspectos gerais da região metropolitana de São Paulo}

A região metropolitana de São Paulo (RMSP) está localizada a 23ํㅗำ 23' 51'S e 46³8'10'W, conforme relatório do Instituto Brasileiro de Geografia e Estatística (IBGE, 2009) e do Programa Nações Unidas para o Desenvolvimento (PNUD, 2000). A RMSP conhecida como Grande São Paulo, reúne 39 municípios e ocupa uma área cerca de $8051 \mathrm{~km}^{2}$ do território paulista. Também, possui cerca de 33.921 indústrias espalhadas nas cinco regiões (Norte, Sul, Leste, Oeste e Centro) e aproximadamente 9,7 milhões de veículos circulando pela cidade. Com 19.616.060 habitantes, a RMSP é o maior centro urbano do Brasil e da América do Sul, e a sexta maior área urbana do mundo.

A região é drenada pela Bacia do Rio Tietê no sentido leste-oeste e tem como seus principais afluentes os rios Pinheiros e Tamanduateí. Ao longo desses rios, ficam as várzeas, ladeadas por terraços de 725 a $735 \mathrm{~m}$. Mais acima, ficam as colinas que atingem $750 \mathrm{~m}$. No interflúvio dos rios Tietê e Pinheiros 
encontram-se o Espigão Central (Espigão da Paulista) com altitudes superiores a 800m (CETESB, 1993).

O clima na RMSP pode ser resumido como seco no inverno e úmido no verão. De setembro a abril, a área é dominada por um vento úmido do sul e ocorrência freqüente de sistemas frontais, resultando em precipitações e nuvens de baixa altitude, com pouca radiação solar. Durante o inverno, sistemas de alta pressão no oceano Atlântico leste, dirigem-se para o norte, produzindo ventos fracos provenientes da costa, forte inversão térmica de subsidência e céu claro. $A$ precipitação pluviométrica torna-se muito menos freqüente para São Paulo, o que empurra o anticiclone subtropical marítimo e o vento passa a soprar de Nordeste e, finalmente, de Noroeste, com a chegada da frente fria (CETESB, 1993).

Ao longo dos anos, foram observadas algumas mudanças na temperatura, na umidade e na visibilidade, bem como mudanças na radiação, na nebulosidade, precipitação e nos nevoeiros. Apesar do decréscimo da radiação solar induzido pela poluição atmosférica, as temperaturas observadas em São Paulo são geralmente mais elevadas do que as áreas rurais circunvizinhas. As temperaturas nesta região variam aproximadamente de $8^{\circ} \mathrm{C}$ (média das mínimas) durante o inverno, a $30^{\circ} \mathrm{C}$ (média das máximas) durante o verão. A brisa marítima e as circulações entre a região plana e a montanha produzem forte variação diurna no campo de vento nos baixos níveis (superfície). Estas circulações diurnas são mais fortes durante os meses de verão, quando a incidência solar é mais intensa e de maior duração (CETESB, 1993).

A poluição aérea da cidade de São Paulo é afetada pelas emissões veiculares uma vez que partem da RMSP os complexos viários dos Sistemas Anhangüera-Bandeirantes, Dutra-Trabalhadores e Anchieta-Imigrantes, além das Rodovias Raposo Tavares, Castello Branco, Marechal Rondon e Régis Bittencourt. A recente incorporação do Rodoanel, que deverá interligar esses sistemas, embora parcialmente ainda em construção, supõe que as cargas forâneas circulantes pelos vários complexos viários poderão completar seu percurso sem necessidade de trafegar pelas marginais paulistanas, o que sobrecarrega o tráfego municipal.

O movimento de veículos das dez grandes rodovias converge para a RMSP, onde o tráfego de passagem destes veículos se junta ao tráfego local. $\mathrm{O}$ 
grande fluxo de veículos que chega diariamente a São Paulo e, em grande parte, atravessa a capital rumo a outra localidade, ocasiona um imenso fluxo viário na região.

Relativamente às emissões industriais convém salientar que a capital é o principal pólo industrial do Estado e do país, mantendo uma indústria vigorosa, sobretudo a produtora de bens com maior valor agregado, que necessita de tecnologia e mão-de-obra especializada ou da proximidade do centro consumidor para se desenvolver.

O estudo realizado pelas pesquisadoras Mariani e Martins (2009) revelou que os efeitos gerados pela poluição aérea da cidade de São Paulo podem afetar moradores de cidades distantes até $300 \mathrm{~km}$ da capital paulista e, dependendo da umidade e das condições de ventos, os poluentes podem chegar ainda mais longe. A estimativa de emissão por tipo de fonte para a cidade de São Paulo é mostrada na Tabela 1.1.

Tabela 1.1. Contribuição relativa das fontes de poluição do ar na RMSP em 2009 (Fonte CETESB, 2010).

\begin{tabular}{|c|c|c|c|c|c|c|}
\hline \multirow{2}{*}{\multicolumn{2}{|c|}{ Fonte de Emissão }} & \multicolumn{5}{|c|}{ Poluentes } \\
\hline & & \multirow{2}{*}{$\frac{\mathrm{CO}}{41,14}$} & \multirow{2}{*}{$\begin{array}{c}\mathrm{HC} \\
17,35\end{array}$} & \multirow{2}{*}{$\begin{array}{c}\mathrm{NO}_{\mathrm{x}} \\
11,27\end{array}$} & \multirow{2}{*}{$\frac{\mathrm{SO}_{\mathrm{x}}}{14,51}$} & \multirow{2}{*}{$\begin{array}{r}\mathrm{MP}_{10}{ }^{2} \\
8,91\end{array}$} \\
\hline \multirow{5}{*}{$\begin{array}{l}\text { Tubo de escapamentos de } \\
\text { veículos }\end{array}$} & Gasolina $\mathrm{C}^{1}$ & & & & & \\
\hline & Álcool & 13,01 & 5,94 & 3,72 & - & - \\
\hline & Diesel & 26,10 & 16,44 & 79,88 & 16,47 & 28,51 \\
\hline & Taxi & 0,12 & 0,29 & 0,58 & - & - \\
\hline & $\begin{array}{l}\text { Motocicleta e } \\
\text { similares }\end{array}$ & 17,18 & 9,55 & 0,82 & 1,96 & 2,57 \\
\hline \multirow{3}{*}{ Cárter e Evaporativa } & Gasolina C & - & 29,70 & - & - & - \\
\hline & Álcool & - & 5,23 & - & - & - \\
\hline & $\begin{array}{l}\text { Motocicleta e } \\
\text { Similares }\end{array}$ & - & 8,14 & - & - & - \\
\hline Operações de transferência & Gasolina C & - & 3,35 & - & - & - \\
\hline de combustível & Alcool & - & 0,86 & - & - & - \\
\hline \multicolumn{2}{|c|}{ Operação de processo industrial (1990) } & 2,46 & 3,14 & 3,72 & 67,06 & 10,00 \\
\hline \multicolumn{2}{|c|}{ Ressuspensão de partículas } & - & - & - & - & 25,00 \\
\hline \multicolumn{2}{|c|}{ Aerossóis secundários } & - & - & - & - & 25,00 \\
\hline \multicolumn{2}{|l|}{ TOTAL } & 100 & 100 & 100 & 100 & 100 \\
\hline
\end{tabular}


Este inventário de emissão para a cidade de São Paulo é baseado nas informações disponíveis no ano-referência de 2009. Os fatores de emissão foram extraídos do Compilation of Air Pollutant Emission Factors da EPA Environmental Protection Agency (Agência de Proteção Ambiental dos Estados Unidos) e dos ensaios de emissão das próprias fontes (CETESB, 2010).

De acordo com o relatório de qualidade do ar da CETESB (2010), a contribuição relativa de cada fonte de poluição do ar na cidade de São Paulo pode ser mais facilmente observada em que os veículos automotores são as principais fontes de monóxido de carbono, hidrocarbonetos totais e óxidos de nitrogênio no ar. Para os óxidos de enxofre, as indústrias e os veículos são importantes fontes e, no caso das partículas inaláveis, contribuem ainda outros fatores como a ressuspensão de partículas do solo e a formação de aerossóis secundários.

Também, de acordo com a CETESB (2010), a redução dos hidrocarbonetos e óxidos de nitrogênio, considerados os principais precursores de ozônio, pode contribuir para a diminuição das concentrações destes poluentes na atmosfera. Entretanto, é importante lembrar que, além do aumento da frota circulante, outras fontes de precursores de $\mathrm{O}_{3}$ na cidade de São Paulo são consideradas importantes, como as emissões evaporativas que ocorrem no momento do reabastecimento dos tanques dos veículos e dos postos de gasolina, bem como de fontes industriais que emitem compostos orgânicos voláteis. 


\section{OBJETIVOS}

\subsection{Objetivos gerais e específicos}

O objetivo geral deste trabalho foi avaliar os níveis de elementos químicos da poluição aérea da cidade de São Paulo por meio de biomonitoramento passivo, usando a espécie epifítica Canoparmelia texana.

Os objetivos específicos deste trabalho são:

- Avaliar a qualidade dos resultados com relação à exatidão e precisão, por meio dos dados obtidos na análise por ativação com nêutrons (NAA);

- Avaliar a reprodutibilidade dos resultados das análises de liquens por meio das determinações de elementos em replicatas;

- Obter as concentrações de elementos em liquens, coletados nos diferentes pontos de estudo de São Paulo e do ponto de referência, na cidade de Ubatuba-SP;

- Fazer um estudo comparativo entre as concentrações de elementos obtidos nos liquens coletados em diferentes pontos de amostragens e verificar a possibilidade de identificar a fonte de origem dos elementos poluentes da atmosfera da cidade de São Paulo. 


\section{METODOLOGIA}

\subsection{Metodologia de análise por ativação com nêutrons}

Sendo a análise por ativação com nêutrons (NAA) a metodologia a ser aplicada neste trabalho será apresentada a seguir sobre a técnica, de maneira resumida.

A análise de ativação com nêutrons foi descoberta em 1936 quando Hevesy e Levi descobriram que amostras contendo certos elementos de terras raras se tornavam altamente radioativos quando expostas a um feixe de nêutrons. Dessa observação, eles reconheceram o potencial do emprego das reações nucleares pela medição da radioatividade induzida para determinação qualitativa e quantitativa dos elementos presentes na amostra.

A NAA se baseia na medição de radioatividade induzida aos elementos da amostra pela sua irradiação com fluxo de nêutrons de um reator nuclear. Neste processo de irradiação, os isótopos estáveis são transformados em isótopos radioativos ou radionuclídeos artificiais.

$\mathrm{Na}$ irradiação, quando um nêutron interage com um núcleo alvo por meio de uma colisão não-elástica, forma-se um núcleo composto num estado excitado. A energia de excitação do núcleo composto é devida à energia de ligação do nêutron com o núcleo e a energia cinética do nêutron. O núcleo composto, quase que instantaneamente, sofre des-excitação para uma configuração mais estável, por meio da emissão de raios gama "pronto" característicos.

O tempo de vida do núcleo composto é da ordem de $10^{-16}$ a $10^{-14} \mathrm{~s}$. Em muitos casos, esta nova configuração produz um núcleo radioativo, que também sofre des-excitação por meio da emissão de um ou mais raios gama de decaimento característicos, mas a uma razão mais lenta, de acordo com o tempo de meia-vida do nuclídeo radioativo. Este processo de formação de um nuclídeo radioativo é representado por meio da reação nuclear apresentada na Figura 3.1. 


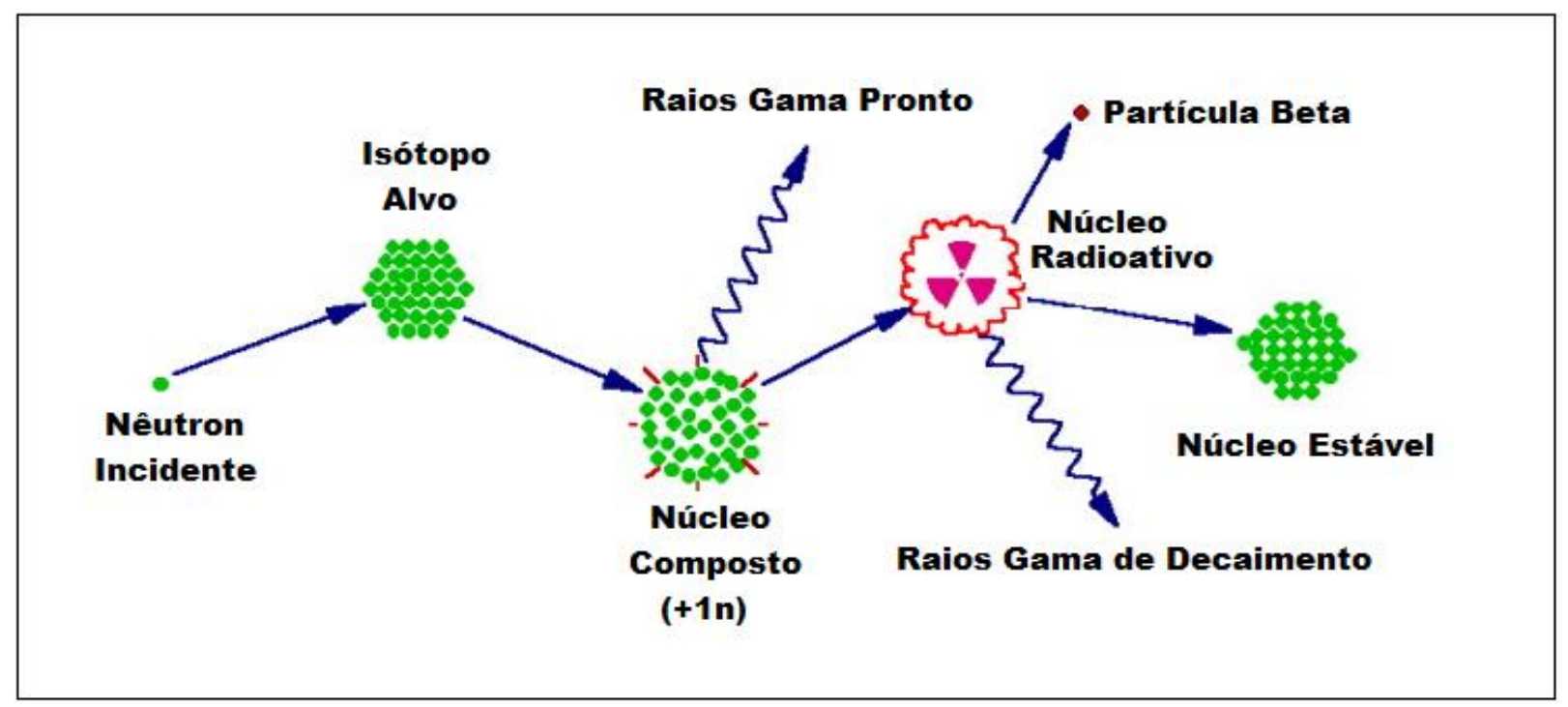

Figura 3.1. Esquema que ilustra o processo de captura de nêutron por um núcleo seguida da emissão de raios de gama pronto e de decaimento. Fonte: FCF-USP (modificado).

A medição da radiação emitida por ${ }^{\mathrm{A}+1}{ }_{z} \mathrm{X}$ permite a análise qualitativa e quantitativa do elemento que deu origem a este radioisótopo. Como cada radionuclídeo decai com uma determinada meia vida e, como a maioria deles emitem um ou mais raios gama, a identificação do radioisótopo é feita pela meia vida e energias dos raios gama.

$\mathrm{Na}$ irradiação com nêutrons de um reator nuclear, a atividade em taxas de contagens $(A)$ induzida a um elemento após certo tempo de irradiação (ti) é dada por (De Soete et al., 1972):

$$
A=\left\{z \phi \sigma N m f\left[1-e^{-0,693 t i / t}{ }_{1 / 2}\right]\right\} /\{M\}
$$

onde:

$A=$ atividade em taxas de contagens;

$z=$ coeficiente de detecção ou eficiência do detector;

$\phi=$ fluxo de nêutrons, em $\mathrm{n} \mathrm{cm}^{-2} \mathrm{~s}^{-1}$;

$t_{i}=$ tempo de irradiação;

$t_{1 / 2}=$ meia vida do radioisótopo;

$\sigma=$ secção de choque, em barns;

$N=$ constante de Avogadro;

$m=$ massa do elemento; 
$f=$ abundância isotópica e

$M=$ massa atômica do elemento.

A determinação da concentração do elemento pode ser feita pelo método comparativo, que foi utilizado neste trabalho, em que um padrão do elemento de massa conhecida é irradiado e medido nas mesmas condições da amostra.

Isto é, escrevendo a relação (3.1), para amostra e padrão que foram irradiados e mensurados na mesma geometria de contagem para tempo de decaimento $t=0$, e dividindo membro a membro uma relação pela outra, tem se:

$$
\frac{A_{\mathrm{a}} o}{A_{p} o}=\frac{m_{a}}{m_{p}}
$$

onde os índices a e $p$ se referem à amostra e padrão, respectivamente e $A_{a} O \mathrm{e}$ $A_{p} O$ são as taxas de contagens da amostra e padrão para tempo de decaimento $t=0$.

Pela lei do decaimento (Friedlander et al. 1981) tem se:

$$
A=A o e^{-0,693 t t 1 / 2}
$$

$\mathrm{Na}$ relação (3.3) $A$ e $A o$ são as taxas de contagens para tempos de decaimento $t$ e $t=0$, respectivamente.

Escrevendo a relação (3.3) para amostra e padrão medidos respectivamente para tempos de decaimento $t_{d a}$ e $t_{d p}$, e substituindo-as na equação (3.2), tem-se:

$$
m_{a}=\frac{m_{p} A_{a} e^{0,693 \frac{t_{d a}}{t_{1 / 2}}}}{A_{p} e^{0,693 \frac{t_{d p}}{t_{1 / 2}}}}
$$

Sendo $C_{a}$ a concentração do elemento na amostra tem-se $C_{a}=\frac{m_{a}}{M_{a}}$, $\log 0$ 


$$
C_{a}=\frac{m_{p} A_{a} e^{0,693 \frac{t_{d a}}{t_{1 / 2}}}}{M_{a} A_{p} e^{0,693 \frac{t_{d p}}{t_{1 / 2}}}}
$$

ou

$$
C_{a}=\frac{m_{p} A_{a} e^{0,693^{\left(t_{d a}-t_{d p}\right)}}}{M_{a} A_{p}}
$$

onde $A_{a}$ e $A_{p}$ são os valores das taxas de contagens da amostra e padrão medidos para tempos de decaimento, $t_{d a}$ e $t_{d p}$, respectivamente; $M_{a}=$ massa total de amostra e $m_{p}=$ massa do elemento no padrão.

A relação (3.6) será utilizada no cálculo da concentração do elemento na amostra.

A instrumentação para medir a radiação gama consiste de um detector de $\mathrm{Ge}$ hiperpuro conectado a um sistema multianalisador (MCA/computador) e sistema eletrônico associado. O tipo de detector, geralmente utilizado é coaxial que permite a medição de raios gama com energias de cerca de $60 \mathrm{keV}$ a 3,0 MeV.

\subsection{Vantagens e desvantagens da utilização da técnica de NAA}

O método de NAA tem sido muito utilizado na análise de diversos tipos de amostras devido às seguintes vantagens:

- Alta sensibilidade. Esta técnica permite determinar elementos traço em concentrações muito baixas da ordem de partes por milhão (ppm) ou partes por bilhão (ppb), dependendo do elemento;

- Capacidade multielementar, ou seja, permite determinar simultaneamente diversos elementos em uma única amostra;

- Os resultados das análises são independentes da forma química do elemento. A ativação com nêutrons é baseada no fenômeno físico ocorrido no núcleo do átomo. Portanto, a forma química, como definido por ligação química, não tem influência nos resultados. Além disso, não há efeito da matriz como pode 
ocorrer em outras técnicas analíticas baseadas na propriedade atômica de troca de cargas entre eles;

- Boa exatidão e precisão dos resultados de um grande número de elementos;

- Não há necessidade de destruição física da amostra, no caso da NAA instrumental, e pode ser usada para outras investigações, principalmente para amostras submetidas a irradiações de curto período no reator nuclear;

- Quantidade da amostra requerida é muito pequena;

- Não é necessária a determinação do branco analítico quando a irradiação é realizada em invólucros de alta pureza;

- Pode ser utilizada de forma automatizada como, por exemplo, em processos de rotina (IAEA,1990; Alfassi, 1990).

Entre as desvantagens da análise por ativação com nêutrons estão:

- A necessidade de um reator nuclear bem como da exposição de um analista à radiação;

- Tempo requerido para determinações de elementos cujos radioisótopos apresentam meias vidas longas;

- A não determinação de elementos como o oxigênio (O), nitrogênio $(N)$, carbono $(\mathrm{C})$ e chumbo $(\mathrm{Pb})$ e a impossibilidade de identificação da forma química do elemento na amostra.

Alguns elementos tais como $\mathrm{O}, \mathrm{N}, \mathrm{C}$ e $\mathrm{Pb}$ não apresentam características nucleares favoráveis à ativação com nêutrons. 


\section{PARTE EXPERIMENTAL}

\section{1 Áreas de estudo}

As áreas de estudo deste trabalho foram na cidade de São Paulo (2332'51" S; 46³8'10" W), localizada na chamada Região Metropolitana de São Paulo (RMSP) e também em um ponto de referência fora da RMSP, na cidade de Ubatuba-SP.

Quando possíveis, os locais de amostragens dos liquens foram escolhidos próximos às redes de monitoramento automático da CETESB. Em alguns pontos, os liquens não foram encontrados próximos às redes de monitoramento.

No momento da coleta foi preenchido um formulário contendo as informações sobre o local da coleta, data e coordenadas geográficas (elevação, latitude e longitude), obtidas do aparelho GPS (Geographical Position System). Na Figura 4.1 é apresentada uma parte do mapa da RMSP, isto é, da área em que foram realizadas as coletas das amostras de liquens neste trabalho. Também, no mapa da Figura 4.1 são apresentadas as rodovias que compõem o sistema rodoviário da RMSP, de acordo com os códigos apresentados na Tabela 4.1.

Na Tabela 4.2 são apresentadas a localidade, posição geográfica e elevação (em metros), de cada ponto onde foram realizadas as coletas de amostras de líquen. 




Figura 4.1. Mapa das principais rodovias que compõem o sistema rodoviário da Região Metropolitana de São Paulo. Fonte: São Paulo SP - Turismo (2008) (modificado). 
Tabela 4.1. Códigos e nomes das principais rodovias que compõem o sistema rodoviário da RMSP.

\begin{tabular}{cc}
\hline Código da Rodovia & Nome da Rodovia \\
BR 116 & Presidente Dutra \\
BR 381 & Fernão Dias \\
SP 015 & Marginal Pinheiros e Marginal Tietê \\
SP 019 / SP 070 & Ayrton Senna \\
SP 021 & Rodoanel Mário Covas \\
SP 036 / SP 060 & Estrada Guarulhos - Nazaré Paulista \\
SP 056 / SP 066 & Estrada Alberto Hinoto \\
SP 150 & Anchieta \\
SP 176 & Estrada Divisa São Paulo - Diadema \\
SP 214 & José Simões Louro Junior \\
SP 228 & Armando Salles \\
SP 234 & Bento Rotger Domingues \\
SP 270 & Raposo Tavares \\
SP 280 & Castello Branco \\
SP 312 & Estrada dos Romeiros \\
SP 330 & Anhanguera \\
SP 348 & Rodovia dos Bandeirantes
\end{tabular}


Tabela 4.2. Dados dos locais de amostragens de líquen na cidade de São Paulo e na região de Ubatuba, SP.

\begin{tabular}{|c|c|c|c|c|c|c|}
\hline \multirow{2}{*}{$\begin{array}{l}\text { Código das } \\
\text { Amostras }\end{array}$} & \multirow{2}{*}{$\begin{array}{l}\text { Localização da rede de } \\
\text { estações automáticas } \\
\text { próximas ao local de coleta }\end{array}$} & \multirow{2}{*}{ Nome do bairro ou distrito } & \multirow{2}{*}{$\begin{array}{l}\text { Data da } \\
\text { Coleta }\end{array}$} & \multicolumn{3}{|c|}{$\begin{array}{c}\text { Coordenadas geográficas do local } \\
\text { de coleta }\end{array}$} \\
\hline & & & & $\begin{array}{l}\text { Elevação } \\
(\mathbf{m})\end{array}$ & Latitude & Longitude \\
\hline PDP & Av. do Estado s/no & $\begin{array}{l}\text { Parque Dom Pedro II - São } \\
\text { Paulo, SP. }\end{array}$ & 15/01/09 & 752,9 & $23^{\circ} 32,788^{\prime}$ & $46^{\circ} 37,623^{\prime}$ \\
\hline CGN & Av. dos Bandeirantes, no 4860 & Congonhas - São Paulo, SP. & $22 / 01 / 09$ & 762,3 & $23^{\circ} 36,929^{\prime}$ & $46^{\circ} 39,742^{\prime}$ \\
\hline USP & Av. Lineu Prestes, no 2242 & $\begin{array}{c}\text { Cidade Universitária / IPEN - } \\
\text { São Paulo, SP. }\end{array}$ & $18 / 09 / 08$ & 741,3 & $23^{\circ} 32,459^{\prime}$ & $46^{\circ} 41,231^{\prime}$ \\
\hline LAP & Rua Major Paladino, № 300 & Lapa - São Paulo, SP. & $16 / 01 / 09$ & 737,4 & $23^{\circ} 31,222$ & $46^{\circ} 43,320^{\prime}$ \\
\hline MOC & Rua Bresser, no 1954 & Moóca - São Paulo, SP. & $30 / 01 / 09$ & 740,9 & $23^{\circ} 33,039^{\prime}$ & $46^{\circ} 36,012^{\prime}$ \\
\hline MOR & Rua Barão do Triunfo, no 464 & Morumbi- São Paulo, SP. & 29/01/09 & 765,2 & $23^{\circ} 36,148$ & $46^{\circ} 43,131^{\prime}$ \\
\hline NSO & Av. Elísio Teixeira Leite, no 1155 & $\begin{array}{l}\text { Nossa Senhora do Ó - São } \\
\text { Paulo, SP. }\end{array}$ & $23 / 01 / 09$ & 788,1 & $23^{\circ} 24,206^{\prime}$ & $46^{\circ} 45,634^{\prime}$ \\
\hline PIB & Av. República do Líbano, no 390 & $\begin{array}{l}\text { Parque Ibirapuera - São } \\
\text { Paulo, SP. }\end{array}$ & $22 / 01 / 09$ & 754,4 & $23^{\circ} 35,502^{\prime}$ & $46^{\circ} 39,488^{\prime}$ \\
\hline PIN & Rua Cardeal Arco Verde, № 1217 & Pinheiros - São Paulo, SP. & 09/01/09 & 763,1 & $23^{\circ} 35,541^{\prime}$ & $46^{\circ} 41,163^{\prime}$ \\
\hline SAN & Av. Santos Dumont, № 1979 & Santana - São Paulo, SP. & 05/02/09 & 747,0 & $23^{\circ} 30,312^{\prime}$ & $46^{\circ} 37,680^{\prime}$ \\
\hline STA & Av. Santo Amaro, no 6161 & Santo Amaro, São Paulo - SP & $29 / 01 / 09$ & 760,5 & $23^{\circ} 30,894^{\prime}$ & $46^{\circ} 43,131^{\prime}$ \\
\hline TAS & Rua Mário Latorre, № 96. & Taboão da Serra - RMSP & $15 / 01 / 09$ & 820,7 & $23^{\circ} 33,243^{\prime}$ & $46^{\circ} 40,311^{\prime}$ \\
\hline UBA & Rodovia Rio-Santos, km 75,5 & Ubatuba - SP. & $16 / 01 / 09$ & 3,1 & $23^{\circ} 26,299^{\prime}$ & $45^{\circ} 04,340^{\prime}$ \\
\hline
\end{tabular}




\subsection{Procedimento utilizado na coleta dos liquens}

Os liquens foram coletados dos troncos das árvores, com auxílio de uma faca de titânio a uma altura de aproximadamente $1,50 \mathrm{~m}$ do solo e foram guardados em sacos de papel, no lugar de sacos plásticos, para evitar possível formação de bolores causada pela umidade presente nos liquens. Foi utilizada uma faca de titânio de alta pureza para evitar a contaminação das amostras por outros elementos, como àqueles presentes nas facas de aço inoxidável. A Figura 4.2 mostra a foto da coleta do líquen.

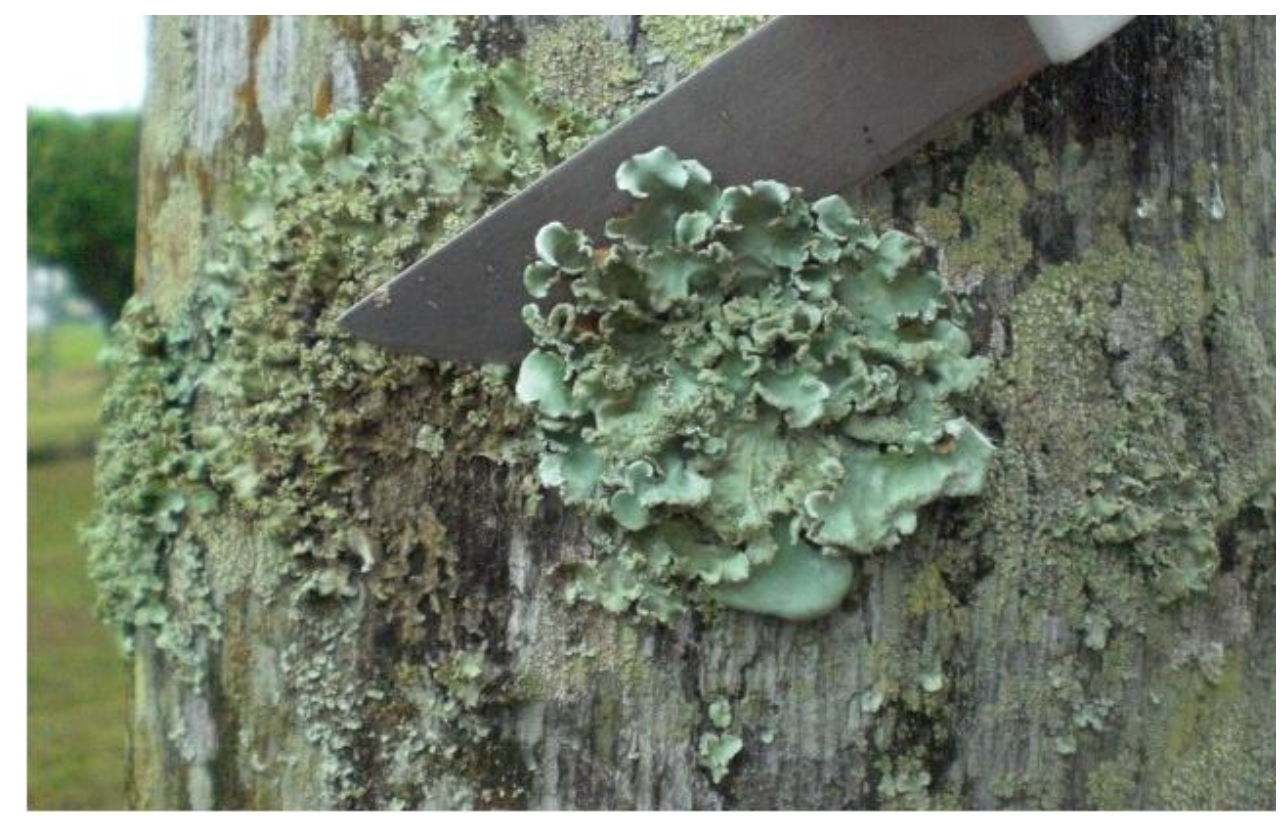

Figura 4.2. Foto mostrando a remoção do líquen na casca da árvore.

Como no presente trabalho foi realizado biomonitoramento passivo, procurou-se coletar liquens com diâmetros inferiores a $10 \mathrm{~cm}$, ou seja, com faixas de tempo de exposição mais próximas. A Canoparmelia texana tendo um crescimento radial as mais altas concentrações de elementos estariam na parte central do líquen. Os liquens dos troncos de árvores apresentaram dificuldade na sua remoção devido à rugosidade e espessura da casca de tronco em que se encontravam.

Para remover os materiais estranhos como cascas de árvores e insetos, o líquen foi examinado utilizando um microscópio estereoscópio modelo 4060, da marca Olympus. Para evitar possíveis contaminações, foi efetuada a limpeza das pinças utilizadas para a extração dos materiais estranhos nos líquens 
com papel higiênico e álcool etílico p.a. Após este procedimento de limpeza, as amostras foram colocadas em recipientes de plástico, para posterior lavagem.

Neste procedimento, as amostras permaneceram imersas em água purificada MilliQ, por cerca de três minutos. O líquen foi separado da água usando uma peneira com telas de nylon. Após esta limpeza, as amostras foram colocadas em potes de plástico e guardadas em freezer para serem congeladas, a uma temperatura próxima de $-18^{\circ} \mathrm{C}$, para posterior secagem por liofilização.

A liofilização das amostras foi feita por um período aproximadamente 8 horas, em liofilizador Micro Modulyo da Edwards, a uma pressão de aproximadamente $8,0 \times 10^{-2}$ mbar.

A moagem das amostras secas foi feita em um micromoinho Pulverisette 0 da Fritsch. Após cada moagem, o almofariz de ágata do moinho foi lavado com uma espuma de nylon e água deionizada, seguida de secagem com álcool etílico p.a. e papel higiênico. A amostra pulverizada foi transferida para recipiente de polietileno previamente desmineralizado com solução de ácido nítrico diluído e enxaguado com água purificada MilliQ. A tampa deste recipiente contendo a amostra moída foi vedada com parafilme e a amostra foi identificada e guardada em um dessecador, o qual continha em seu interior, sílica como agente dessecante. Desta forma, a amostra foi armazenada em condições que evitassem a absorção de umidade.

\subsubsection{Pesagens das amostras de líquen para análise por ativação com nêutrons}

As pesagens das amostras de líquen para análise foram feitas em balança analítica da marca Mettler do modelo H16 para capacidade até $80 \mathrm{~g} \mathrm{e}$ precisão de $\pm 0,05 \mathrm{mg}$. Primeiramente, pesou-se um invólucro de polietileno vazio e em seguida, no seu interior, colocou-se a amostra desejada (aproximadamente $150 \mathrm{mg}$ ) e pesou-se novamente. Por meio da diferença entre estas pesagens foi obtida a massa da amostra pesada. Finalmente, o invólucro contendo a amostra foi selado com o auxílio de uma seladora elétrica e folha de celofane.

O invólucro de polietileno, utilizado para a irradiação das amostras no reator, foi confeccionado utilizando uma seladora elétrica e folhas de plástico polietileno que foram previamente lavadas, com soluções diluídas de ácido nítrico p.a. e água purificada MilliQ. 


\subsection{Preparação de padrões sintéticos dos elementos}

Visto que será utilizada a NAA comparativa foi necessário preparar os padrões sintéticos dos elementos a serem quantificados.

Para preparação dos padrões sintéticos elementares, foram utilizadas soluções padrão estoques certificadas dos seguintes elementos: $\mathrm{As}, \mathrm{Br}$, $\mathrm{Ca}, \mathrm{Cd}, \mathrm{Co}, \mathrm{Cr}, \mathrm{Cs}, \mathrm{Cu}, \mathrm{K}, \mathrm{Fe}, \mathrm{La}, \mathrm{Mo}, \mathrm{Rb}, \mathrm{Sb}, \mathrm{Sc}$, Se e $\mathrm{Zn}$, as quais foram adquiridas da Spex Certiprep, USA. A partir destas soluções estoques foram preparadas soluções padrões mais diluídas contendo um ou mais elementos (simples ou multielementar).

As concentrações dos elementos das soluções padrão, mistas e simples e as massas de cada um dos elementos dos padrões pipetados estão apresentadas na Tabela 4.3.

Tabela 4.3. Concentrações de elementos nas soluções padrão e respectivas massas dos elementos utilizadas.

\begin{tabular}{cccc}
\hline Código do Padrão & Elemento & $\begin{array}{c}\text { Concentração } \\
\left(\mu \mathbf{~ m ~ m}^{-1}\right)\end{array}$ & $\begin{array}{c}\text { Massa } \\
(\mu \mathbf{g})\end{array}$ \\
\hline Br7 & $\mathrm{Br}$ & 100,0 & 5,0 \\
\hline L7 & $\mathrm{Ka}$ & 10016 & 500,8 \\
& $\mathrm{Cs}$ & 12,0 & 0,600 \\
& $\mathrm{Sc}$ & 12,0 & 0,600 \\
& $\mathrm{Co}$ & 1,6 & 0,080 \\
& $\mathrm{Cd}$ & 3,003 & 0,150 \\
& $\mathrm{Ca}$ & 200,28 & 10,014 \\
\hline \multirow{2}{*}{$\mathbf{F 7}$} & $\mathrm{Fe}$ & 10037 & 501,85 \\
& $\mathrm{Rb}$ & 7022,4 & 351,12 \\
& $\mathrm{Zn}$ & 199,80 & 9,990 \\
& $\mathrm{As}$ & 719,58 & 35,98 \\
\hline & $\mathrm{Cu}$ & 30,105 & 1,505 \\
& $\mathrm{Se}$ & 2009,2 & 100,46 \\
& $\mathrm{Cr}$ & 160,14 & 8,007 \\
& $\mathrm{Mo}$ & 39,98 & 1,999 \\
& $\mathrm{Sb}$ & 60,12 & 3,006 \\
& & 12,005 & 0,600 \\
\hline
\end{tabular}

Foram pipetados $50 \mu \mathrm{l}$ de cada uma das soluções simples ou multielementares sobre tiras de papel de filtro Whatman $n^{\circ} 40$, de dimensões 1,33 
$\mathrm{cm} \times 2,00 \mathrm{~cm}$, usando um pipetador automático da marca Eppendorf, previamente verificado quanto à sua calibração. Estas tiras de papel com as soluções pipetadas foram colocadas em um dessecador para secagem à temperatura ambiente, por aproximadamente 24 horas. Posteriormente, elas foram dobradas e colocadas em invólucros de polietileno para irradiação no reator, junto com as amostras.

\subsection{Análise de materiais de referência certificados}

A demanda por um controle de qualidade dos resultados necessita o uso de materiais rastreáveis definidos como padrões, com características similares às das amostras. Os materiais de referência certificados são indicados para uso na avaliação dos resultados, na garantia da rastreabilidade em métodos de análise química e para controle de qualidade.

Neste trabalho, o controle analítico dos resultados com relação à precisão e exatidão foi realizado por meio das análises dos materiais biológicos de referência certificados: IAEA-336 Lichen, proveniente da Agência Internacional de Energia Atômica (Áustria) e INCT-TL-1 Tea Leaves, do Instituto de Química Nuclear e Tecnologia (Polônia). As condições experimentais utilizadas para a análise dos materiais certificados de referência foram as mesmas utilizadas para as análises de liquens.

Para expressar os resultados das análises dos materiais de referência, na sua base seca, foram feitas as determinações das percentagens de perda de umidade na secagem à temperatura de $85^{\circ} \mathrm{C}$ por 24 horas. $\mathrm{O}$ valor da percentagem de perda de peso para o material de referência IAEA-336 Lichen foi de $6,2 \%$ e para o material de referência INCT-TL-1 Tea Leaves foi de 5,1\% e estes valores foram utilizados no cálculo das massas dos materiais na base seca.

\subsection{Procedimento para análise por ativação com nêutrons}

As amostras e os padrões elementares foram irradiados no reator de pesquisas IEA-R1, do Instituto de Pesquisas Energéticas e Nucleares, IPENCNENSP. Para isso cerca de $150 \mathrm{mg}$ de líquen pesados em invólucros de polietileno e os padrões sintéticos foram envoltos em folha de alumínio e colocados dentro de um dispositivo de alumínio, denominado "coelho". 
Este dispositivo, contendo amostras e padrões, foi submetido a uma irradiação longa no reator, sob fluxo de nêutrons térmicos da ordem de $6,0 \times 10^{12} \mathrm{n}$ $\mathrm{cm}^{-2} \mathrm{~s}^{-1}$ e por um período de 16 horas.

As amostras, os padrões sintéticos e os materiais de referência certificados irradiados foram medidos, usando um detector de Ge hiperpuro ligado a um espectrômetro de raios gama e um sistema eletrônico associado. O sistema utilizado apresentava uma resolução de $0,97 \mathrm{keV}$ para o pico de 121,38 keV do ${ }^{57} \mathrm{Co}$ e de $1,97 \mathrm{keV}$ para o pico de $1332,02 \mathrm{keV}$ do ${ }^{60} \mathrm{Co}$. O equipamento utilizado foi verificado, quanto ao seu funcionamento, por meio da contagem de uma fonte de ${ }^{57} \mathrm{Co}+{ }^{60} \mathrm{Co}$. Para a aquisição dos dados foi utilizado o programa MAESTRO da EG \& G Ortec.

Também foi escolhida a geometria de contagem da amostra, de maneira que a medida não fosse realizada com um tempo morto maior do que $12 \%$.

As medições das atividades gama foram feitas em dois períodos diferentes de decaimento. A primeira medição foi iniciada após dois dias de decaimento com tempos de contagens de 5400 segundos para os padrões e 25000 segundos para as amostras. Esta primeira contagem foi para a determinação dos elementos $\mathrm{As}, \mathrm{Br}, \mathrm{Ca}, \mathrm{K}$, La e Sb.

A segunda contagem foi iniciada após cerca de nove dias de decaimento e neste caso o tempo de medição para os padrões também foi de 5400 segundos, e para as amostras foi de 50000 segundos para determinação dos elementos $\mathrm{Co}, \mathrm{Cr}, \mathrm{Cs}$, Fe, Rb, Sc, Se e Zn.

Para o processamento dos espectros foi utilizado o programa de computação Vispect2 (Piccot, 1989), o qual nos fornece os valores de energias de raios-gama dos picos dos espectros e as taxas de contagens com os seus respectivos desvios padrão. Os radionuclídeos foram identificados pelas energias de raios gama e meia vida consultando os dados compilados da Agência Internacional de Energia Atômica (IAEA, 1990). Na Tabela 4.4, estão apresentados os radioisótopos utilizados no presente trabalho. 
Tabela 4.4. Dados dos radioisótopos com suas respectivas energias de raios gama e meias vidas (IAEA, 1990), utilizados neste estudo.

\begin{tabular}{cccc}
\hline Elemento & $\begin{array}{c}\text { Radioisótopo } \\
\text { medido }\end{array}$ & Energia (keV) & Meia-vida \\
\hline $\mathrm{As}$ & ${ }^{76} \mathrm{As}$ & 559,1 & $26,3 \mathrm{~h}$ \\
$\mathrm{Br}$ & ${ }^{82} \mathrm{Br}$ & 776,5 & $35,3 \mathrm{~h}$ \\
$\mathrm{Ca}$ & ${ }^{47} \mathrm{Ca}$ & $159,38 / 1297,09$ & $4,54 \mathrm{~d}$ \\
$\mathrm{Co}$ & ${ }^{60} \mathrm{Co}$ & $1173,24 / 1332,50$ & $5,3 \mathrm{a}$ \\
$\mathrm{Cr}$ & ${ }^{51} \mathrm{Cr}$ & 320,1 & $27,7 \mathrm{~d}$ \\
$\mathrm{Cs}$ & ${ }^{134} \mathrm{Cs}$ & 795,85 & $2,06 \mathrm{a}$ \\
$\mathrm{Fe}$ & ${ }^{59} \mathrm{Fe}$ & $1099,25 / 1291,60$ & $44,5 \mathrm{~d}$ \\
$\mathrm{~K}$ & ${ }^{42} \mathrm{~K}$ & 1524,58 & $12,36 \mathrm{~h}$ \\
$\mathrm{La}$ & ${ }^{140} \mathrm{La}$ & 1596,21 & $40,27 \mathrm{~h}$ \\
$\mathrm{Rb}$ & ${ }^{86} \mathrm{Rb}$ & 1076,60 & $18,66 \mathrm{~d}$ \\
$\mathrm{Sb}$ & ${ }^{122} \mathrm{Sb}$ & 564,2 & $2,7 \mathrm{~d}$ \\
$\mathrm{Sc}$ & ${ }^{46} \mathrm{Sc}$ & 889,3 & $83,8 \mathrm{~d}$ \\
$\mathrm{Se}$ & ${ }^{75} \mathrm{Se}$ & 264,7 & $119,77 \mathrm{~d}$ \\
$\mathrm{Zn}$ & ${ }^{65} \mathrm{Zn}$ & 1115,5 & $243,9 \mathrm{~d}$ \\
\hline
\end{tabular}

O cálculo de concentrações dos elementos foi feito pelo método comparativo, aplicando a relação (3.6) já descrita na seção 3.1 . 


\section{RESULTADOS E DISCUSSÃO}

\subsection{Resultados das análises de materiais de referência certificados IAEA-336}

\section{Lichen e INCT-TL-1 Tea Leaves}

Conforme já descrito no capítulo anterior, foram analisados os materiais de referência certificados para avaliar a exatidão e a precisão dos resultados.

As fórmulas utilizadas para os cálculos das grandezas ou parâmetros estatísticos apresentados neste item 5.1 estão na Tabela 5.1. Estes parâmetros foram calculados de acordo com Vogel (1992) e Magalhães \& Pedroso (2004).

Tabela 5.1. Fórmulas utilizadas para o cálculo das grandezas.

\begin{tabular}{|c|c|}
\hline Grandezas & Fórmulas \\
\hline Média das Concentrações & $\bar{X}=\frac{\left(X_{1}+X_{2}+\ldots+X_{n}\right)}{n}$ \\
\hline Desvio Padrão & $D P=\sqrt{\frac{1}{n-1} \sum_{i=0}^{n}\left(X_{i}-\bar{X}\right)^{2}}$ \\
\hline Desvio Padrão Relativo & $D P R=\frac{D P \times 100}{\bar{X}}$ \\
\hline Limite de Confiança & $\begin{array}{l}L C=\frac{t \text { de Student } * \times D P}{\sqrt{n}} \text {, em que } t \text { é um } \\
\text { parâmetro que depende do número de graus de } \\
\text { liberdade e do nível de confiança. }\end{array}$ \\
\hline Erro Relativo & $\begin{array}{c}E R=\frac{100 \times(\bar{X}-\mu)}{\mu}, \text { em que } \mu \text { é o valor } \\
\text { certificado do material de referência. }\end{array}$ \\
\hline
\end{tabular}


Foram realizadas determinações de elementos nos materiais de referência IAEA-336 Lichen e INCT-TL-1 Tea Leaves e cujos resultados obtidos estão apresentados, respectivamente, nas Tabelas 5.2 e 5.3, juntamente com os valores dos certificados. Nestas Tabelas estão os resultados da média aritmética das concentrações de elementos, desvio padrão $(D P)$, desvio padrão relativo $(D P R)$, erro relativo $(E R)$, limite de confiança $(L C)$, valores de $t$ de Student tabelados e calculados e os valores da diferença padronizada ou Z-score (Bode, 1996).

Os valores de Z-score, ou também conhecido como diferença padronizada foram calculadas aplicando-se a seguinte relação (Bode, 1996):

$$
Z-\text { score }=\frac{\left(C_{i}-C_{r e f, i}\right)}{\left(\sigma_{i}^{2}+\sigma_{r e f, i}^{2}\right)^{\frac{1}{2}}}
$$

onde:

$C_{i}$ é a concentração do elemento i obtido na análise do material de referência;

$C_{r e f, i}$ é a concentração certificada do elemento $i$;

$\sigma_{i}$ é o desvio padrão da concentração do elemento $i$ obtida da análise do material de referência;

$\sigma_{r e f, i}$ é a incerteza do valor certificado para o elemento $i$.

Estes valores do Z-score foram calculados somente para os elementos que contém valores recomendados ou certificados nos seus certificados. 
Tabela 5.2. Concentrações de elementos no material de referência certificado IAEA-336 Lichen

\begin{tabular}{|c|c|c|c|c|c|c|c|c|}
\hline \multirow{2}{*}{ Elementos } & \multicolumn{7}{|c|}{ Este trabalho } & \multirow{2}{*}{$\begin{array}{c}\text { Valor do } \\
\text { Certificado } \\
\text { (IAEA, 1999) }\end{array}$} \\
\hline & Média $\pm D P(n)$ & DPR (\%) & Z-Score & ER (\%) & LC & т Tab & T Calc & \\
\hline As, $\mathbf{n g ~ g}^{-1}$ & $628 \pm 9(5)$ & 1,4 & $-0,01$ & 0,3 & $(630,0-646,2)$ & 2,7764 & 0,4906 & $630(550-710)$ \\
\hline $\mathrm{Br}, \boldsymbol{\mu g} \mathbf{g}^{-1}$ & $12,7 \pm 1,1(8)$ & 8,7 & $-0,06$ & 1,6 & $(12,9-16,3)$ & 2,3646 & 0,5143 & $12,9(11,2-14,6)$ \\
\hline $\mathrm{Ca}, \mathrm{mg} \mathrm{g}^{-1}$ & $2550 \pm 190(7)$ & 7,5 & - & - & - & 2,4469 & - & - \\
\hline Co, $\mathrm{ng} \mathrm{g}^{-1}$ & $291,5 \pm 2,3(7)$ & 0,7 & 0,01 & 0,5 & $(290,0-299,1)$ & 2,5705 & 1,5975 & $290(240-340)$ \\
\hline $\mathrm{Cr}, \mathbf{n g ~ g}^{-1}$ & $1058 \pm 6(6)$ & 0,6 & - & - & $(1056,0-1060,0)$ & 2,5705 & 0,8764 & $1060(890-1230)^{*}$ \\
\hline Cs, $n g \mathbf{g}^{-1}$ & $117 \pm 8(6)$ & 7,0 & 0,26 & 6,4 & $(110,0-134,8)$ & 2,5705 & 1,9629 & $110(97-123)$ \\
\hline $\mathrm{Fe}, \mu \mathrm{g} \mathrm{g^{-1 }}$ & $436 \pm 6(6)$ & 1,4 & 0,04 & 1,4 & $(430,0-441,8)$ & 2,5705 & 2,3055 & $430(380-480)$ \\
\hline $\mathrm{K}, \boldsymbol{\mu} \mathbf{g} \mathbf{g}^{-1}$ & $1844 \pm 6(6)$ & 0,4 & 0,01 & 0,2 & $(1839,7-1840,4)$ & 2,5705 & 2,0726 & $1840(1640-2040)$ \\
\hline La, $\mathbf{n g} \mathbf{g}^{-1}$ & $662 \pm 3(6)$ & 0,5 & 0,01 & 0,3 & $(660,0-665,3)$ & 2,5705 & 1,6016 & $660(560-760)$ \\
\hline $\mathbf{R b}, \boldsymbol{\mu g} \mathbf{g}^{-1}$ & $1,7 \pm 0,1(6)$ & 5,8 & - & - & $(1,7-1,8)$ & 2,5705 & 0,3062 & $1,76(1,54-1,98)^{*}$ \\
\hline $\mathrm{Sb}, \mathrm{ng} \mathbf{g}^{-1}$ & $72 \pm 3(5)$ & 4,2 & 0,02 & 1,4 & $(73,0-106,4)$ & 2,7764 & 0,2236 & $73(63-83)$ \\
\hline Sc, $\mathrm{ng} \mathrm{g}^{-1}$ & $174 \pm 5(6)$ & 3,0 & - & - & $(170,0-188,0)$ & 2,5705 & 1,9596 & $170(150-190)^{*}$ \\
\hline Se, $\mathrm{ng} \mathrm{g}^{-1}$ & $216 \pm 12(6)$ & 6,0 & $-0,06$ & 1,8 & $(183,6-220,0)$ & 2,5708 & 0,8165 & $220(180-260)$ \\
\hline $\mathrm{Zn}, \mu \mathrm{g} \mathrm{g}^{-1}$ & $32,5 \pm 2,0(6)$ & 6,2 & 0,19 & 6,9 & $(30,4-35,5)$ & 2,5708 & 2,5705 & $30,4(27,0-33,8)$ \\
\hline
\end{tabular}

$\mathrm{DP}=$ Desvio Padrão individual; $\mathrm{n}$ - Número de determinações; DPR - Desvio Padrão Relativo (em porcentagem); ER - Erro Relativo (em porcentagem); LC= Limite de confiança (intervalo de confiança estimado dentro do qual se espera encontrar a média a um nível de confiança de 95\%); $\mathrm{T}$ Calc $=\mathrm{T}$ de Student calculado; $\mathrm{T}$ Tab = $\mathrm{T}$ de Student tabelado; * - Valor Informativo. 
Tabela 5.3. Concentrações de elementos no material de referência INCT TL-1 Tea Leaves.

\begin{tabular}{|c|c|c|c|c|c|c|c|c|}
\hline \multirow{2}{*}{ Elementos } & \multicolumn{7}{|c|}{ Este trabalho } & \multirow{2}{*}{\begin{tabular}{|c|} 
Valor do \\
Certificado \\
(INCT, 2002) \\
\end{tabular}} \\
\hline & Média $\pm D P(n)$ & DPR (\%) & Z-Score & ER (\%) & LC & т Tab & T Calc & \\
\hline As, $\mathrm{ng} \mathrm{g}^{-1}$ & $104 \pm 1(5)$ & 0,9 & $-0,1$ & 2,0 & $(101,7-106,0)$ & 2,7764 & 2,2631 & $106,0 \pm 21,0$ \\
\hline $\mathrm{Br}, \mathrm{mg} \mathrm{kg}^{-1}$ & $13 \pm 0,2(6)$ & 1,6 & 0,2 & 0,8 & $(12,5-12,9)$ & 2,5705 & 0,3266 & $12,9 \pm 1,0$ \\
\hline $\mathrm{Ca}, \%$ & $0,56 \pm 0,03(6)$ & 5,4 & $-0,4$ & 3,5 & $(0,55-0,58)$ & 2,5705 & 1,6330 & $0,58 \pm 0,05$ \\
\hline Co, $\mathrm{ng} \mathrm{g}^{-1}$ & $385 \pm 5(6)$ & 1,3 & $-0,4$ & 0,5 & $(382,5-387,0)$ & 2,5705 & 1,1975 & $387,0 \pm 42,0$ \\
\hline $\mathrm{Cr}, \mathrm{mg} \mathrm{kg}^{-1}$ & $2,00 \pm 0,03(6)$ & 1,5 & 0,4 & 4,7 & $(1,91-2,09)$ & 2,5705 & 2,4465 & $1,91 \pm 0,22$ \\
\hline Cs, mg kg ${ }^{-1}$ & $3,80 \pm 0,1(4)$ & 2,5 & 0,3 & 5,3 & $(3,61-4,13)$ & 3,1824 & 0,6190 & $3,61 \pm 0,37$ \\
\hline $\mathrm{Fe}, \mathrm{mg} \mathrm{kg}^{-1}$ & $420 \pm 13(6)$ & 3,1 & - & - & $(407,3-432,0)$ & 2,5705 & 2,3356 & $432^{*}$ \\
\hline $\mathrm{K}, \%$ & $1,8 \pm 0,2(6)$ & 11,0 & 0,2 & 5,9 & $(1,70-1,87)$ & 2,5705 & 0,0170 & $1,70 \pm 0,12$ \\
\hline $\mathrm{La}, \mathrm{mg} \mathrm{kg}^{-1}$ & $1,01 \pm 0,1(6)$ & 10,0 & 0,1 & 1,0 & $(1,00-1,03)$ & 2,5705 & 0,0700 & $1,00 \pm 0,07$ \\
\hline $\mathbf{R b}, \mathrm{mg} \mathrm{kg}^{-1}$ & $85 \pm 7(6)$ & 8,3 & 0,4 & 4,3 & $(81,5-88,5)$ & 2,5705 & 1,3190 & $81,5 \pm 6,5$ \\
\hline $\mathrm{Sb}, \mathrm{mg} \mathrm{kg}^{-1}$ & $0,06 \pm 0,01(6)$ & 17,0 & - & - & $(0,05-0,06)$ & 2,5705 & 2,4495 & $0,05^{\star}$ \\
\hline Sc, $n g \mathbf{g}^{-1}$ & $243 \pm 36(5)$ & 14,8 & $-0,5$ & 8,7 & $(218,9-266,0)$ & 2,7764 & 1,1180 & $266 \pm 24$ \\
\hline $\mathrm{Se}, \mathrm{mg} \mathrm{kg}^{-1}$ & $0,078 \pm 0,009$ (5) & 11,5 & - & - & $(0,08-0,09)$ & 2,7764 & 0,4472 & $0,076^{\star}$ \\
\hline $\mathrm{Zn}, \mathrm{mg} \mathrm{kg}^{-1}$ & $34 \pm 2(6)$ & 6,0 & $-0,2$ & 2,0 & $(33,3-34,7)$ & 2,5705 & 1,0086 & $34,7 \pm 2,7$ \\
\hline
\end{tabular}

DP= Desvio Padrão individual; $\mathrm{n}$ - Número de determinações; DPR - Desvio Padrão Relativo (em porcentagem); ER - Erro Relativo (em porcentagem); $\quad \mathrm{LC}=$ Limite de confiança (intervalo de confiança estimado dentro do qual se espera encontrar a média a um nível de confiança de 95\%); $\mathrm{T}$ Calc $=\mathrm{T}$ de Student calculado; $\mathrm{T}$ Tab $=\mathrm{T}$ de Student tabelado; ${ }^{*}$ - Valor Informativo. 
Para a interpretação dos valores de Z-score foram adotados os seguintes conceitos:

$\mid Z$-score $\mid<1$ = resultado aceitável, a um nível de confiança de 68\%;

$\mid Z$-score $\mid<2$ = resultado questionável, a um nível de confiança de 95\%;

$\mid Z$-score $\mid<3$ = resultado não aceitável, a um nível de confiança de 99\%;

Como o certificado do material de referência IAEA-336 Lichen fornece o intervalo de confiança de $95 \%$ da média e o número de determinações, o desvio padrão do valor do certificado foi calculado por meio da relação (Beiguelman, 2002):

$$
I C=\bar{X} \pm\left(t_{c} \frac{\sigma_{r e f i}}{\sqrt{n}}\right)
$$

onde:

$I C$ = intervalo de confiança;

$\bar{X}=$ valor médio do intervalo de confiança;

$t_{c}=$ valor de $t$ de Student;

$\sigma_{r e f i}=$ desvio padrão do valor certificado para o elemento;

$n=$ número de determinações.

Conforme mostra a Tabela 5.2, os resultados obtidos para material de referência IAEA 336 - Lichen apresentaram uma boa precisão para a maioria dos elementos, com valores do desvio padrão relativo variando de 0,4 a $8,7 \%$. Também foi verificado que os erros relativos do material de referência IAEA 336 Lichen variaram de 0,2 a 6,9\%, indicando uma boa exatidão para os resultados obtidos neste material de referência certificado.

Na Tabela 5.3 os resultados obtidos para o material INCT-TL-1 Tea Leaves apresentaram uma boa exatidão, com erros relativos variando de 0,5 a 8,7\% e uma boa precisão, para os elementos As, Br, Ca, Co, Cr, Cs, Fe, K, La, $\mathrm{Rb}$, Sc, Se e Zn, com valores de desvios padrão relativos entre 0,9 e 14,8\%. O resultado menos precisos, com desvio padrão relativo superior a $15 \%$ foi obtido para o elemento $\mathrm{Sb}$, devido ao baixo teor deste elemento na amostra. 
Os limites de confiança $(L C)$ das Tabelas 5.2 e 5.3 indicam a proximidade em que a concentração média do elemento está em relação à média verdadeira, ou seja, do valor do certificado. Desta forma calculou-se o intervalo de confiança dentro do qual se espera encontrar a média, a um nível de confiança de $95 \%$.

Para testar a igualdade da concentração obtida de um determinado elemento com o valor do certificado, foi aplicado o teste de $T$ de Student a um nível de confiança de $95 \%$. Os valores de $t$ de Student foram obtidos por meio do software Statistica 9.0 permitindo verificar se a média obtida apresenta diferença significativa do valor certificado. Quando verificado que os valores de $\tau$ Calc foram inferiores aos valores de $\tau$ Tab, as concentrações são estatisticamente iguais, ao nível de confiança de $95 \%$.

Como se pode observar nas Tabelas 5.2 e 5.3, os valores do $r$ Calc são menores que $T$ Tab, de modo que as concentrações determinadas são estatisticamente aos valores dos certificados, ao nível de confiança de 95\%.

Os valores de Z-score obtidos para os elementos determinados no material certificado de referência IAEA-336 Lichen foram apresentados na Figura 5.1 .

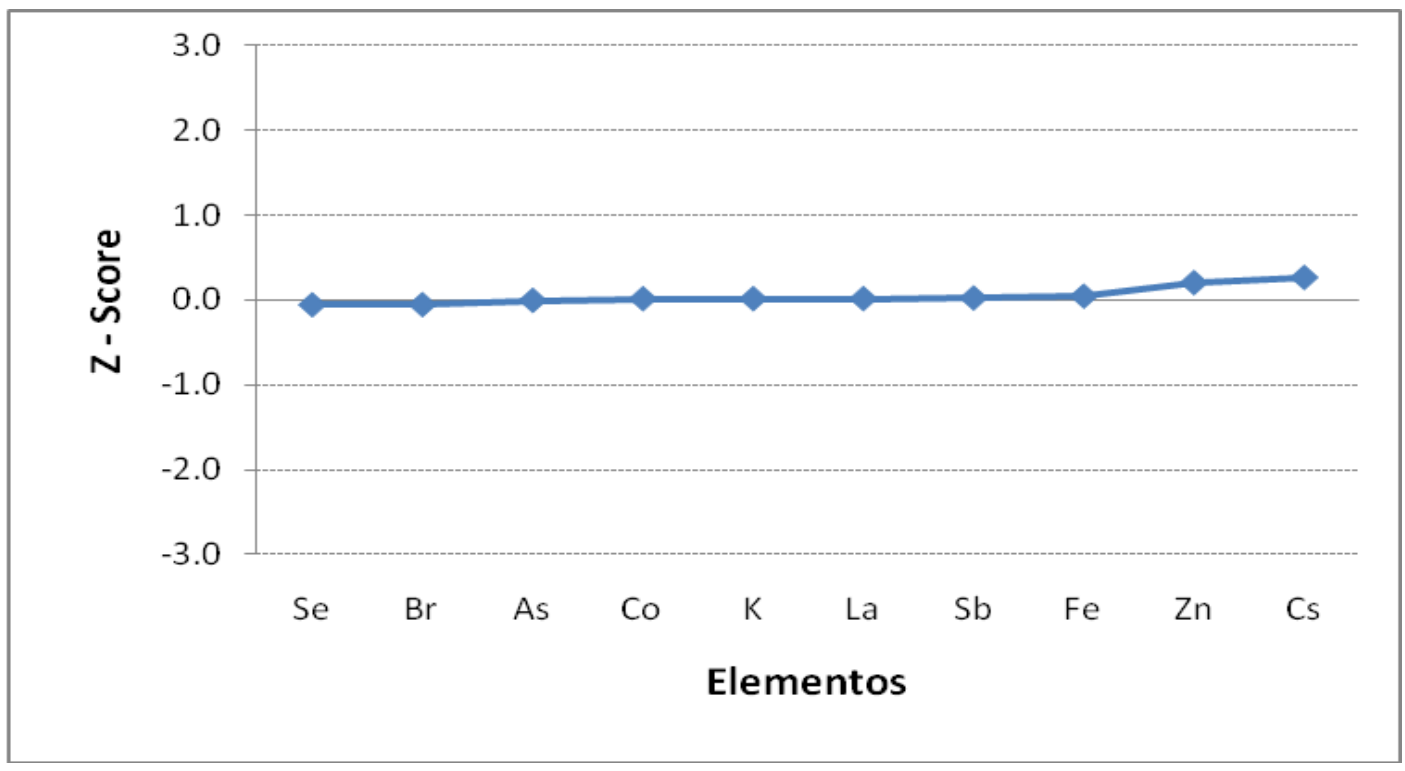

Figura 5.1. Valores de Z-score obtidos para o material de referência IAEA-336 Lichen. 
Como se pode observar na Figura 5.1, os valores obtidos para $Z$-score foram $\mid Z$-score $\mid<1$. Isto significa que os resultados obtidos para 0 material IAEA-336 Lichen estão dentro das faixas de valores apresentados no certificado a um nível de confiança de 68\% (Bode, 1996). Os valores de Z-score obtidos para o material Tea Leaves apresentados na Figura 5.2 também foram $\mid Z$-score $\mid<1$. Isto significa que os resultados obtidos para este material de referência certificado também estão dentro das faixas de valores apresentados no certificado a um nível de confiança de $68 \%$.

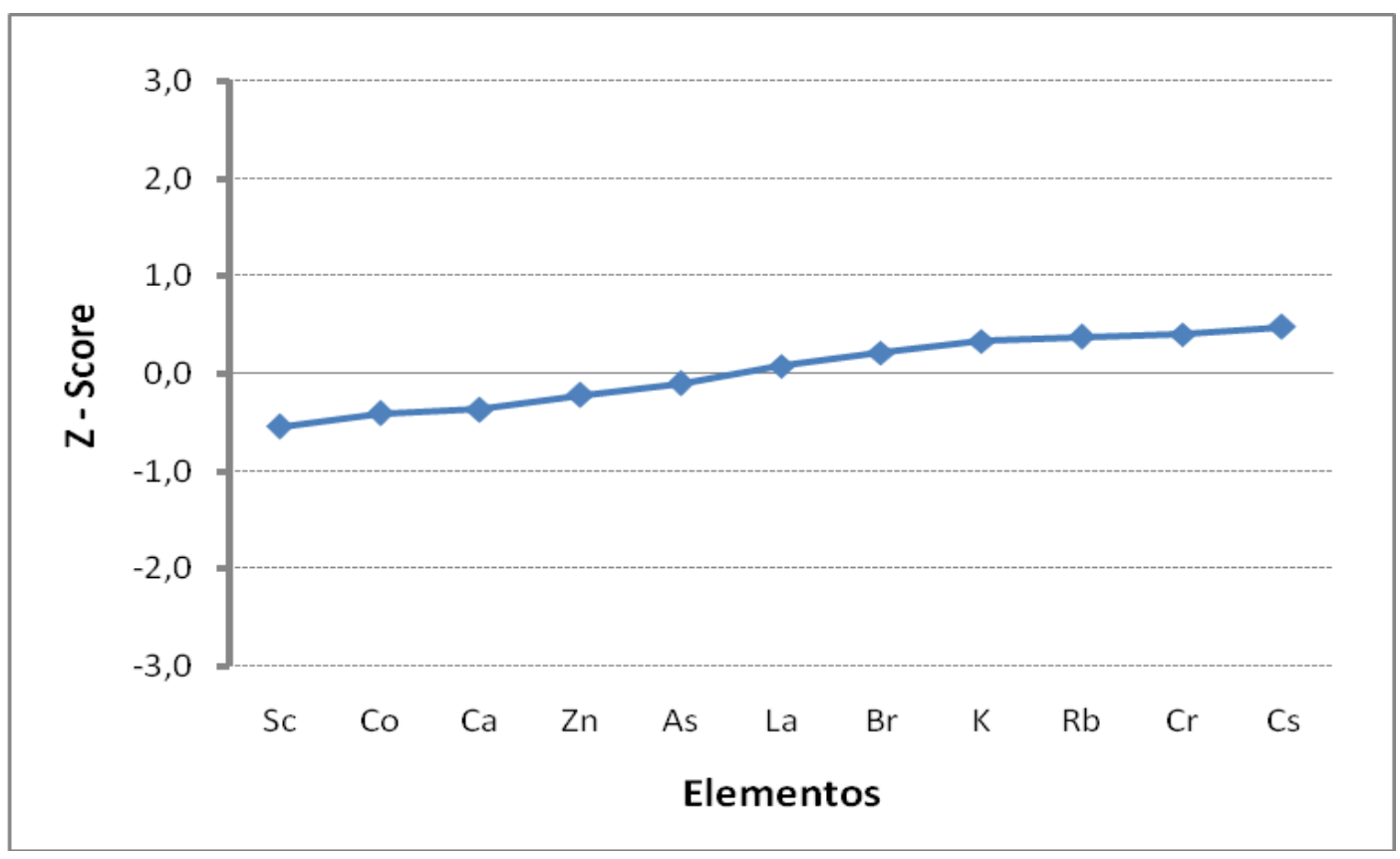

Figura 5.2. Valores de Z-score obtidos para o material certificado de referência INCT-TL-1 Tea Leaves.

\subsection{Verificação da homogeneidade das amostras de liquens preparadas para análise}

Para avaliar a homogeneidade da amostra de líquen preparada, com relação a sua análise elementar, foram realizadas análises em replicatas de três amostras distintas utilizando cerca de 150 mg em cada alíquota.

A metodologia adotada para o teste de homogeneidade das amostras foi a avaliação do desvio padrão relativo dos resultados da análise de cada uma das amostras. Os resultados de quatro determinações de cada amostra 
foram tratados usando o software Statistica 9.0. Os resultados destas análises estão apresentados na Tabela 5.4.

Foi verificado que os desvios padrão relativos dos resultados variaram de 0,6 a 9,6\% indicando a homogeneidade das amostras preparadas, com relação aos elementos.

Tabela 5.4. Concentrações de elementos obtidas nas análises em replicatas de três amostras de liquens.

\begin{tabular}{|c|c|c|c|c|c|c|}
\hline \multirow{2}{*}{ Elementos } & \multicolumn{2}{|c|}{ Amostra 1} & \multicolumn{2}{|c|}{ Amostra 2} & \multicolumn{2}{|c|}{ Amostra 3} \\
\hline & Média \pm DP (n) & DPR \% & Média \pm DP (n) & DPR \% & Média \pm DP $(n)$ & DPR \% \\
\hline As $\left(n g g^{-1}\right)$ & $1,50 \pm 0,01$ & 0,6 & $1,20 \pm 0,02(4)$ & 1,7 & $1,25 \pm 0,04(4)$ & 3,2 \\
\hline $\mathrm{Br}\left(\mu \mathrm{g} \mathrm{g}^{-1}\right)$ & $2,6 \pm 0,1(4)$ & 3,8 & $4,1 \pm 0,1(4)$ & 2,5 & $9,5 \pm 0,2(4)$ & 2,1 \\
\hline $\operatorname{Cr}\left(\mu g g^{-1}\right)$ & $4,8 \pm 0,1(4)$ & 2,1 & $10,4 \pm 0,2(4)$ & 2,0 & $10,4 \pm 1,0(4)$ & 9,6 \\
\hline $\mathrm{Fe}\left(\mu \mathrm{g} \mathrm{g}^{-1}\right)$ & $2,0 \pm 0,1(4)$ & 5,0 & $12,0 \pm 0,1(4)$ & 1,0 & $4,7 \pm 0,4(3)$ & 8,5 \\
\hline $\operatorname{La}\left(\mu g g^{-1}\right)$ & $2,3 \pm 0,1(4)$ & 4,3 & $6,6 \pm 0,1(4)$ & 1,5 & $6,6 \pm 0,1(4)$ & 1,6 \\
\hline $\mathrm{Rb}\left(\mu \mathrm{g} \mathrm{g}^{-1}\right)$ & $5,8 \pm 0,2(4)$ & 3,5 & $18 \pm 1(4)$ & 5,5 & $17 \pm 1(4)$ & 6,0 \\
\hline $\mathrm{Zn}\left(\mu \mathrm{g} \mathrm{g}^{-1}\right)$ & $116 \pm 11(4)$ & 9,5 & $240 \pm 13(4)$ & 5,4 & $238 \pm 12(4)$ & 5,0 \\
\hline
\end{tabular}

(n) = Número de determinações; DP = Desvio Padrão; DPR = Desvio Padrão Relativo.

\subsection{Resultados das análises das amostras de liquens coletadas neste trabalho}

Os resultados das análises dos liquens coletados nos diferentes pontos da cidade de São Paulo e na amostra de Ubatuba, SP estão apresentados na Tabela 5.5. Nestas análises foram obtidas concentrações mais elevadas de Ca e K aos níveis de percentagens, $\mathrm{Br}, \mathrm{Cr}$, Fe, La, Rb, Se e $\mathrm{Zn}$, da ordem de $\mu \mathrm{g} \mathrm{g}^{-1} \mathrm{e}$ os elementos As, Co, Cs e Sc em teores mais baixos, aos níveis de $\mathrm{ng} \mathrm{g}^{-1}$. 
Tabela 5.5 - Concentrações de elementos obtidas para os liquens coletados em diferentes pontos da cidade de São Paulo e de Ubatuba, SP.

\begin{tabular}{|c|c|c|c|c|c|c|c|}
\hline Elementos & $\begin{array}{c}\text { Ubatuba } \\
\text { Média } \pm D P(n)\end{array}$ & $\begin{array}{l}\text { Parque Dom } \\
\text { Pedro II } \\
\text { Média } \pm D P(n)\end{array}$ & $\begin{array}{l}\text { Congonhas } \\
\text { Média } \pm D P(n)\end{array}$ & $\begin{array}{c}\text { Cidade } \\
\text { Universitária } \\
\text { Média } \pm D P(n) \\
\end{array}$ & $\begin{array}{c}\text { Lapa } \\
\text { Média } \pm D P(n)\end{array}$ & $\begin{array}{c}\text { Morumbi } \\
\text { Média } \pm D P(n)\end{array}$ & $\begin{array}{c}\text { Moóca } \\
\text { Média } \pm D P(n)\end{array}$ \\
\hline As, $\mathrm{ng} \mathrm{g}^{-1}$ & $0,36 \pm 0,02(4)$ & $1,25 \pm 0,04(4)$ & $1,20 \pm 0,02(4)$ & $0,66 \pm 0,03(4)$ & $1,30 \pm 0,01(4)$ & $1,50 \pm 0,01$ & $0,70 \pm 0,01(4)$ \\
\hline $\mathrm{Br}, \mu \mathrm{g} \mathrm{g}^{-1}$ & $8,3 \pm 0,5(4)$ & $9,5 \pm 0,2(4)$ & $4,1 \pm 0,1(4)$ & $5,6 \pm 0,1(4)$ & $6,6 \pm 0,1(4)$ & $2,6 \pm 0,1(4)$ & $4,15 \pm 0,05(4)$ \\
\hline $\mathrm{Ca}, \%$ & $4,6 \pm 0,5(4)$ & $4,7 \pm 0,6(4)$ & $3,6 \pm 0,2(4)$ & $2,4 \pm 0,3$ (3) & $4,6 \pm 0,3(4)$ & $3,3 \pm 0,4(4)$ & $9,0 \pm 0,2(4)$ \\
\hline Co, ng g ${ }^{-1}$ & $0,60 \pm 0,03$ (3) & $1,22 \pm 0,02(4)$ & $1,24 \pm 0,02(4)$ & $0,44 \pm 0,01(4)$ & $1,20 \pm 0,01$ (3) & $0,60 \pm 0,01$ (3) & $0,60 \pm 0,01$ (3) \\
\hline $\mathrm{Cr}, \mu \mathrm{g} \mathrm{g}^{-1}$ & $8,8 \pm 0,4(4)$ & $10,4 \pm 1,0(4)$ & $10,4 \pm 0,2(4)$ & $2,3 \pm 0,3(3)$ & $17 \pm 1(4)$ & $4,8 \pm 0,1(4)$ & $4,70 \pm 0,05(4)$ \\
\hline Cs, $\mathrm{ng} \mathrm{g}^{-1}$ & $0,50 \pm 0,01(4)$ & $0,40 \pm 0,01(4)$ & $0,10 \pm 0,01$ (3) & $0,35 \pm 0,01(4)$ & $0,60 \pm 0,01(4)$ & $0,41 \pm 0,03(4)$ & $0,70 \pm 0,01(4)$ \\
\hline $\mathrm{Fe}, \mu \mathrm{g} \mathrm{g}^{-1}$ & $1273 \pm 8(4)$ & $4774 \pm 9(3)$ & $11830 \pm 12(4)$ & $4745 \pm 12(3)$ & $4353 \pm 24(3)$ & $2147 \pm 15(4)$ & $2127 \pm 13(4)$ \\
\hline $\mathrm{K}, \%$ & $0,97 \pm 0,02(4)$ & $0,43 \pm 0,02(4)$ & $0,42 \pm 0,01(4)$ & $0,70 \pm 0,01(4)$ & $0,54 \pm 0,02(4)$ & $0,32 \pm 0,01(4)$ & $0,12 \pm 018(4)$ \\
\hline $\mathrm{La}, \mu \mathrm{g} \mathrm{g}^{-1}$ & $2,0 \pm 0,1$ (4) & $6,6 \pm 0,1(4)$ & $6,5 \pm 0,1(4)$ & $2,40 \pm 0,05$ (3) & $6,0 \pm 0,1(3)$ & $2,3 \pm 0,1(4)$ & $2,7 \pm 0,1$ (4) \\
\hline$R b, \mu g g^{-1}$ & $6,1 \pm 0,1(4)$ & $17 \pm 1(4)$ & $18 \pm 1(4)$ & $17 \pm 3(4)$ & $4,3 \pm 0,1(4)$ & $5,8 \pm 0,2(4)$ & $4,2 \pm 0,1(4)$ \\
\hline $\mathrm{Sb}, \mu \mathrm{g} \mathrm{g}^{-1}$ & $1,20 \pm 0,02$ (3) & $1,5 \pm 0,02(4)$ & $1,50 \pm 0,02(4)$ & $0,78 \pm 0,01(3)$ & $1,50 \pm 0,01(4)$ & $0,50 \pm 0,01$ (3) & $7,0 \pm 0,1$ (3) \\
\hline $\mathrm{Sc}, \mathrm{ng} \mathrm{g}^{-1}$ & $0,24 \pm 0,01(4)$ & $0,93 \pm 0,02(3)$ & $0,93 \pm 0,03(3)$ & $1,0 \pm 0,1(4)$ & $0,90 \pm 0,06$ (3) & $0,50 \pm 0,01(4)$ & $0,6 \pm 0,1$ \\
\hline Se, $\mu g_{g^{-1}}$ & $2,30 \pm 0,03(3)$ & $2,0 \pm 0,4(4)$ & $1,7 \pm 0,2(4)$ & $0,65 \pm 0,06(4)$ & $2,0 \pm 0,03(4)$ & $3,2 \pm 0,2(3)$ & $5,6 \pm 0,2(3)$ \\
\hline $\mathrm{Zn}, \mu \mathrm{g} \mathrm{g}^{-1}$ & $534 \pm 10(4)$ & $238 \pm 12(4)$ & $240 \pm 13(4)$ & $138 \pm 17(4)$ & $156 \pm 20(3)$ & $116 \pm 11(4)$ & $163 \pm 15(4)$ \\
\hline
\end{tabular}


Tabela 5.5 (continuação) - Concentrações de elementos obtidas para os liquens coletados em diferentes pontos da cidade de São Paulo e de Ubatuba, SP.

\begin{tabular}{|c|c|c|c|c|c|c|}
\hline Elementos & $\begin{array}{c}\text { Nossa Senhora do ó } \\
\text { Média } \pm D P(n)\end{array}$ & $\begin{array}{l}\text { Parque Ibirapuera } \\
\text { Média } \pm D P(n)\end{array}$ & $\begin{array}{c}\text { Pinheiros } \\
\text { Média } \pm D P(n)\end{array}$ & $\begin{array}{c}\text { Santana } \\
\text { Média } \pm D P(n)\end{array}$ & $\begin{array}{l}\text { Santo Amaro } \\
\text { Média } \pm D P(n)\end{array}$ & $\begin{array}{c}\text { Taboão da Serra } \\
\text { Média } \pm D P(n)\end{array}$ \\
\hline As, $\mathbf{n g ~ g}^{-1}$ & $1,40 \pm 0,01$ & $1,53 \pm 0,01(4)$ & $0,7 \pm 0,1$ (4) & $1,35 \pm 0,01(3)$ & $0,80 \pm 0,01$ (4) & $0,60 \pm 0,01(4)$ \\
\hline $\mathrm{Br}, \mu \mathrm{g} \mathrm{\textrm {g } ^ { - 1 }}$ & $5,7 \pm 0,1(4)$ & $3,6 \pm 0,1(4)$ & $4,5 \pm 0,4(4)$ & $6,4 \pm 0,1(4)$ & $5,7 \pm 0,1(4)$ & $4,7 \pm 0,1(4)$ \\
\hline $\mathrm{Ca}, \%$ & $2,2 \pm 0,1(4)$ & $4,6 \pm 0,3(4)$ & $4,6 \pm 0,4(4)$ & $4,7 \pm 0,2(3)$ & $5,5 \pm 0,7(4)$ & $5,0 \pm 0,5(4)$ \\
\hline Co, $\mathbf{n g ~ g}^{-1}$ & $0,53 \pm 0,01$ & $0,40 \pm 0,01(4)$ & $0,30 \pm 0,01$ & $0,40 \pm 0,01$ & $1,20 \pm 0,01$ & $1,10 \pm 0,01$ (3) \\
\hline $\mathrm{Cr}, \mu \mathrm{g} \mathrm{g}^{-1}$ & $8,2 \pm 0,1(4)$ & $3,60 \pm 0,05(3)$ & $9,3 \pm 0,1(4)$ & $11,4 \pm 0,7(4)$ & $14 \pm 2(4)$ & $12 \pm 1(4)$ \\
\hline Cs, $\mathbf{n g ~ g}^{-1}$ & $0,22 \pm 0,01$ & $0,16 \pm 0,02(4)$ & $0,13 \pm 0,01$ (3) & $0,33 \pm 0,01$ & $0,60 \pm 0,01$ & $0,50 \pm 0,02(3)$ \\
\hline $\mathrm{Fe}, \mu \mathrm{g} \mathrm{g}^{-1}$ & $4302 \pm 16(4)$ & $1278 \pm 15(3)$ & $1208 \pm 10(4)$ & $3297 \pm 15(4)$ & $4458 \pm 19(4)$ & $3988 \pm 11(4)$ \\
\hline $\mathrm{K}, \%$ & $0,50 \pm 0,02(4)$ & $0,11 \pm 0,02(4)$ & $0,50 \pm 0,01(4)$ & $0,50 \pm 0,01$ & $0,64 \pm 0,02(3)$ & $0,52 \pm 0,03(3)$ \\
\hline $\mathrm{La}, \boldsymbol{\mu g} \mathrm{g}^{-1}$ & $7,2 \pm 0,1(4)$ & $1,23 \pm 0,01(4)$ & $7,0 \pm 0,1(4)$ & $4,6 \pm 0,1(3)$ & $9,0 \pm 0,1(4)$ & $8,4 \pm 0,2(4)$ \\
\hline $\mathrm{Rb}, \mu \mathrm{g} \mathrm{g}^{-1}$ & $19 \pm 6(4)$ & $6,0 \pm 0,1(4)$ & $17 \pm 0,9(4)$ & $17,4 \pm 0,5(4)$ & $17 \pm 2(4)$ & $15 \pm 2(4)$ \\
\hline $\mathrm{Sb}, \boldsymbol{\mu g} \mathbf{g}^{-1}$ & $1,40 \pm 0,01(3)$ & $0,42 \pm 0,01(4)$ & $1,40 \pm 0,03(4)$ & $1,50 \pm 0,01$ & $1,60 \pm 0,01(4)$ & $1,40 \pm 0,01(4)$ \\
\hline Sc, $\mathbf{n g ~ g ^ { - 1 }}$ & $0,92 \pm 0,01(4)$ & $0,40 \pm 0,01$ (3) & $0,9 \pm 0,1(3)$ & $0,65 \pm 0,01$ & $1,20 \pm 0,02(3)$ & $1,30 \pm 0,03(3)$ \\
\hline Se, $\mu \mathrm{g} \mathrm{g}^{-1}$ & $2,0 \pm 0,1(4)$ & $4,0 \pm 0,1(4)$ & $2,0 \pm 0,1(4)$ & $6,6 \pm 0,1(4)$ & $6,3 \pm 0,1(4)$ & $5,0 \pm 0,1(4)$ \\
\hline $\mathrm{Zn}, \boldsymbol{\mu g} \mathrm{g}^{-1}$ & $212 \pm 17(4)$ & $114 \pm 4(4)$ & $210 \pm 12(4)$ & $154 \pm 3(4)$ & $194 \pm 16(4)$ & $148 \pm 12(4)$ \\
\hline
\end{tabular}


Para uma melhor visualização e comparação dos resultados das concentrações dos elementos nos liquens da Tabela 5.5, foram elaborados gráficos que estão apresentados nas Figuras de 5.3 a 5.16. A discussão destes resultados é apresentada a seguir, separadas por elementos ou grupo de elementos.

\subsubsection{Arsênio e Bromo}

Analisando os resultados das análises de liquens da Tabela 5.5 e o gráfico das Figuras 5.3 e 5.4 verifica-se que as concentrações mais elevadas de As foram obtidas para amostras de Moóca, Parque Dom Pedro II, Congonhas, Lapa, Nossa Senhora do Ó, Parque Ibirapuera e Santana. Já as amostras da Cidade Universitária, Morumbi, Pinheiros, Santo Amaro e Taboão da Serra apresentaram teores mais próximos, em ordem de grandeza, da amostra de Ubatuba, considerada região de controle.

A legenda para as Figuras 5.3 a 5.17 é a abreviatura dos pontos de coleta, a saber: PDP - Parque Dom Pedro II, CGN - Congonhas, USP - Cidade Unievrsitária, LAP - Lapa, MOC - Mooca, NOS - Nossa Senhora do Ó, PIB Parque Ibirapuera, PIN - Pinheiros, SAN - Santana, STA - Santo Amaro, TAS Taboão da Serra, UBA - Ubatuba.

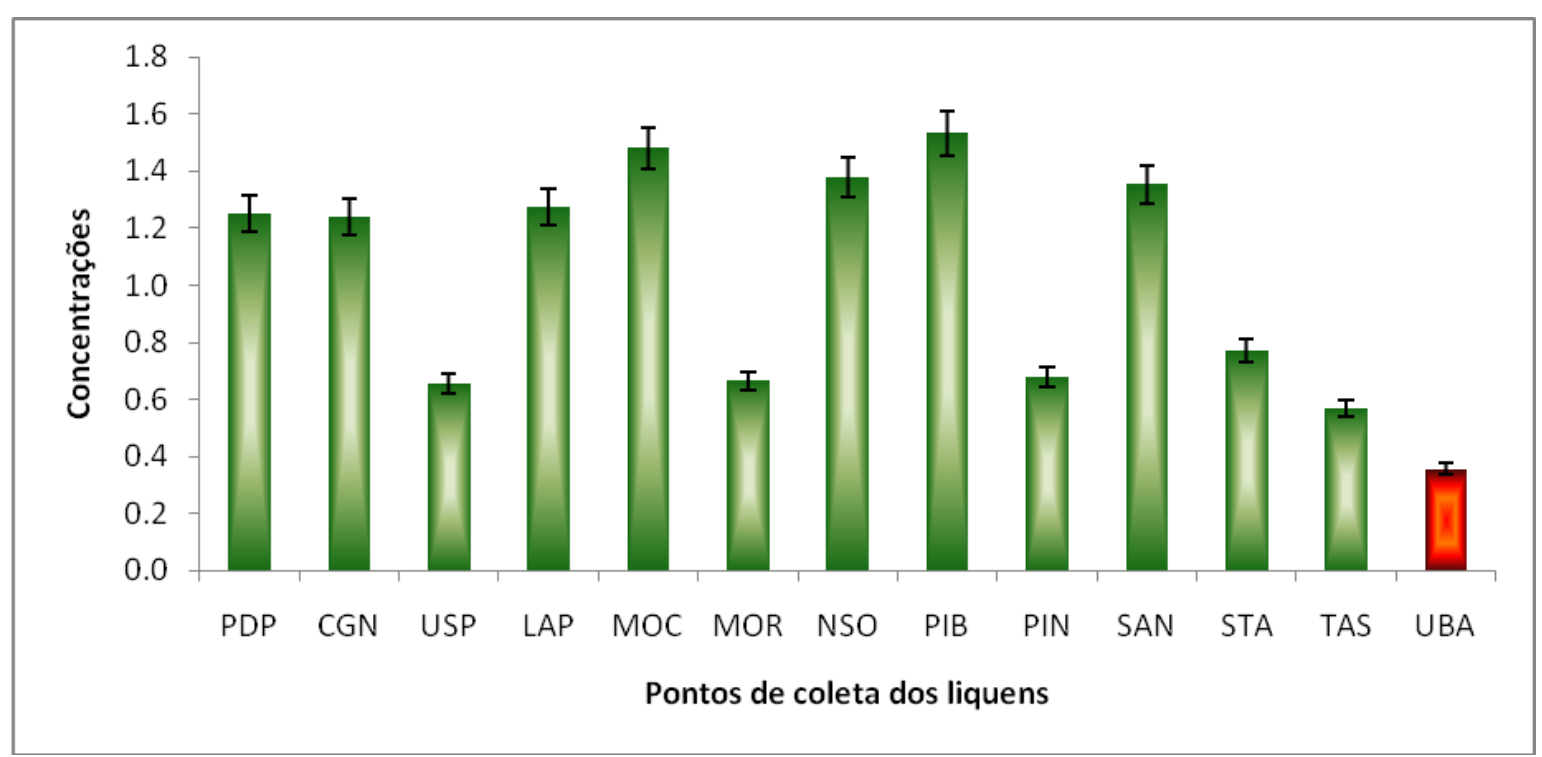

Figura 5.3. Concentrações de As (ng g $\left.\mathrm{g}^{-1}\right)$ em liquens coletados nos diversos pontos da cidade de São Paulo e em Ubatuba. 
Com relação ao As convém salientar que este elemento tem sido utilizado em ligas, substâncias conservantes de madeira, munições, materiais semicondutores, baterias, pinturas, indústrias de tecidos e também o As é geralmente incorporado ao meio ambiente por meio da combustão de carvão e óleo diesel, processamento e fundição de jazidas sulfídricas, dos detritos de porcos e aves, fertilizantes fosfatados, inseticidas e fungicidas (Reimann \& Caritat, 1998).

No caso do As, a presença deste elemento tóxico seria um risco à saúde humana (Guyton \& Hall, 2002). As concentrações encontradas principalmente no centro da cidade de São Paulo, nas ruas próximas às grandes avenidas e de intenso tráfego e também a áreas rurais (bairro de Nossa Senhora do Ó), indicam provável origem deste elemento das emissões veiculares. Segundo Salgado (1996) o arsênio é um elemento tóxico com propriedades cancerígenas da pele e dos brônquios.

Em relação ao $\mathrm{Br}$, os seus teores nos liquens analisados foram da mesma ordem de grandeza, para a maioria dos pontos de amostragem, variando de 2,6 a 9,5 $\mathrm{ug} \mathrm{g}^{-1}$ (Figura 5.4). As mais altas concentrações foram obtidas para a amostra de Ubatuba $\left(8,3 \mu \mathrm{g} \mathrm{g}^{-1}\right)$ e do Parque Dom Pedro II $\left(9,5 \mu \mathrm{g} \mathrm{g}^{-1}\right)$. As altas concentrações de $\mathrm{Br}$ na região do Parque Dom Pedro II podem ter origem devido às emissões veiculares nesta região (Fuga, 2008).

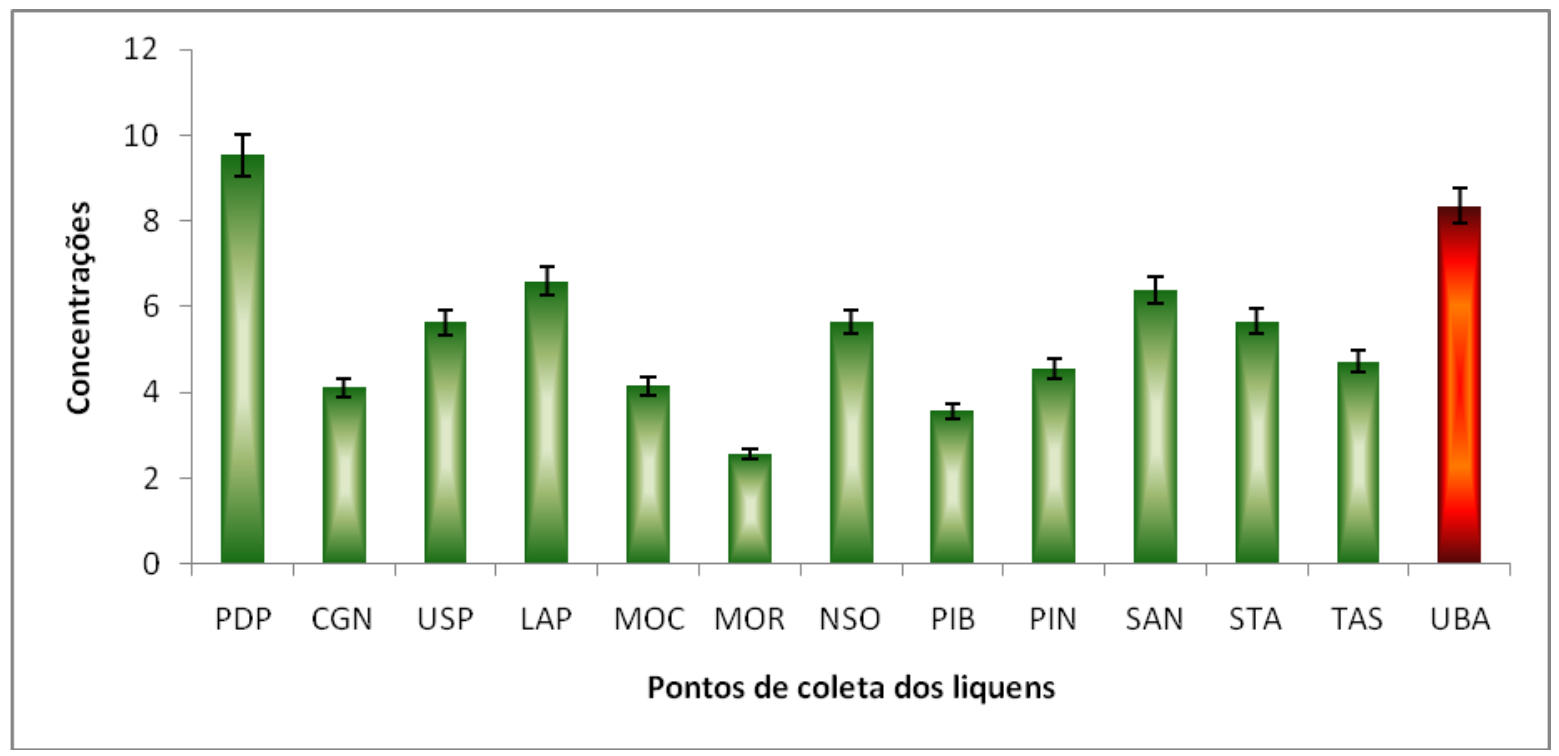

Figura 5.4. Concentrações de $\operatorname{Br}\left(\mu \mathrm{g} \mathrm{g}^{-1}\right)$ em liquens coletados nos diversos pontos da cidade de São Paulo e em Ubatuba. 
A alta concentração de $\mathrm{Br}$ em Ubatuba pode estar associada à influência marinha (França et. al, 2004), pois a amostra de Ubatuba foi coletada próxima à do Parque Estadual da Serra do Mar e neste local há a predominância de ventos oceânicos e como a coleta foi realizada no período do verão, a alta concentração de $\mathrm{Br}$ pode estar associada à predominância da grande quantidade de veículos automotores naquela região.

\subsubsection{Cromio e Ferro}

Os liquens da zona oeste da cidade de São Paulo apresentaram altas concentrações de Cr (Figura 5.5), nas amostras da Lapa e de Fe (Figura 5.6), nas amostras de Congonhas. Nogueira (2006), após análise de clusters para verificar o comportamento do $\mathrm{Br}, \mathrm{Cr}, \mathrm{Fe}, \mathrm{Rb}$ e $\mathrm{Sc}$ em plantas de Tillandsia usneoides atribuiu que as concentrações destes elementos não eram originadas devido às ações antrópicas, mas sim de suspensão do material particulado do solo. Entretanto, em geral, a presença de $\mathrm{Cr}$ e $\mathrm{Fe}$ na poluição aérea tem sido atribuída às emissões de indústrias metalúrgicas.

Segundo Salgado (1996), os compostos de $\mathrm{Cr}$ em altas concentrações podem ocasionar efeitos cutâneos, nasais, bronco-pulmonares, renais, gastrointestinais e carcinogênicos. Os cutâneos são caracterizados por irritação no dorso das mãos e dos dedos, podendo transformar-se em úlceras. As lesões nasais iniciam-se com um quadro irritativo inflamatório, supuração e formação crostosa. Em níveis bronco-pulmonares e gastrointestinais produzem irritação bronquial, alteração da função respiratória e úlceras gastroduodenais.

O Fe ativa várias enzimas e encontra-se presente na constituição de proteínas da planta (Epstein \& Bloom, 2006). 


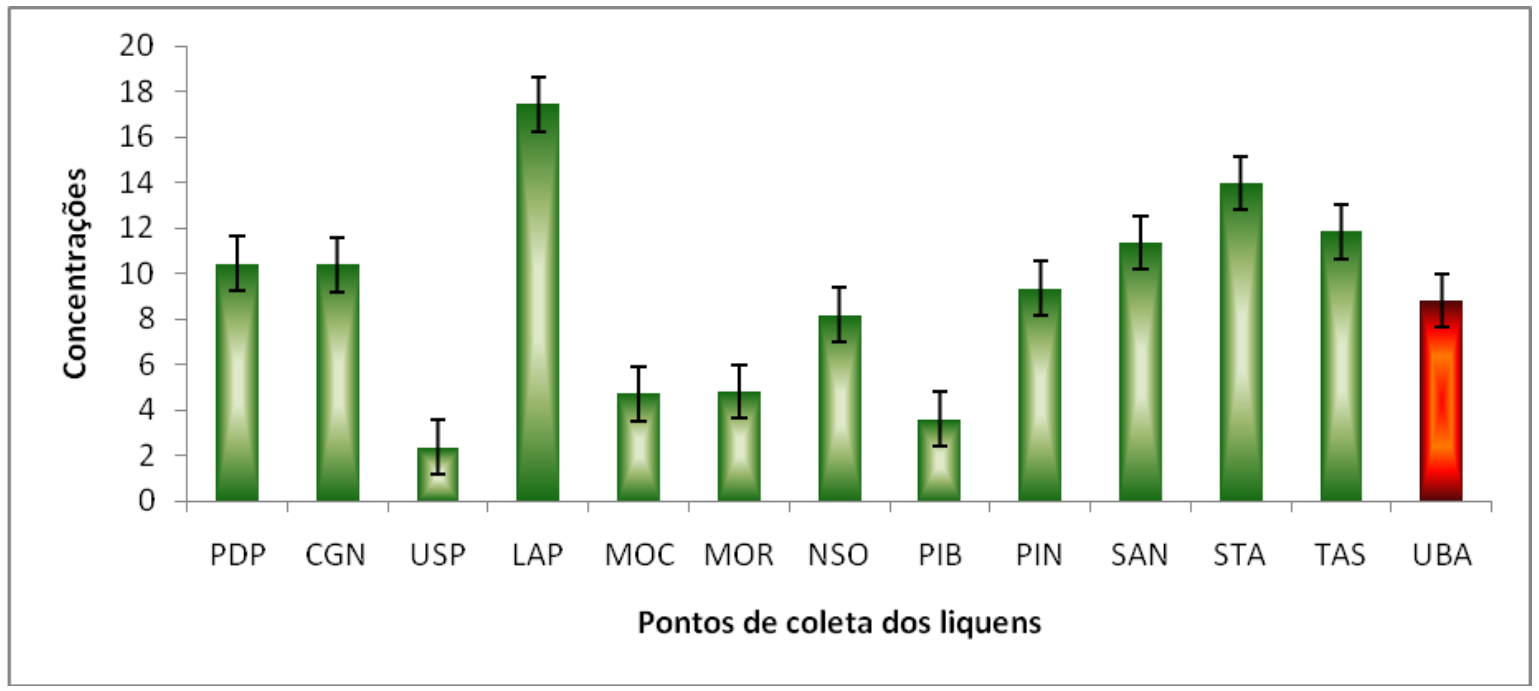

Figura 5.5. Concentrações de $\mathrm{Cr}\left(\mu \mathrm{g} \mathrm{g}^{-1}\right)$ em liquens coletados nos diversos pontos da cidade de São Paulo e em Ubatuba.

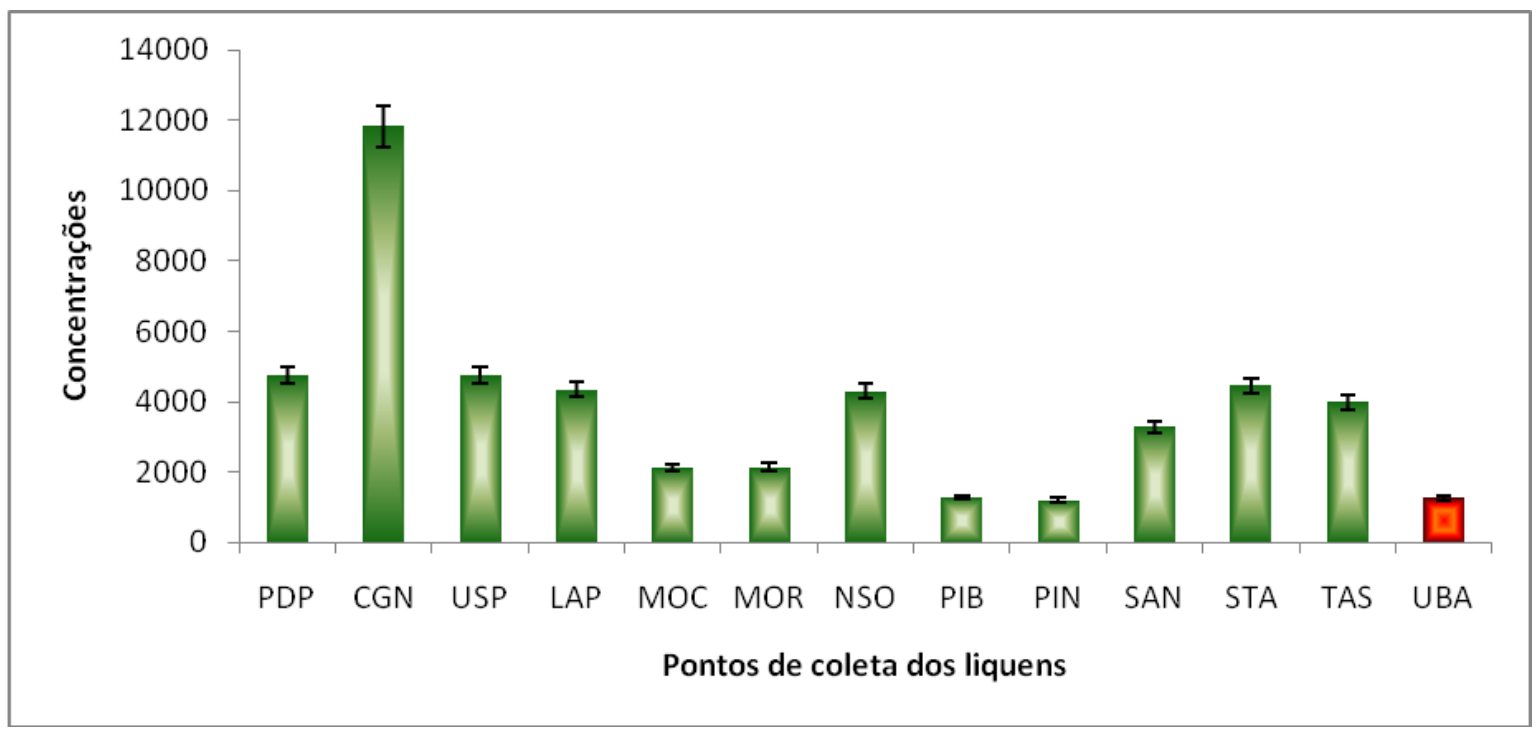

Figura 5.6. Concentrações de $\mathrm{Fe}\left(\mu \mathrm{g} \mathrm{g}^{-1}\right)$ em liquens coletados nos diversos pontos da cidade de São Paulo e em Ubatuba.

\subsubsection{Cobalto}

$\mathrm{Na}$ Figura 5.7 verifica-se que colbalto (Co) nos liquens coletados estão presentes em altas concentrações nos liquens do Parque Dom Pedro II $\left(1,22 \mathrm{ng} \mathrm{g}^{-1}\right)$, Aeroporto de Congonhas $\left(1,24 \mathrm{ng} \mathrm{g}^{-1}\right)$, Lapa $\left(1,20 \mathrm{ng} \mathrm{g}^{-1}\right)$, Santo Amaro $\left(1,20 \mathrm{ng} \mathrm{g}^{-1}\right)$ e Taboão da Serra $\left(1,10 \mathrm{ng} \mathrm{g}^{-1}\right)$ do que nos demais pontos de amostragem. 
A origem do Co na poluição aérea tem sido atribuída às emissões industriais, assim como veiculares, da queima de combustíveis.

Relativamente ao elemento Co, sabe-se que é um elemento químico essencial aos seres humanos, presente na vitamina B12, apresenta sua aplicação principal na indústria metalúrgica para produção de aços com características especiais de dureza e resistência. Na forma de óxidos é utilizado como catalisador na indústria química e de óleos. Na forma de sais, uma das utilizações é na indústria de cerâmica, como pigmento (Alves e Della Rosa, 2003). Também, sabe-se que o Co é um importante componente de ligas metálicas usado em ligas resistentes à oxidação em altas temperaturas, em hélices, turbinas de aviões e ferramentas de corte. Também, sabe-se que o Co é derivado de várias fontes de combustão (Gioda e Gioda, 2006).

Indivíduos expostos às altas concentrações de Co do ar podem sofrer de inflamações da parte nasal da faringe ou rinite alérgica (Alves e Della Rosa, 2003).

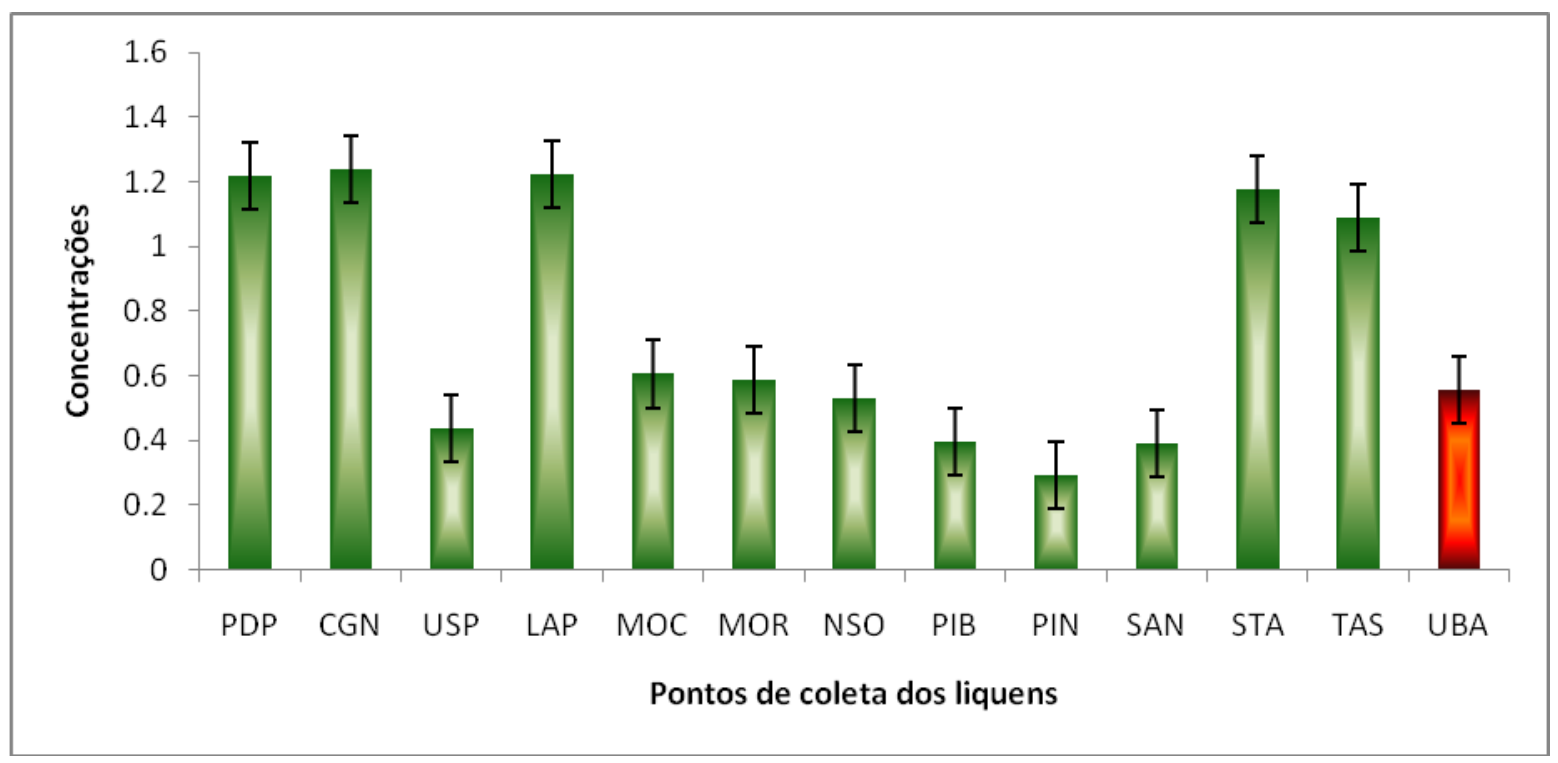

Figura 5.7. Concentrações de Co $\left(\mathrm{ng} \mathrm{g}^{-1}\right)$ em liquens coletados nos diversos pontos da cidade de São Paulo e em Ubatuba.

\subsubsection{Césio}

Os liquens do Parque Dom Pedro II, Lapa, Moóca e Santo Amaro e também em Ubatuba apresentaram as mais altas concentrações de Cs do que nos demais pontos, como podem ser vistas na Figura 5.8 . 
A origem do Cs nos pontos de coleta da cidade de São Paulo se deve, provavelmente, de poeiras advindas do solo (Fuga, 2008). Para liquens coletados no ponto de referência, na cidade de Ubatuba, SP, não foi possível identificar a origem desta alta concentração nos liquens. O papel do Cs no organismo não tem sido divulgado.

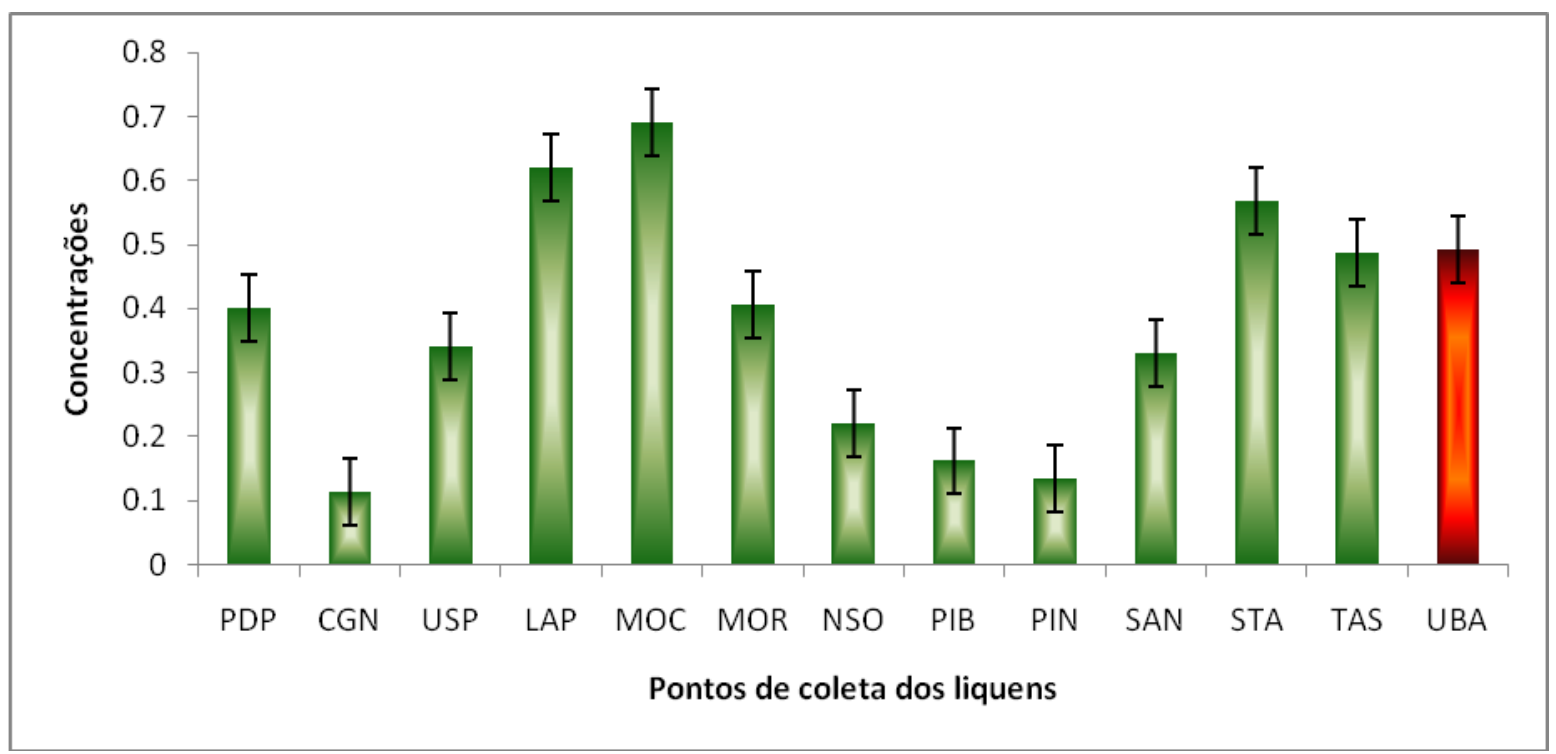

Figura 5.8. Concentrações de Cs (ng g $\left.{ }^{-1}\right)$ em liquens coletados nos diversos pontos da cidade de São Paulo e em Ubatuba.

\subsubsection{Antimônio}

As concentrações de $\mathrm{Sb}$ obtidas nos diversos pontos de amostragens são apresentadas na Figura 5.9. No caso do Sb, a mais alta concentração de $7 \mu \mathrm{g} \mathrm{g}^{-1}$ foi encontrada no líquen do bairro de Moóca e as mais baixas, nos liquens da Cidade Universitária, Morumbi e Parque Ibirapuera. Nos liquens da região de Moóca, foi também obtida alta concentração de As, isto é, o seu modelo de distribuição coincidiu com o de Sb.

Para o Sb, sabe-se que se trata de um elemento encontrado em diversos tipos de plásticos, uma vez que o óxido deste elemento é utilizado como catalisador no processamento de polímeros. A presença de Sb no ar pode ter sua origem devido à queima de materiais plásticos e de pneus (Fuga, 2008). 


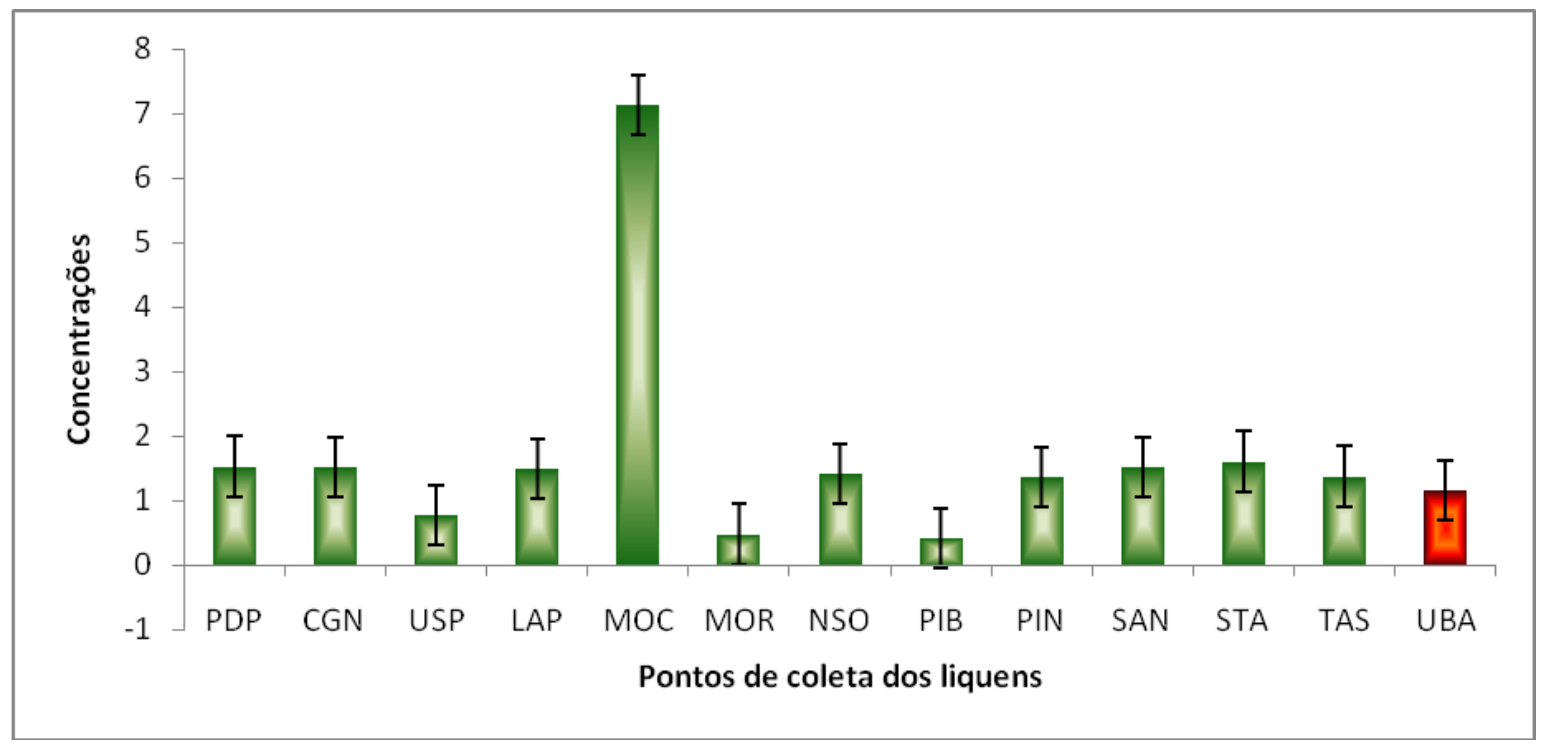

Figura 5.9. Concentrações de $\mathrm{Sb}\left(\mu \mathrm{g} \mathrm{g}^{-1}\right)$ em liquens coletados nos diversos pontos da cidade de São Paulo e em Ubatuba.

O Sb é liberado ao meio ambiente por fontes naturais e industriais. Pode permanecer no ar aderido a partículas muito pequenas por muitos dias. $\mathrm{O}$ Sb presente no ar deposita-se no solo, aderindo-se partículas que contêm ferro, manganésio ou aluminio. Indivíduos expostos a altos níveis de Sb por períodos muito longos podem adquirir irritação nos olhos e nos pulmões e como consequência desenvolver problemas respiratórios, do coração e do estômago (INSHT, 2010).

De acordo com o relatório de qualidade do ar da estação automática da CETESB no bairro de Moóca (CETESB, 2010), as análises mostraram que a qualidade do ar observada nesta região é influenciada principalmente por emissões veiculares provenientes das vias localizadas a oeste: Avenida Alcântara Machado (Radial Leste) e Rua Bresser, bem como por fontes de re-suspensão de poeiras localizadas em micro-escala.

\subsubsection{Lantânio, Escândio e Rubídio}

Os dados obtidos para La, Sc, e Rb mostraram ser dispersos em todos os pontos de estudo e em geral, na amostra de Ubatuba, apresentaram teores mais baixos. Apenas a amostra do Parque do Ibirapuera apresentou concentração inferior à amostra de Ubatuba (Figuras 5.10 a 5.12). 
Com relação ao elemento La, sabe-se que este elemento é utilizado em eletrodos de carbono para a produção de luz, principalmente para iluminação de estúdios e projeções na indústria cinematográfica e também como catalisador nos processos de beneficiamento do petróleo. O La é empregado também como aditivo metalúrgico nas cerâmicas, ímãs permanentes e fósforos. As concentrações de La obtidos nas regiões estudadas são mostradas na Figura 5.10 .

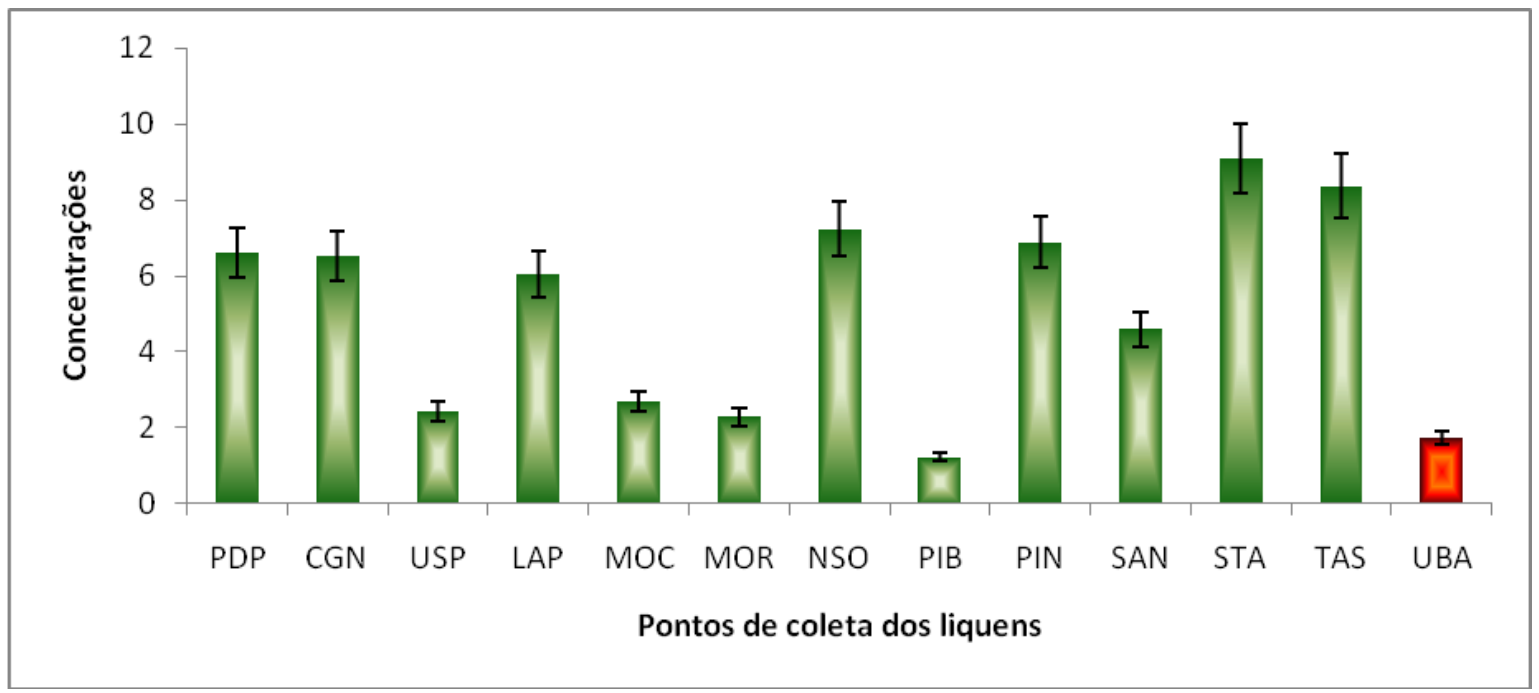

Figura 5.10. Concentrações de $\mathrm{La}\left(\mu \mathrm{g} \mathrm{g}^{-1}\right)$ em liquens coletados nos diversos pontos da cidade de São Paulo e em Ubatuba.

Com relação aos elementos $\mathrm{Sc}$ e $\mathrm{Rb}$, conclui-se que estes elementos não indicaram uma tendência particular e de acordo com os autores Wyttenbach \& Tobler (1998), a origem destes elementos tem como principal fonte, as partículas do solo. 


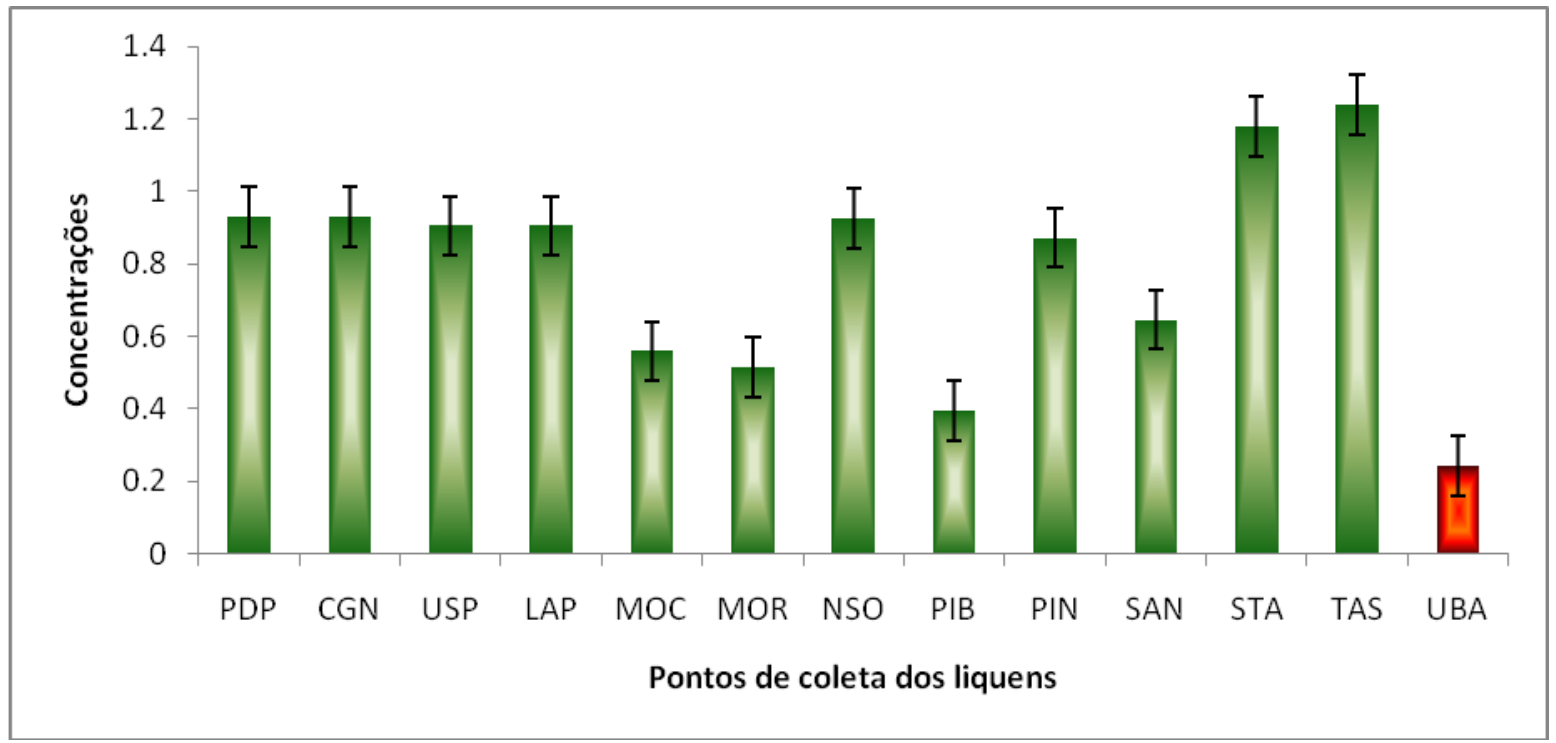

Figura 5.11. Concentrações de Sc $\left(\mathrm{ng} \mathrm{g}^{-1}\right)$ em liquens coletados nos diversos pontos da cidade de São Paulo e em Ubatuba.

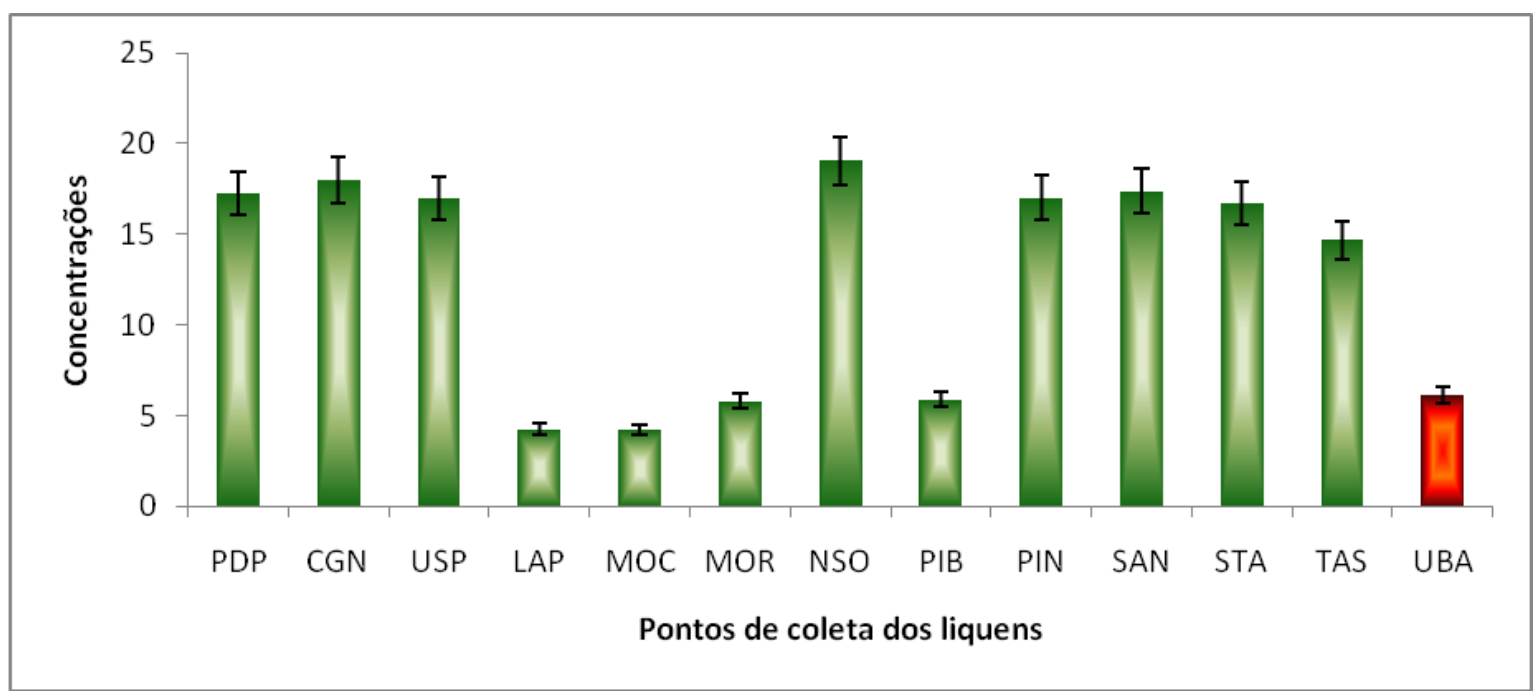

Figura 5.12. Concentrações de $\mathrm{Rb}\left(\mu \mathrm{g} \mathrm{g}{ }^{-1}\right)$ em liquens coletados nos diversos pontos da cidade de São Paulo e em Ubatuba.

\subsubsection{Potássio}

As concentrações de $\mathrm{K}$ presentes nos liquens coletados em diferentes pontos de amostragem da cidade de São Paulo e em Ubatuba estão apresentadas na Figura 5.13. 


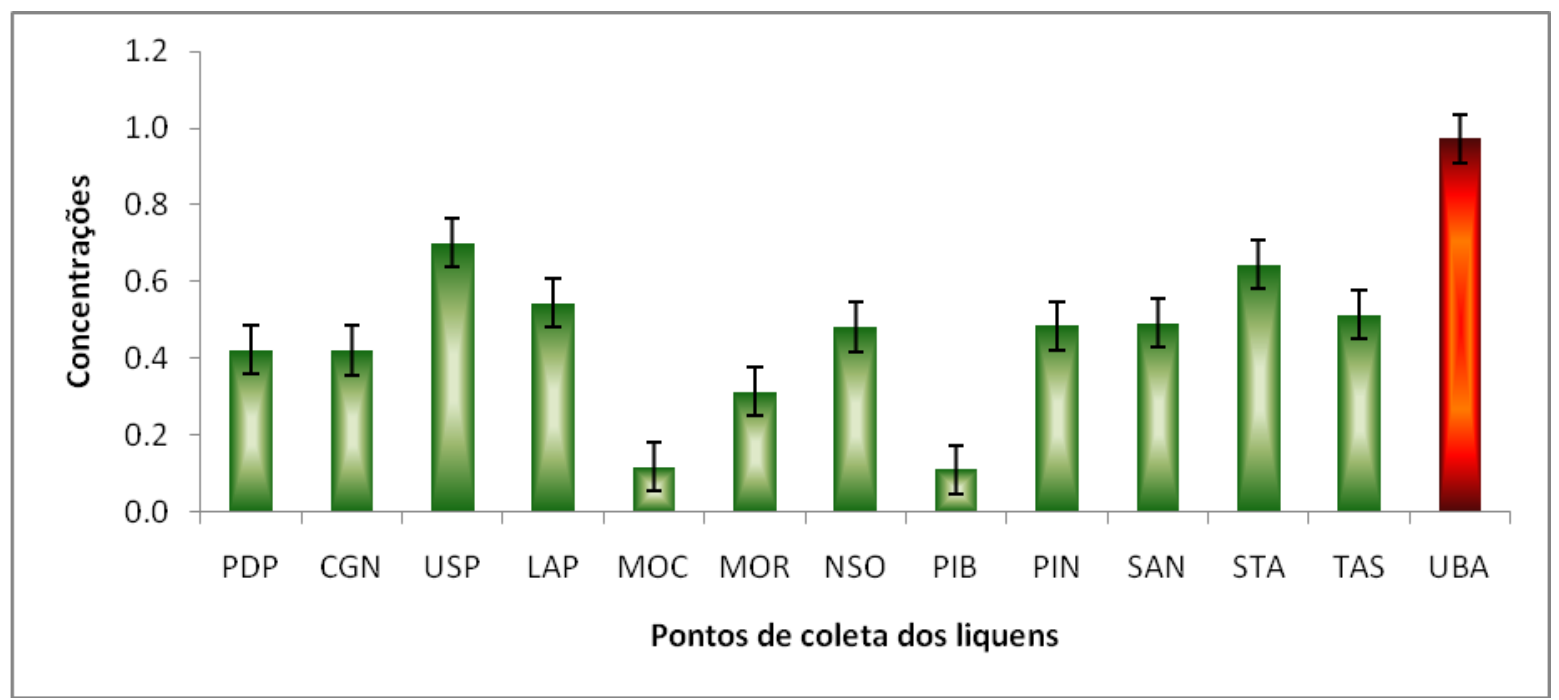

Figura 5.13. Concentrações de K (em \%) em liquens coletados nos diversos pontos da cidade de São Paulo e em Ubatuba.

As mais altas concentrações de $\mathrm{K}$ foram obtidas nas amostras de Ubatuba $(0,97 \%)$ e na amostra da Cidade Universitária $(0,70 \%)$. Com relação a outros pontos houve uma diminuição da concentração deste elemento nos liquens da cidade de São Paulo. O decréscimo do K é esperado em liquens de locais com poluição elevada, devido ao stress ocasionado ao líquen (Klumpp, 2001). Contudo, a concentração de K está, em geral, na faixa esperada de 0,5 a 3,4\%, proposta por Markert (1998).

Com relação ao $\mathrm{K}$, convém salientar que este elemento é um nutriente das plantas e se origina não somente da atmosfera, mas também das lavagens das folhagens das árvores (Läuchli e Pflüger, 1978). O K também é importante para a manutenção da quantidade de água nas plantas. A absorção de água pela célula e pelos tecidos é classificada como conseqüência da absorção ativa do K (Läuchli e Pflüger, 1978).

\subsubsection{Selênio}

Na Figura 5.14 observa-se que as mais altas concentrações de Se nos liquens estão nas regiões de Santana, Santo Amaro, Taboão da Serra e Moóca e a menor concentração foi detectada nos liquens da Cidade Universitária. 


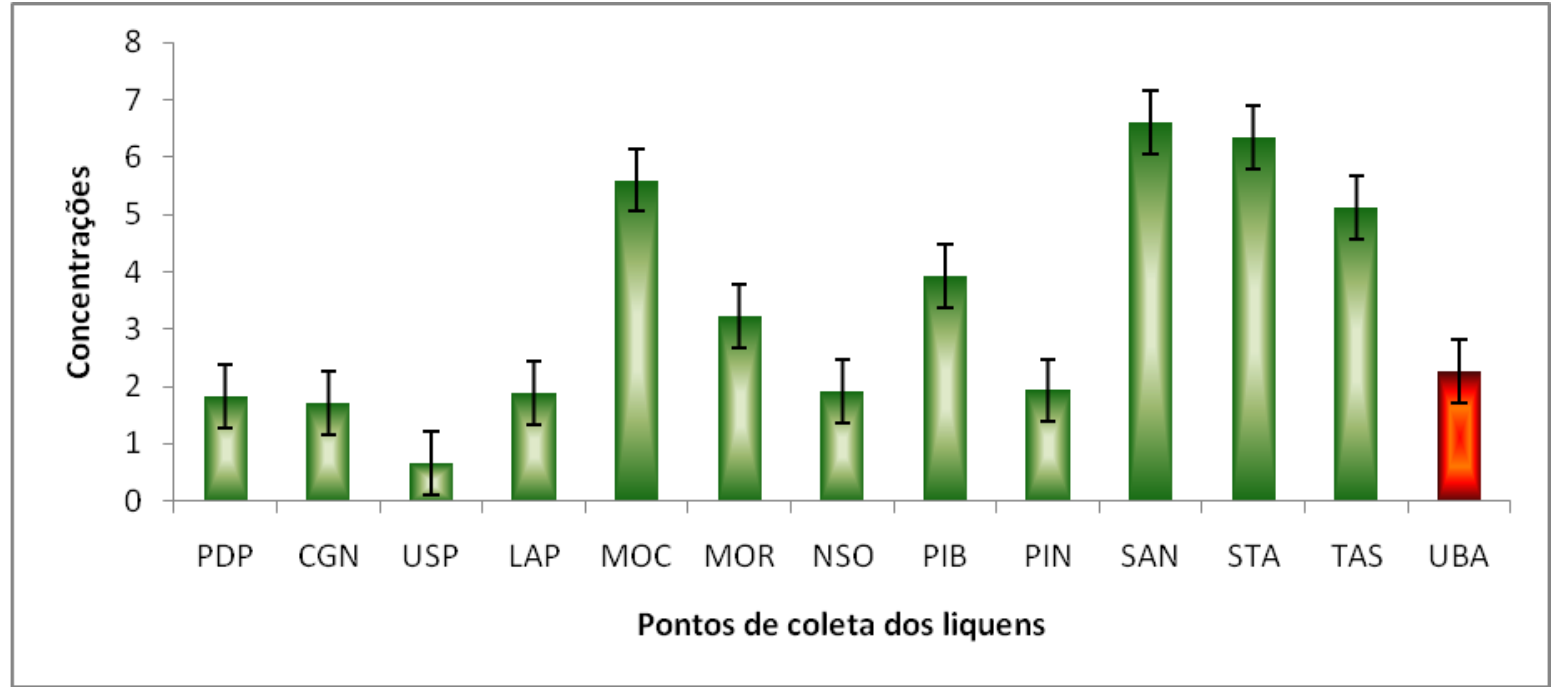

Figura 5.14. Concentrações de Se $\left(\mu \mathrm{g} \mathrm{g}^{-1}\right)$ em liquens coletados nos diversos pontos da cidade de São Paulo e em Ubatuba.

Os compostos de Se entram no meio ambiente por intermédio de fontes antrópicas, podendo-se citar as indústrias de refino de cobre, indústrias produtoras de vidro e equipamentos eletrônicos, refinarias e uso em fertilizantes (Eisler, 1985). Também é possível encontrar o elemento Se nas tintas, materiais galvanizados e tubulações metálicas (Branco, 1987).

O elemento Se é considerado essencial à saúde humana, entretanto, a deficiência deste elemento no organismo humano está relacionado com a descoloração da pele e alguns problemas psicológicos e gastrointestinais (Chang et al., 1995). Na literatura não foram encontradas evidências de doenças pulmonares nos seres humanos causadas por selênio.

\subsubsection{Cálcio}

Com relação ao cálcio $(\mathrm{Ca})$, a menor concentração deste elemento foi encontrada nos liquens da Moóca (Figura 5.15). 


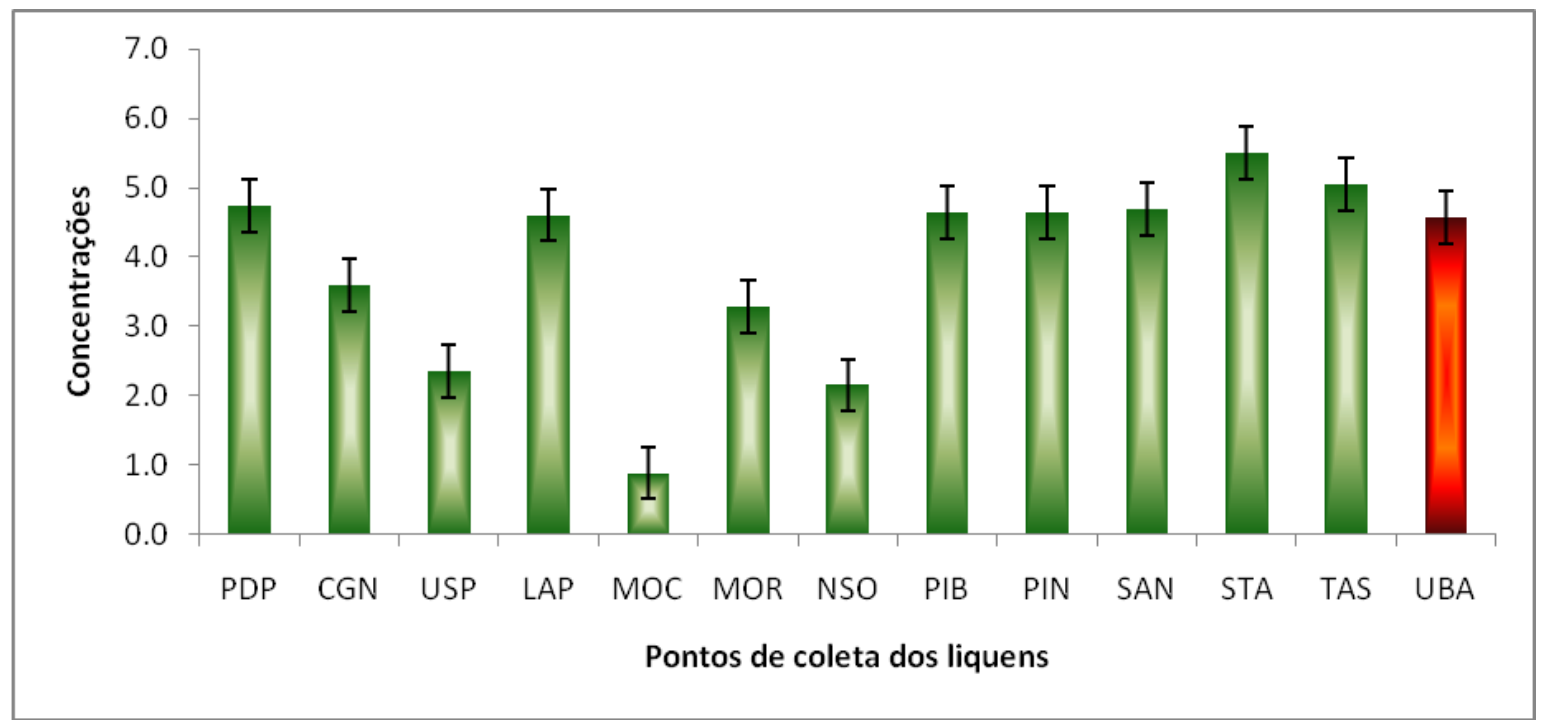

Figura 5.15. Concentrações de Ca ( em \%) em liquens coletados nos diversos pontos da cidade de São Paulo e em Ubatuba.

Sobre o $\mathrm{Ca}$, neste trabalho ficou evidenciada uma distribuição uniforme deste elemento, nos liquens coletados na cidade de São Paulo. A presença de altas concentrações de $\mathrm{Ca}$ nos liquens se deve ao fato deste elemento ser um nutriente das plantas bem como devido às inúmeras construções com o uso de cimento, na cidade de São Paulo.

Sabe-se que é um nutriente muito importante à saúde humana (Pharmaterra, 2010). Não tem sido divulgada sobre as evidências de doenças provocadas por altas concentrações deste elemento no ar.

\subsubsection{Zinco}

Para Zn, as concentrações obtidas nas amostras da cidade de São Paulo (Figura 5.16) variaram de $114 \mathrm{\mu g} \mathrm{g}^{-1}$ (amostra do Parque do Ibirapuera) a $534 \mu^{-1} g^{-1}$ (amostra de Ubatuba).

O Zn é continuamente mobilizado e transportado no meio ambiente, como resultado dos processos naturais de erosão, incêndios das florestas, formação e aerossol acima do mar, erupções vulcânicas e atividade biológica. Conseqüentemente, o $\mathrm{Zn}$ está naturalmente presente em todo o meio ambiente (ICZ, 2010). 


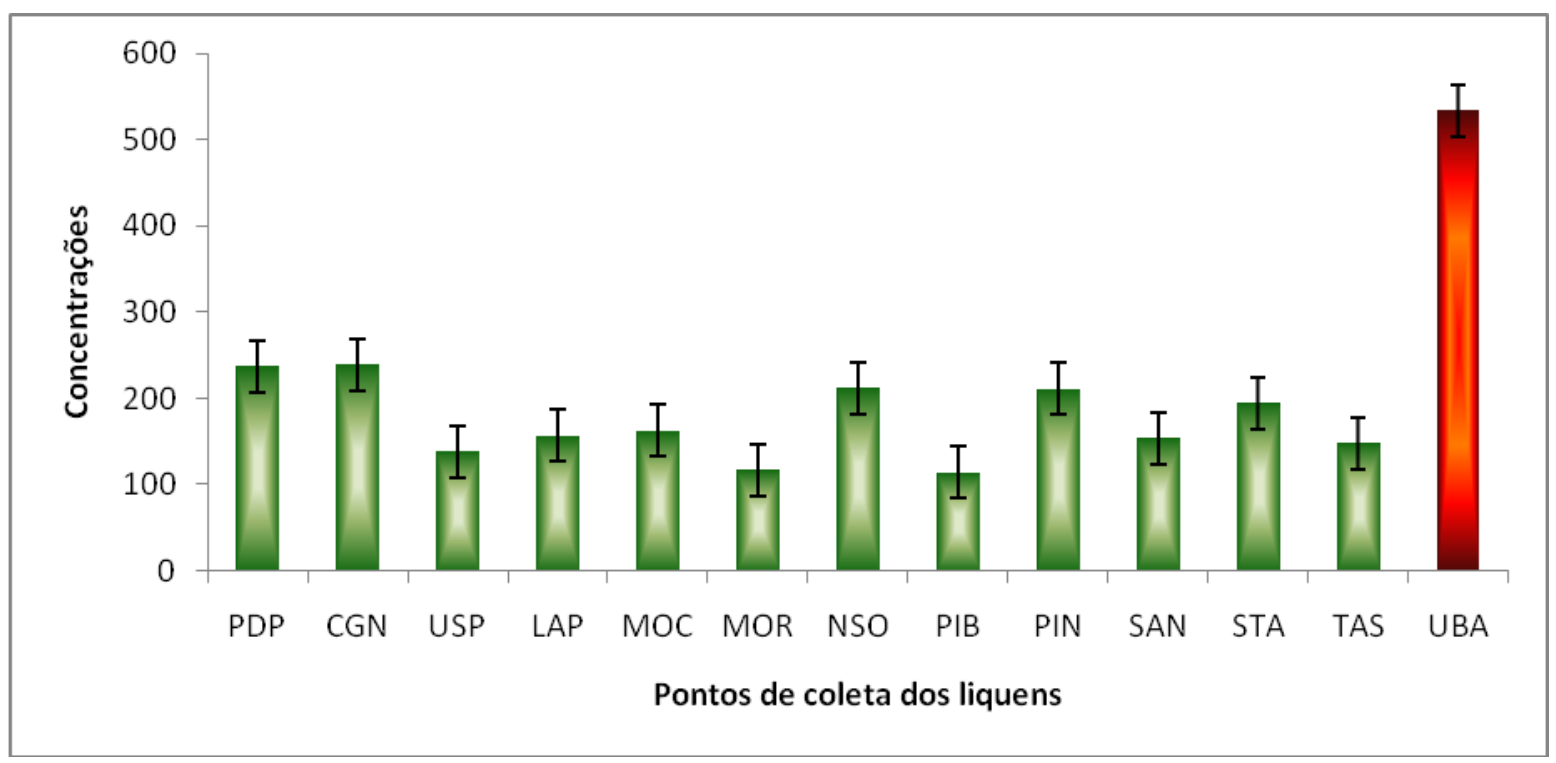

Figura 5.16. Concentrações de $\mathrm{Zn}\left(\mu \mathrm{g} \mathrm{g}^{-1}\right)$ em liquens coletados nos diversos pontos da cidade de São Paulo e em Ubatuba.

As fontes antrópicas de $\mathrm{Zn}$ advêm-se da mineração, instalações de produção de zinco e de metal, corrosão de estruturas galvanizadas, combustão de carvão e combustível, remoção e incineração de lixo e ao uso de fertilizantes e agroquímicos que contém zinco (ICZ, 2010).

Com relação ao $\mathrm{Zn}$ convém salientar que as concentrações deste elemento presente nos liquens de São Paulo provavelmente se devem às fontes industriais e veiculares, devido ao desgaste dos pneus dos veículos (Carreras e Pignata, 2007). A alta concentração deste elemento nos liquens coletados no ponto de referência (Ubatuba-SP) provavelmente se deve provavelmente ao grande movimento de veículos naquela região.

Sobre os efeitos à saúde humana do elemento $\mathrm{Zn}$ convém salientar que o Zn é um elemento essencial, com uma média diária de 10-200 mg para os seres humanos, à maior absorção do $\mathrm{Zn}$ no organismo provém da dieta alimentar, mas as inalações de vapores de $\mathrm{Zn}$ produzidos nos processos de solda e fabricação de ligas de $\mathrm{Zn}$ causam grande irritabilidade e lesões ao sistema respiratório (Brito Filho, 1988).

\subsection{Análise de Cluster e Análise Discriminante}

Os resultados obtidos nas amostras coletadas nos diversos pontos da cidade de São Paulo e em Ubatuba foram submetidos ao tratamento de 
análise de clusters. A formação de clusters revela quais regiões estão funcionalmente relacionadas, de acordo com as similaridades em relação às concentrações determinadas, com o objetivo de organizar informações sobre as variáveis. O dendrograma gerado na análise de clusters é mostrado na Figura 5.17 .

Para a aplicação desta técnica estatística multivariada, as concentrações dos elementos químicos foram colocadas na mesma unidade de medida e foi adotada a distância Euclidiana, como medida de similaridade. Para que os dados fossem ligados entre si foi utilizada a opção do método de Ward (Barroso e Artes, 2003).

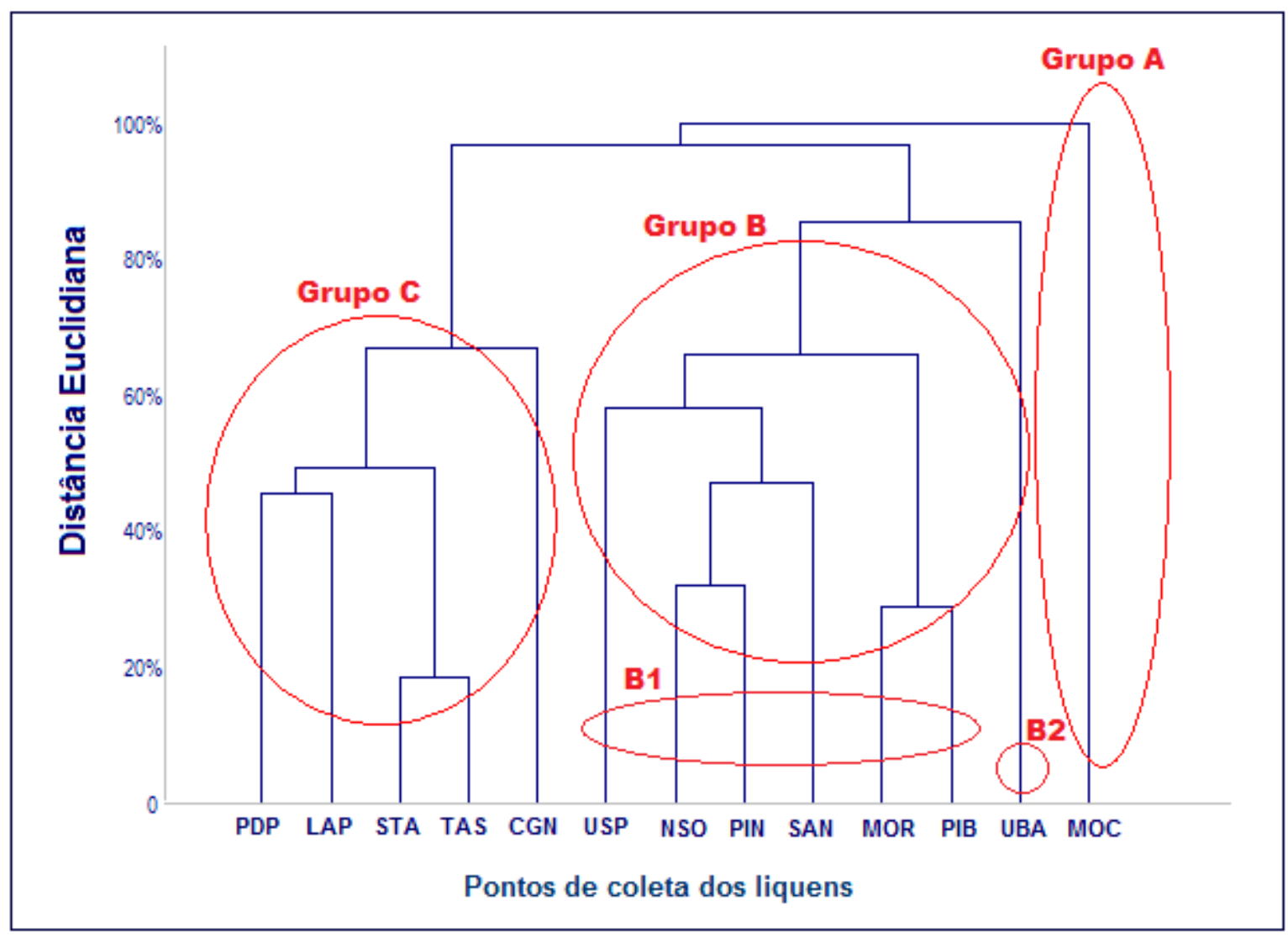

Figura 5.17. Dendrograma obtido por meio da análise de clusters nos diferentes pontos de amostragem da cidade de São Paulo e em Ubatuba, SP.

Na Figura 5.17 é possível observar que os pontos de amostragem subdividiram-se basicamente em três grandes grupos ( $A, B$ e $C$ ) heterogêneos, relacionando os casos mais semelhantes entre si, com relação às concentrações dos elementos. O primeiro grupo (A) é composto pela amostra de Moóca; o segundo grupo (B), pelas regiões da Cidade Universitária, Nossa Senhora do Ó, 
Pinheiros, Santana, Morumbi, Parque do Ibirapuera e Ubatuba e o terceiro grupo (C), pelas regiões do Parque Dom Pedro II, Lapa, Santo Amaro, Taboão da Serra e Congonhas. Verifica-se também que o grupo B subdivide-se em dois subgrupos: B1, formado pela amostra de Ubatuba e subgrupo B2, formado pelas amostras da Cidade Universitária, Nossa Senhora do Ó, Pinheiros, Santana, Morumbi e Parque do Ibirapuera. Desta análise de clusters resulta que as regiões que compõem o segundo grupo B pertencem ao mesmo grupo da cidade de Ubatuba, ou seja, da região-controle deste trabalho.

Os grupos B e C são formados por praticamente todos os pontos da cidade de São Paulo, estando associado entre si, com um maior ou menor grau de similaridade, com exceção da amostra de Ubatuba, que pode ser considerada um subgrupo (B2) de classificação dos pontos de amostragem pertencente ao grupo B.

$\mathrm{Na}$ amostra da região de Moóca, que por sua vez é a região que apresentou maior dissimilaridade em relação às outras regiões estudadas, vale ressaltar que para os liquens coletados em Moóca, foram encontradas concentrações relativamente altas para os elementos $\mathrm{Br}, \mathrm{Cs}$, Sb e Se.

O grupo A é formada do ponto de amostragem da Moóca e foram obtidas altas concentrações de elementos As, Cs, Sb e Se e baixas concentrações de $\mathrm{Fe}, \mathrm{Rb}$ e K.

No grupo B foram obtidos casos em que as concentrações apresentaram teores de grandeza próximos às concentrações dos liquens de Ubatuba, para os elementos Co e La.

Já no grupo C são demonstrados casos em que as concentrações são mais altas para alguns elementos, por exemplo, Co, Cr e Zn.

Analisando a composição destes três grupos verifica-se que são classificados três grupos de regiões diferentes, quanto às concentrações das regiões estudadas. A confirmação dos resultados da análise de clusters foi aplicada a análise discriminante, por meio do software Bioestat 5.0, como é apresentado na Figura 5.18. 


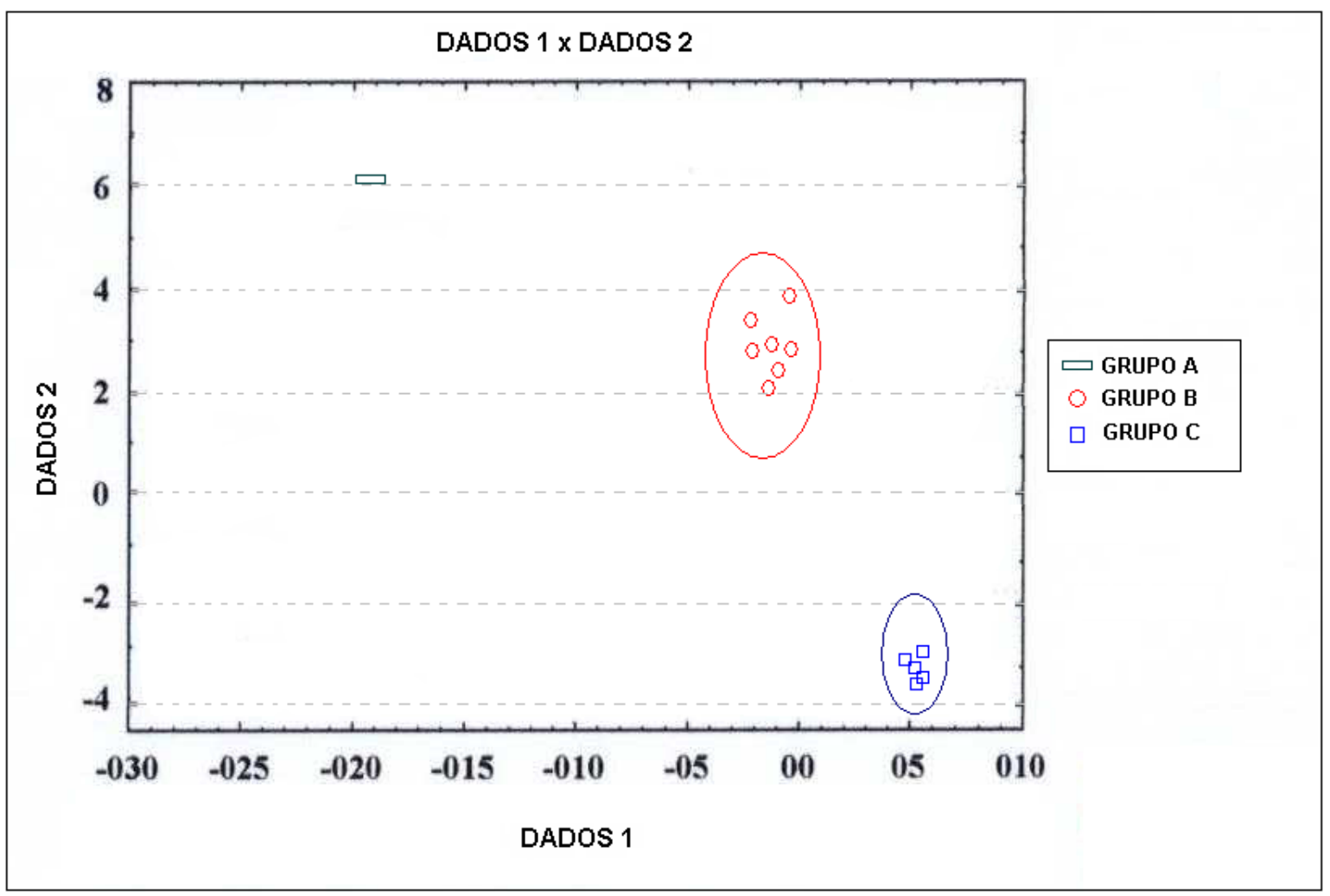

Figura 5.18. Análise discriminante dos resultados das amostras de liquens coletados em diferentes regiões da cidade de São Paulo e de Ubatuba.

De acordo com a Figura 5.18 foi verificada a classificação dos grupos $\mathrm{B}$ e $\mathrm{C}$ e a dissimilaridade da amostra de Mooca (Grupo $\mathrm{A}$ ), em relação às outras regiões estudadas. 


\section{CONCLUSÕES}

Os resultados das análises de materiais de referência certificados IAEA-336 Lichen e INCT-TL-1 Tea Leaves demonstraram a viabilidade do uso do procedimento de análise por ativação com nêutrons, na análise elementar de liquens. Os resultados das análises dos materiais de referência indicaram boa precisão com desvios padrão relativos, em geral, inferiores a 15\% e uma boa concordância com os valores do certificado com erros relativos menores que $10 \%$.

Também, no que se refere à exatidão pode-se afirmar que os resultados obtidos foram concordantes com os valores certificados para a maioria dos elementos. Por outro lado, os valores do Z-score foram $\mid Z$ score $\mid<1$ para todos os resultados o que indica que os dados obtidos podem ser considerados exatos.

Os resultados das análises de amostras de liquens em replicatas indicaram a homogeneidade da amostra preparada com relação aos elementos analisados neste trabalho. Este fato mostra que o procedimento de preparo de amostras utilizado foi adequado para a análise elementar.

Nos liquens analisados foram quantificados os elementos $\mathrm{As}, \mathrm{Br}, \mathrm{Ca}$, $\mathrm{Co}, \mathrm{Cr}, \mathrm{Cs}, \mathrm{Fe}, \mathrm{K}$, La, Rb, Sc, Se e Zn. As concentrações de elementos obtidos em diferentes pontos indicaram uma grande variabilidade.

A comparação entre os resultados das amostras de liquens da cidade de São Paulo e de Ubatuba mostrou que a amostra de Ubatuba apresentou concentrações mais baixas para os elementos As, La, Fe e Sc, concentrações mais elevadas de $\mathrm{Br}, \mathrm{K}$ e $\mathrm{Zn}$ e, concentrações da mesma ordem de grandeza para os demais elementos $\mathrm{Ca}, \mathrm{Co}, \mathrm{Cr}, \mathrm{Cs}$, $\mathrm{Rb}$ e Sb.

As emissões veiculares (combustíveis e desgaste de pneus) indicaram como a principal fonte de poluição aérea da cidade de São Paulo, uma vez que os liquens indicaram acúmulo dos elementos como $\mathrm{Br}$, Co, Sb e Zn cuja origem são consideradas de fontes veiculares. Acredita-se que as emissões industriais e o material particulado do solo também tenham responsáveis para o acúmulo dos elementos como As, Cr, La, Fe, Rb, Sc e Se nos liquens. 
Os resultados obtidos comprovaram que o biomonitoramento com o uso da espécie Canoparmelia texana permite obter informações de interesse para o estudo dos níveis de poluentes. Nos liquens puderam ser determinados os elementos chamados marcadores das fontes de poluição veiculares, industriais ou do solo.

Os resultados obtidos neste trabalho indicaram a necessidade de desenvolver um estudo sistemático sobre a identificação da origem de poluentes, devido à diversidade do perfil da cidade de São Paulo, do ponto de vista da poluição, com grande número de fontes de emissões. 


\section{REFERÊNCIAS BIBLIOGRÁFICAS}

ADAMO, A.; ARIENZO, M.; PUGlieSe, M.; ROCA, V.; VIOLANTE, P. Accumulation history of radionuclides in the lichen Stereocaulon vesuvianum from Mt. Vesuvius (South Italy). Environ. Pollut., v. 127, p. 455-461, 1994.

ALFASSI, Z. B. Activation analysis. Boca Raton, Florida: CRC, v. 2, p. 4, 1990.

ALVES, A. N. L.; DELLA ROSA, H. V.. Exposição ocupacional ao cobalto: aspectos toxicológicos. Rev. Bras. Cienc. Farm., São Paulo, v. 39, n. 2, 2003.

BAKONYI, S. M. C.; DANNI-OLIVEIRA, I. M.; MARTINS, L. C.; BRAGA, A. L. F. Poluição atmosférica e doenças respiratórias em crianças na cidade de Curitiba, PR. Rev. Saúde Púb., v. 38, n. 5, p: 695-700, 2004.

BARROSO, L. P.; ARTES, R. Análise multivariada. Lavras: UFLA, 2003. 151p.

BEIGUELMAN, B. Curso prático de bioestatística. Ribeirão Preto, SP: FUNPEC, Editora, 2002. $272 \mathrm{p}$.

BIAZROV, L. G. The radionuclides in lichen thalli in Chernobyl and East Urals after nuclear accidents. Phyton, v. 34, p. 85-94, 1994.

$\mathrm{BODE}, \mathrm{P}$. Instrumental and organizational aspects of a neutron activation analysis laboratory. Interfacultair Reactor Institut, Delft PhD Thesis. University of Techonology, The Netherlands. p. 142-172, 1996.

BRANCO, S. M. Elementos de ciências do ambiente: CETESB. $2^{\text {a }}$ Ed. São Paulo: CETESB. pg. 110 - 114 e 133 - 134, 1987.

BRITO FILHO, D. Toxicologia humana e geral. 2.ed. Rio de Janeiro: Atheneu, 1988. 678p.

BUSS, P. M. Promoção da saúde e qualidade de vida. Rev. C. S. Col., v. 5, n.1, p. $163-177,2000$. 
CARNEIRO, R. M. A. Bioindicadores vegetais de poluição atmosférica: uma contribuição para a saúde da comunidade. 2004. Dissertação (Mestrado). Escola de Enfermagem de Ribeirão Preto da Universidade de São Paulo.

CARRERAS, H. A.; PIGNATA, M. L. Biomonitoring of heavy metals anda ir quality in Cordoba city, Argentina, using transplante lichens. Environ. Pollut., v. 177, p. 77-87, 2007.

CETESB. Relatório de Qualidade do Ar no Estado de São Paulo no ano de 1992. Companhia Ambiental do Estado de São Paulo. Secretaria do Meio Ambiente. 1993. Disponível em <http://www.cetesb.gov.br>. Acesso em 15 jul. 2010.

CETESB. Introdução ao controle da poluição atmosférica. Companhia Ambiental do Estado de São Paulo. Secretaria do Meio Ambiente. 2007. Disponível em <http://www.cetesb.gov.br>. Acesso em 15 jul. 2009.

CETESB. Relatório de qualidade do ar no estado de São Paulo no ano de 2009. Companhia de Tecnologia de Saneamento Ambiental. Secretaria do Meio Ambiente. 2010. Disponível em <http://www.cetesb.sp.gov.br/Ar/publicações.asp >. Acesso em 21 mai. 2010.

CHANG. Z.; CALLEN, .; FREDRICKSON, .; BUDNY, R. V. ; HEGNA, C. C. ; MCGUIRE; ZARNTORFF, M. C. Observation of nonlinear neoclassical pressure-gradient-driven Tearing Modes in TFTR. Phys. Spotlight. Excep. Res., v. 74, n. 23, p. 4663-4666, 2005.

CISLAGHI, C.; NIMIS P. L. Lichens, air pollution and lung cancer. Nature, v. 387, p. 463-464, 2007.

COCCARO, D. M. B. Estudo da determinação de elementos - traço em liquens para monitoração ambiental. 2001. Dissertação (Mestrado). Instituto de Pesquisas Energéticas e Nucleares, SP, Brasil.

COLE, D.; PENGELLY, L. D.; EYLLES, J.; STIEB, D. M. HUSTLER, R. Consulting the community for environmental health indicator development: the case of air quality. Health Prom. IntI., v.14, n.2, 1999. 
CPA. Coordenadoria de Planejamento e Avaliação. Perfil Econômico. 2007. Disponível em < http://www.planejamento.sp.gov.br>. Acesso em: 15 jun. 2009.

DE SOETE, P. D.; GIYBELS, R.; HOSTE, J. Neutron activation analysis. London, Wiley Interscience, 1972.

DUCHIADE, M. P. Poluição do ar e doenças respiratórias: Uma revisão. Departamento de Epidemiologia e Métodos Quantitativos em Saúde. Escola Nacional de Saúde Pública. Cad. Saúde Pública. Rio de Janeiro, v. 8, p. 311330, 1992.

EC. European Comission, Diretiva 96/62/CE. 2003. Avaliação e gestão da qualidade do ar ambiente. Disponível em <http://europa.eu.int/comm/environment/docum/index.htm>. Acesso em: 12 jan. 2010.

EISLER, R. Selenium hazards to fish, wildlife ans invertebrates: a synoptic review. U.S. Fish ans Wild. Serv. Biol. Rep., v. 85, p. 15:57, 1985.

ELIAS, C.; FERNANDES, E. A. N.; FRANÇA, E.J.; BACCHI, M.A. Seleção de epífitas acumuladoras de elementos químicos na Mata Atlântica. 2006. Biot. Neotrop. v. 6. Disponível em: www.biotaneotropica.org.br. Acesso em: 24 jul. 2010.

EPSTEIN, E.; BLOOM, A. J. Nutrição mineral de plantas: princípios e perspectivas. Londrina. Editora Planta, 2006. 403p.

FELLENBERG, G. Introdução aos problemas da poluição ambiental. São Paulo. Springer, 1980. 321p.

FORATINI, O. P. Ecologia, epidemiologia e sociedade. São Paulo: Artes Médicas. Editora da Universidade de São Paulo, 1992. 529 p.

FRANÇA, E. J.; NADAI. F. E. A.; BACCHI, M. A., SAIKI, M. Native trees as biomonitors of chemical elements in the biodiversity conservations of the Atlantic Forest. J. Atmos. Chem. , v. 49, p. 579-592, 2004. 
FRIEDLANDER, G.; KENNEDY, J. W.; MILLER, J. M. Nuclear and radiochemistry. New York. John Wiley \& Sons, 1981. 305p.

FUGA, A. Uso de líquens epifíticos no biomonitoramento da poluição atmosférica da região metropolitana de São Paulo. Dissertação (Mestrado). Instituto de Pesquisas Energéticas e Nucleares, 2006.

FUGA, A.; SAIKI, M.; MARCELLI, M. P.; SALDIVA, P. H. N. Atmospheric pollutants monitoring by analysis of epiphytic lichens. Environ. Pollut., v. 151, p. 334-340, 2008.

FUNDAÇÃO SEADE. Estatísticas Vitais de 2009. Disponível em: <http://www.seade.gov.br>. Acesso em: 25 mai 2009.

FURLAN, C. Uso de plantas como bioindicadores. Disponível em <felix.ib.usp.br/bib138/bioind_claudia.pdf>. Acesso em 02 ago 2010.

GARTY, J. Biomonitoring atmospheric heavy metals with lichens: Theory and applications. Crit. Rev. Plant Sci., v. 20, p. 309-371, 2001.

GARTY, J.; TOMAER, S.; LEVIN, T.; LEHR, H. Lichen as biomonitors around a coal-fired power station in Israel. Environ. Res., v. 91, p. 186-198, 2003.

GIODA, A.; GIODA, F. R. A influência da qualidade do ar nas doenças respiratórias. Disponível em : <http://rdigital.univille.rctsc.br/index.php/RSA/article/viewFile/81/127>. Acesso em 02 set 2010.

GRAUER, A. Relatório da qualidade do ar na região metropolitana de Curitiba. Instituto Ambiental do Paraná: Curitiba, 2000.

GUIMARÃES, E. T.; DOMINGOS, M.; ALVES, E. S.; CALDINI, N.; LOBO, D. J.; LICHTENFELS, A. J.; SALDIVA, P. H. Detection of the genotoxicity of air pollutants in anda round the city of Sao Paulo (Brazil) with the Tradescantia micronucleos (Trad-MCN) assay. Environ. Exp. Bot., v. 44, p. 1-8, 2000.

GUTBERLET, J. Cubatão: Desenvolvimento social e degradação ambiental. São Paulo, Editora da Universidade de São Paulo, 1996. 129p. 
GUYTON, A. C.; HALL, J. E. Tratado de Fisiologia Médica. v. 10. Rio de Janeiro. Guanabara, 2002.

HONDA, N. K. Técnicas Químicas Aplicadas à Taxonomia de Fungos Liquenizados. In: XAVIER-FILHO, L., LEGAZ, M. E., CORDOBA, C. V. \& PEREIRA, E. C. G, RODRIGUES, S. A. Biologia de liquens. Rio de Janeiro: Âmbito Cultural, p. 391-400, 2006.

IAEA - International Atomic Energy Agency. Practical aspects of operating a neutron activation analysis laboratory. Vienna. IAEA-TEDOC-564. (ISSN 1011-4289), 1990.

IAEA - International Atomic Energy Agency. Reference Scheet. Reference Material. IAEA-336 Trace and minor Element in Lichen. Viena, 4 p., 1999.

IBGE. Instituto Brasileiro de Geografia e Estatística. Estimativas da população para $1^{\circ}$ de julho de 2009. Disponível em: <http://www.ibge.gov.br>. Acesso em: 14 ago. 2009.

IBGE. Divisão Territorial do Brasil e Limites Territoriais. Instituto Brasileiro de Geografia e Estatística. 2008. Disponível em: <http://www.ibge.gov.br>. Acesso em: 01 jul. 2009.

ICZ. Instituto de Metais Não-Ferrosos. O Zinco e o Meio Ambiente. Disponível em: <http://www.icz.org.br/zinco-meio-ambiente.php>. Acesso em: 04 ago. 2010.

INCT - Institute of Nuclear Chemistry and Technology. Polish certified reference material. INCT-TL-1 Tea Leaves, v. 3, p. 1-4, 2002.

INSHT. Instituto Nacional de Segurança e Higiene no Trabalho da Espanha. Disponível em <http://www.insht.es/InshtWeb/Conteúdos/Documentacion/FichasTecnicas/FIS Q/Ficheiros/701a800/nspn0775.pdf>. Acesso 19 set 2010.

KAMPA, M.; CASTAÑAS, E. Human health effects of an pollution. Environ. Pollut. v.151, p. 362-367, 2008. 
KLICKEDUCAÇÃO.

Disponível

em:

<http://www.klickeducacao.com.br/conteudo/pagina/0,6313,POR-948-5179-,00.html>. Acesso em 06 set 2010.

KLUMPP, A.; ANSEL, W.; KLUMPP, G.; FOMIN, A. Um novo conceito de monitoramento e comunicação ambiental: a rede européia para a avaliação da qualidade do ar usando plantas bioindicadoras (EuroBionet). Rev. Bras. Bot., v. 4, p. 511-518, 2001.

LOPPI, S; BONINI, I. Lichens and mosses biomonitors of trace elements in areas with springs and fumarole activity. Chemosphere, v. 41, p. 1333-1336, 2000.

MAGAlHÃES, M. N.; PEDROSO, A. C. L.. Noções de probabilidade e estatística. São Paulo. Editora da Universidade de São Paulo, 2004.

MARKERT, B. Instrumental element and multi-element analysis of plant samples. John Wiley \& Sons Chichester, v. 12, p. 89-108, 1984.

MARKERT, B. Distribution and biogeochemistry of inorganic chemicals in the environment. Ecotoxicology. John Wiley \& Sons, Amsterdam, p.165-222, 1998.

MARIANI, R.; MARTINS, P. M. Biomonitoramento e Poluição do Ar Caracterização do Risco Ambiental no Vale do Paraíba. Disponível em: http://sosriosdobrasil.blogspot.com/2009/05/cptec-realiza-o-1-encontro-meteorologia.html>. Acesso em: 30 jul. 2010.

MARTINE, G. População, meio ambiente e desenvolvimento: verdades e contradições. Campinas. Editora UNICAMP, 1996. 189p.

MOTA FILHO, F. O; PEREIRA, E. C.; LIMA, E. S.; SILVA, N. H.; FIGUEIREDO, C. R. B. Influência de poluentes atmosféricos em Belo Jardim (PE) utilizando Cladonia verticillaris (líquen) como biomonitor. Quím. Nova, v.30, n.5, p.10721076, 2007.

NOGUEIRA, A. C. Avaliação da poluição atmosférica por metais na região metropolitana de São Paulo utilizando a Bromélia Tillandsia usneoides $L$. 
como biomonitor. 2006. Dissertação (Mestrado). Instituto de Pesquisas Energéticas e Nucleares.

PEITER, P.; TOBAR, C. Poluição do ar e condições de vida: uma análise geográfica de riscos à saúde em Volta Redonda, Rio de Janeiro, Brasil. Cad. Saúde Púb., v. 14, p. 473-485, 1998.

PEREIRA. A. J. F.; SANTOS. P. M.; CAMARGIO. R.; FESTA. M.; FUNARI. F. L.; SALUM. S. T.; OLIVEIRA. C. T.; SANTOS. E. M.; LOURENÇO. P. R.; SILVA. E. G.; GARCIA. W.; FIALHO. M. A. Impactos antrópicos no clima da Região Metropolitana de São Paulo. Anais CD-Rom. XIV CBMET Congressos Brasileiros de Meteorologia, p. 123-129, 2005.

PHARMATERRA.

Disponível

em

$<$ http://www.pharmaterra.com.br/index.php?option=com_content\&view=article\&i $d=43 \&$ Itemid $=43>$. Acesso em 02 set 2010 .

PICCOT, D. Comunicação Pessoal, 1989.

PIRES, D. O. Inventário de emissões atmosféricas de fontes estacionárias e sua contribuição para a poluição do ar na região metropolitana do Rio de Janeiro. Dissertação (Mestrado). Universidade Federal do Rio de Janeiro, 2005.

PNUD. Programa das Nações Unidas para o Desenvolvimento do ano de 2000. Disponível em: <http://www.pnud.org.br/atlas/ranking/IDHM\%2091\%2000\%20Ranking\%20decrescente\%20(pelos\%20dados\%20de\%202 000).htm>. Acesso em: 11 out. 2008.

POPE, C. A.; THUN, M. J.; NAMBOORDIRI, M. M. DOCKERY, D. W.; EVANS, J. S.; SPEIZER, F. E. Particulate air pollution as a predictor of mortality in a prospective study of U.S. adults. J. Resp. Crit. Care Med., v.151,p. 669-674, 1995.

REIMANN, C.; CARITAT, P. Chemical elements in the environment: fact sheets for the geochemist environmental scientist, Berlin: Springer-Verlag Berlin Heidelberg, 1998. 
SAIKI, M; CHAPARRO, C. G; VASCONCELLOS, M. B. A.; MARCELLI, M. P. Determination of trace elements in lichens by neutron activation analysis. J. Radioanal. Nucl. Chem., v. 217, p. 111-115, 1997.

SAIKI, M., FUGA, A., ALVES, E.R., VASCONCELLOS, M.B.A. \& MARCELLI, M. The use of Canoparmelia texana lichenized fungi in the study of atmospheric air pollution. In: Third International Workshop on Biomonitoring of Atmospheric Pollution, Bled, Slovenia, p. 21-25, 2003.

SALGADO, P. E. T. Toxicologia dos metais, In: OGA, S. Fundamentos de toxicologia, São Paulo, p. 154-172, 1996.

SARMENTO, S.; WOLTERBEEK, H. TH.; VERBURG, T. G.; FREITAS, M. C. Correlating element atmospheric deposition and cancer mortality in Portugal: Data handling and preliminary results. Environ. Pollut., v. 151, p. 341-351, 2008.

SILVA, M. A. G. Musgos e liquens são iguais? Portal do Professor. Ministério da Educação.

<http://portaldoprofessor.mec.gov.br/fichaTecnicaAula.html?aula=15525>.

Acesso em 01 nov 2010.

SOUSA, F., FERREIRA, T., GASPAR, J.L., VIVEIROS, F., FARIA, C., MARCOS, M., SENOS, L. CO2 soil degassing mapping: a contribution to the volcanic risk assessment at Furnas Village (S. Miguel Island, Azores). In: 1st General Assembly da EGU, 2004.

TUKEY, J. W.; ROUSSEEUW, P. J.; RUTS, I. The Bagplot: A Bivariate Boxplot. Americ. Statist., v. 53, p. 382-387, 1999.

VILLAROUCO, V.; ANDRETO, L. F. M. Identificação de parâmetros para concepção de espaços ergonomicamente adequados à habitação social. In: congresso internacional de ergonomia e usabilidade de interfaces humano-tecnologia: produtos, programa, informação, ambiente construído. ERGODESIG, 5 ed. Rio de Janeiro: LEUI/PUC, 2005. 
VOGEL, J. Sklar on methodological conservatism. Phil. Phenomen. Res. v. 52, p. 125-131, 1992.

WAPPELHORST, O.; KUHN, I.; OEHLMANN, J.; MARKERT, B. Deposition and disease: a moss monitoring project as an approach to ascertaining potential connections. Sci. Total Environ., v. 249, p. 243-256, 2000.

WOlTERBEEK, H. T.; VERBURG, T. G. Atmospheric metal deposition in a moss data correlation study with mortality and disease in the Netherlands. Sci. Total Environ., v. 319, p. 53-64, 2004.

WYTTENBACH, A., TOBLER, L. Effect of surface contamination on results of plant analysis. Commun. Soil Sci. Plant Anal. 29, 1998. p. 809-823. 